\title{
Do I Belong Here? Exploring Black Male Student Perceptions of Retention Initiatives
}

Jason A Ottley

Follow this and additional works at: https://researchrepository.wvu.edu/etd

\section{Recommended Citation}

Ottley, Jason A, "Do I Belong Here? Exploring Black Male Student Perceptions of Retention Initiatives" (2018). Graduate Theses, Dissertations, and Problem Reports. 7224.

https://researchrepository.wvu.edu/etd/7224

This Dissertation is protected by copyright and/or related rights. It has been brought to you by the The Research Repository @ WVU with permission from the rights-holder(s). You are free to use this Dissertation in any way that is permitted by the copyright and related rights legislation that applies to your use. For other uses you must obtain permission from the rights-holder(s) directly, unless additional rights are indicated by a Creative Commons license in the record and/ or on the work itself. This Dissertation has been accepted for inclusion in WVU Graduate Theses, Dissertations, and Problem Reports collection by an authorized administrator of The Research Repository @ WVU.

For more information, please contact researchrepository@mail.wvu.edu. 


\title{
Do I Belong Here?
}

Exploring Black Male Student Perceptions of Retention Initiatives

\author{
Jason A. Ottley \\ Dissertation submitted \\ to the College of Education and Human Services \\ at West Virginia University \\ in partial fulfillment of the requirements for the degree of \\ Doctor of Philosophy in \\ Curriculum and Instruction/Educational Leadership \& Policy Studies
}

Nathan Sorber, Ph.D., Chair

Samuel Stack, Ph.D

Erin McHenry-Sorber, Ph.D.

John Oughton, Ed.D.

Department of Curriculum and Instruction

\author{
Morgantown, West Virginia \\ 2018
}

Keywords: retention, Black males, predominantly white institution, initiative Copyright 2018 Jason A. Ottley 


\begin{abstract}
Do I Belong Here? Exploring Black Male Student Perceptions of Retention Initiatives

Jason A. Ottley

The retention and graduation rate of Black male students at institutions of higher education is dismal when compared to other groups. Approximately, 30\% of Black college males who enroll in a four-year institution earn a college degree compared to $57 \%$ of White male students (Bohrnstedt et al., 2015). Black men find it difficult to persist and complete a college degree, and reasons behind it should be explored. The purpose of this study is to explore student and administrator perceptions of retention strategies for Black male students attending a Predominantly White Institution (PWI).
\end{abstract}




\section{Acknowledgments}

Dear Lord: Thank you for seeing in me what I never believed was possible. This is just the beginning. I Corinthians 2:9

"Climb though the rock be rugged. Walk tall along the way. Set your goal on the highest star and strive for it every day. Success is not won without effort, so be strong when the going gets tough. Take hold of the task and lead the way. Following is not good enough. If you should falter or fail in your efforts get up and start over again. Success is not meant for poor hearted men. So climb though the rocks be rugged. Try always to do your best. And when you have reached your summit, sit down from your labor and rest." Unknown

While embarking on this journey I never imagined experiencing such a number of ups and downs, yet I remained committed to the process. At first, I thought this sacrifice was to better my personal life, but instead, this journey has equipped me to better the lives of those around me.

To my father - my hero, my confidante, and my protector, I so wish you were here to share this moment with me. Because of you, I am!

To my mother - my heart and joy, you have loved me beyond words could articulate. We did this together. There is no me without you.

To my brothers - Jonathan, Jordan, and Joel, this represents a classic example of what we do. We make the impossible, possible!

To my participants - the world belongs to you! Whatever you desire, chase after it. Once you get it, turn around and help your brother get his.

To my dissertation committee - Dr. Samuel Stack, Dr. John Oughton, Dr. Erin McHenrySorber, and Dr. Nathan Sorber. While I know it was up to me to select a committee to oversee 
my dissertation experience, I truly believe you all were the ones who selected me! You all saw that glimmer in my eye - that determined look to succeed no matter the obstacle. Because of the chance you took on me, I will forever make you proud!

A special thank you goes out to my chair, Dr. Nathan Sorber. In so many words, you "took me in" when I lost my footing and you helped me re-imagine, re-focus, and re-organize my thoughts. You were the canvas for my ideas and you challenged me every step of the way. If I can be half of the scholar you are, I would be indestructible. You are an inspiration!

In the words of Jay-Z, "Allow me to reintroduce myself..."

With Humility,

Jason A. Ottley, Ph.D. 
Table of Contents

page

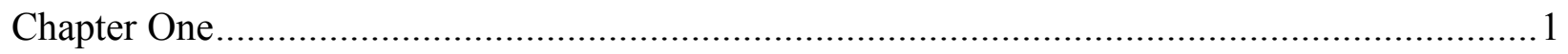

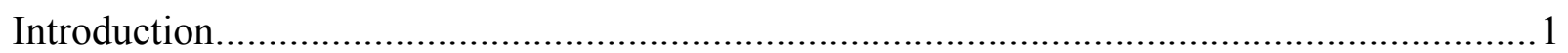

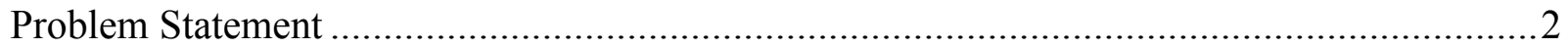

Research Questions ........................................................................................

Introduction to Black College Male Retention .......................................................... 4

Conceptual Framework .................................................................................... 7

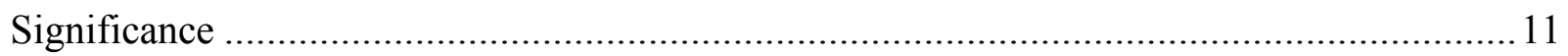

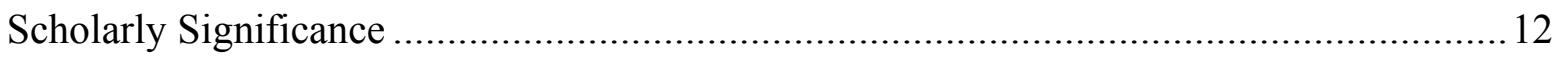

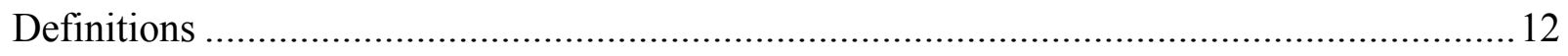

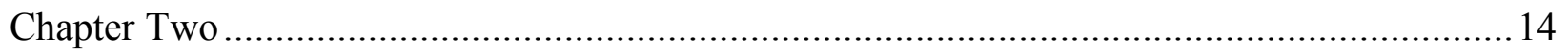

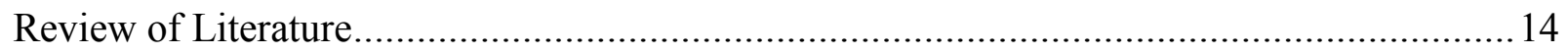

Classical Explanation of College Student Retention............................................... 14

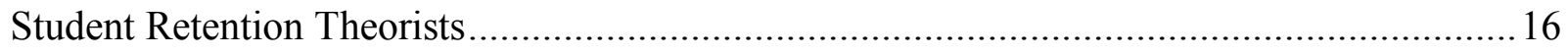

Factors Related to Black College Male Retention .......................................................25

Faculty-Student Interaction................................................................................. 27

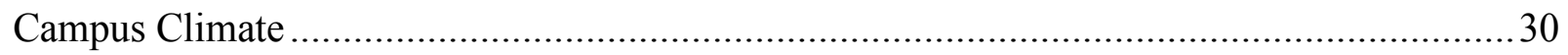

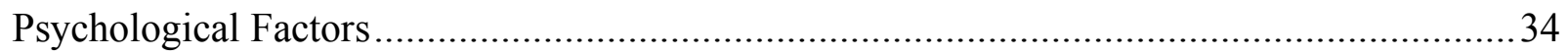

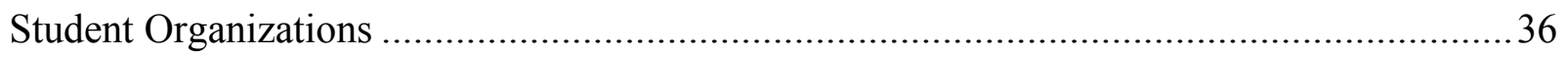


Underpreparedness

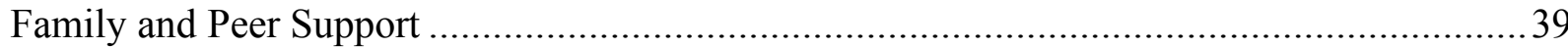

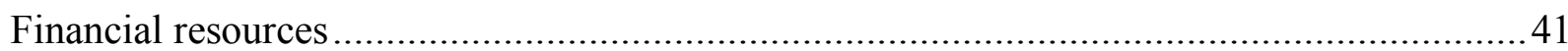

Institutional Retention Strategies for Black College Males ...................................................42

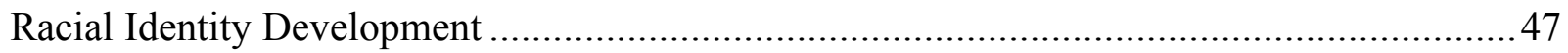

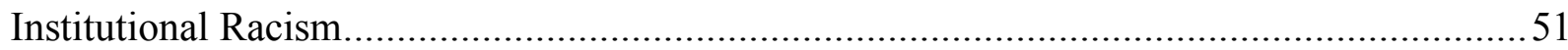

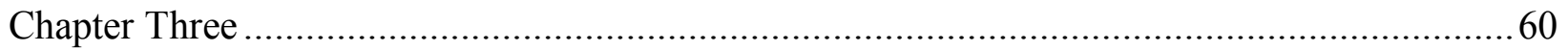

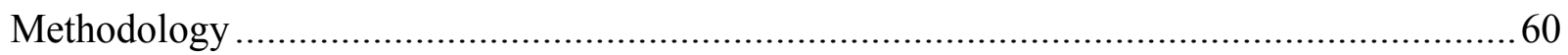

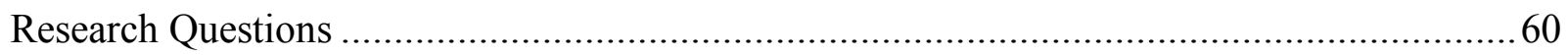

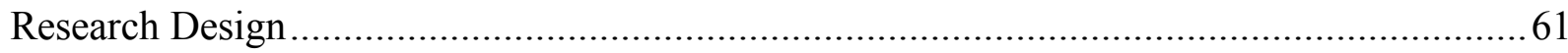

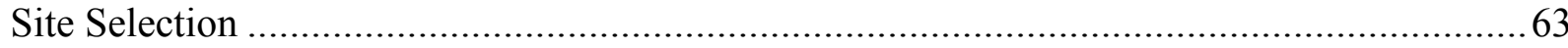

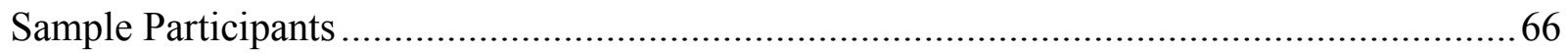

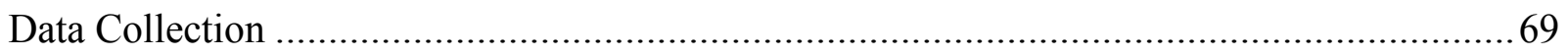

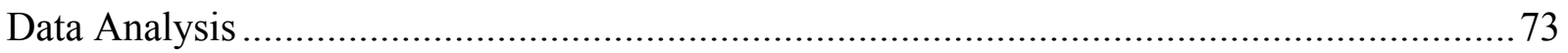

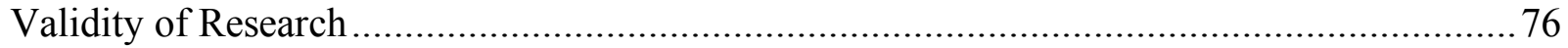

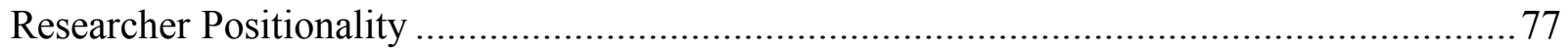

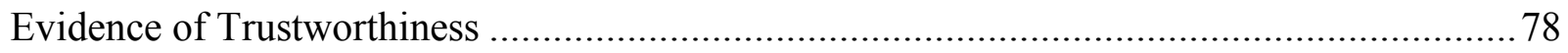

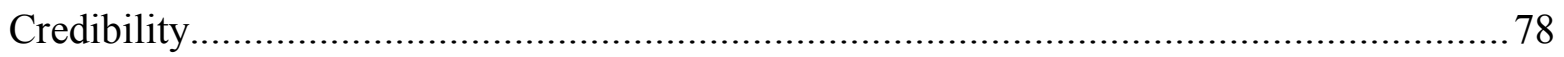

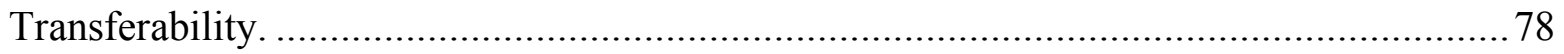




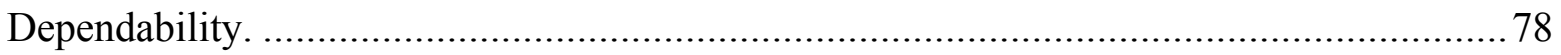

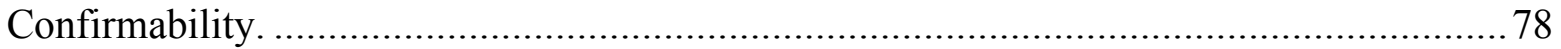

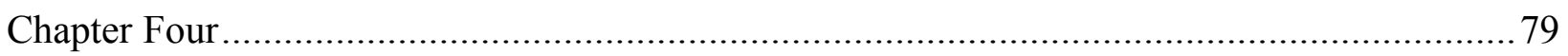

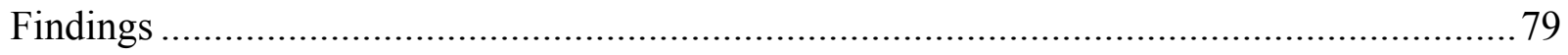

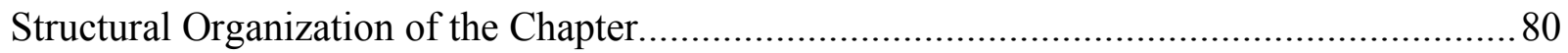

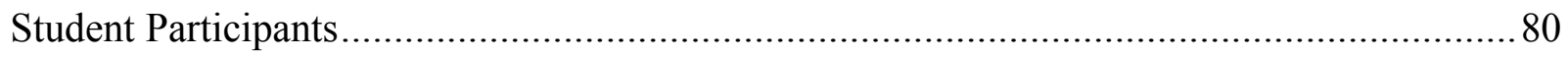

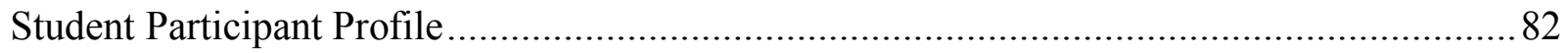

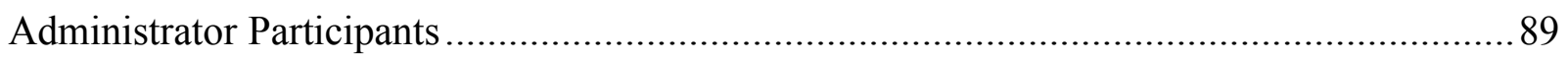

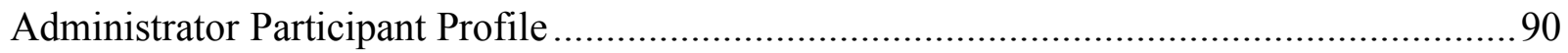

The Case: The Successful M.A.L.E. Initiative ……………............................................. 92

Other Initiatives Supporting Black College Males …….....................................................93

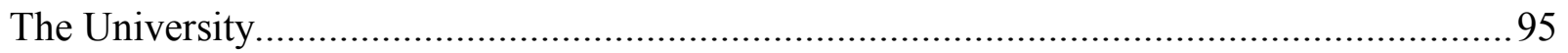

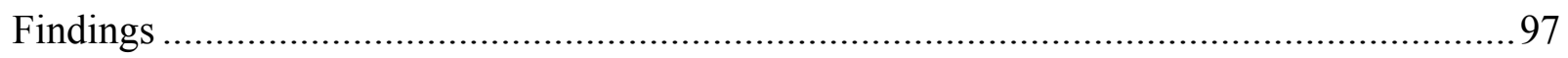

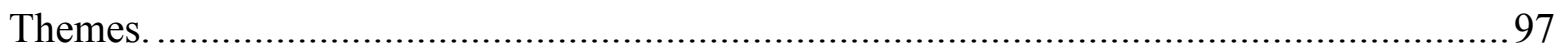

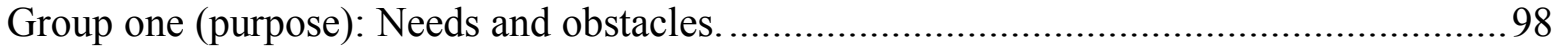

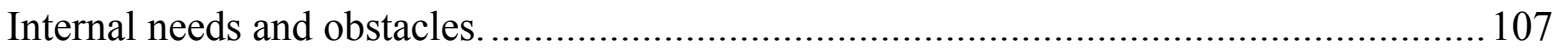

Group two (processes): Support through the program.................................................... 111

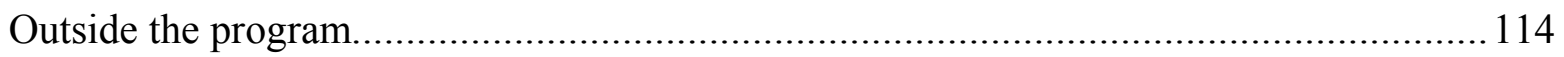

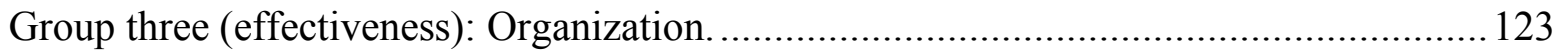


Ways to Improve the Program

Document analysis.

Conclusion

Chapter Five 146

Summary, Limitations, Implications

Consensus: Students vs. Administrators.

Tension: Students vs. Administrators

Literature

Limitations

Implications

Conclusion

References

Appendix A

Appendix B 


\section{List of Tables}

page

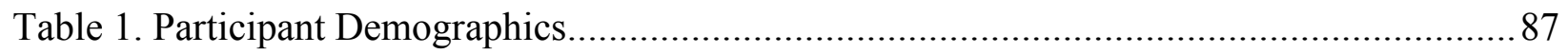

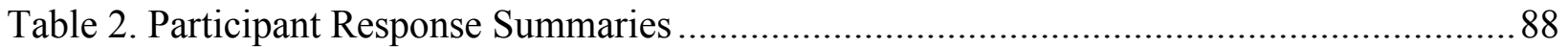

Table 3. Twenty Most Commonly-used Words in the Initiative Documents ......................... 143 


\section{List of Figures}

page

Figure 1. Geometric model of student persistence and achievement ................................. 10

Figure 2. Geometric model of student persistence and achievement .................................. 11

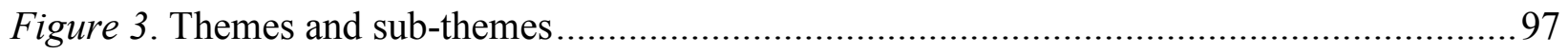




\section{Chapter One}

\section{Introduction}

A college degree increases the likelihood of employment, future earnings and personal satisfaction. However, the challenge in earning a degree differs based on race, gender and socioeconomic status (Palmer et al., 2014). The United States Congress passed Title VI of the Civil Rights Act of 1964 to ensure equal opportunity in federally assisted programs and activities (Rudolph, 1990). Thus, the Civil Rights Act of 1964 protected persons from discrimination based on race, color, and ethnicity by institutions of higher education (Rudolph, 1990). Although Predominantly White Institutions (PWI) are more racially integrated, Black college males face unique challenges from their White counterparts, which make them the least likely of all students to be retained and earn a college degree (Harper, 2006; Strayhorn, 2014). Roughly, $30 \%$ of Black college males who enroll in a four-year institution earn a college degree compared to $57 \%$ of white male students (Bohrnstedt et al., 2015) and less than $30 \%$ of Black college males remain at their first college (Palmer et al., 2014). Consequently, the number of Black college males who enroll in college and never earn a degree, are limited in their ability to achieve goals that require an earned degree. While there are numerous reasons that contribute to Black college males departing from college before earning a degree, there are visible and present reasons that are beyond the control of Black males. According to Palmer et al. (2014) many Black college males are from racially segregated and predominantly Black communities and attend PWI more than Historically Black College and Universities (HBCU). Black college males who attend school in rural locations may be confronted with additional pressures than Blacks who attend school in urban environments. Consequently, by acculturating to the majority lifestyle and being surrounded by faculty, students, and staff who are from mostly rural areas, the 
challenges that Black college males face attending a rural PWI may prove to be more than they anticipated. This dissertation expands knowledge to this area of study by exploring an institutional strategy at a rural PWI aimed to increase Black college male retention and graduation. In addition, this study provides a foundation to understand Black college male perceptions of these institutional strategies and perceptions of the rural environment in which they attend school.

\section{Problem Statement}

There is a significant amount of literature on college retention strategies designed to prevent college student departure (Austin, 1997). The majority of retention research focuses on the white student population and little attention has been given to Black and nontraditional students (Harper, 2006). Research on Black college students groups all Black students together instead of focusing on Black students heterogeneously. The limited amount of information surrounding Black college male retention focuses on students who attend HBCUs, which adds to the complexity institutions face when attempting to increase retention rates for Black college male students who attend PWIs (Watson, 2002).

While colleges and universities are implementing programs to increase Black college male retention, the number of Black college male students who depart from college before earning a degree continues to rise (Baker, 2013). It is unknown why retention programs are not increasing Black college male retention, but present studies do not explore the perceptions of these programs from the perspective of its participants. Due to the limited knowledge on Black college male participants' experiences regarding retention initiatives, institutional leaders have a limited understanding on how to increase Black college male retention. In addition, there is a 
dearth of literature discussing Black college male retention programs at land-grant PWIs located on rural campuses

The retention initiative explored in this study focuses on the development and retention of Black male undergraduate and graduate students. This initiative is designed to provide an extra layer of support for Black men as they adjust college life. Each month, participants and facilitators of the initiative gather together to discuss various topics related to the specific needs and interests of its participants. Collectively, participants are assigned a professional mentor and graduate student peer mentor to support them in a variety of ways throughout their collegiate journey. Mentors and participants meet for meals, evening/weekend activities, tutoring, and any discussion pertinent to participants college experience. In this qualitative single-case study inquiry, the author explored the retention initiative in place to better understand the role this ancillary program plays in advocating and promoting the retention of Black college males who attend a PWI located on a rural college campus. Furthermore, the Black college male student and faculty perceptions of the retention initiative are also explored.

\section{Research Questions}

This research was guided by the following questions:

1. How do Black male students perceive the purpose, processes, and effectiveness of a retention initiative aimed to increase Black college male retention?

2. How do college administrators perceive the purpose, processes, and effectiveness of a retention initiative aimed to increase Black college male retention?

3. Are there differences in how Black male students and college administrators perceive the purpose, processes, and effectiveness of a retention initiative aimed to increase Black college male retention? 


\section{Introduction to Black College Male Retention}

For many years, Black college males enrolled in HBCUs, but presently more Black college males are enrolled in PWIs (Reid, 2013). The increase in Black college males attending PWIs has led to changes in institutional policies that structure how institutions address retention and graduation completion (Sedlacek, 1987). Some of these changes address how institutions have traditionally approached increasing retention and graduation completion rates and specify action items that contribute to increasing these rates for Black college men. Typically, there are two types of situations that lead to a student withdrawing from college; a) involuntary, where a student has to leave because they fail to meet mandatory academic requirements; and b) voluntary, where students leave for various reasons that are not always related to academic requirements (Dodd et al., 2009). There are many studies that discuss the number of Black college male students who do not reach graduation; however, there are only a limited number of studies that focus on understanding retention from the perspective of student participants. Presently, 30\% of Black males who enroll in a four-year bachelor's degree-granting institution return to college the following year compared to the national average of $60 \%$ (Palmer et al., 2014). Due to the rise in the number of Black men who leave college before earning a degree, it is necessary to question if programs currently in place to increase Black male retention are working, and, subsequently, whether administrators and researchers are aware of why students voluntarily leave their first college. Tinto (1975) claimed that colleges will increase retention when students socially and academically integrate into the college environment. However, research shows Black men do not integrate well into a PWIs (Harper, 2006). If Black men are struggling to integrate into PWIs, then there is a need to understand what is hindering their 
integration, reasons for voluntary departure, and how to best support Black men who voluntarily remain in college.

Many Black college males who attend PWIs come from home and school environments that are markedly different from their white peers, which makes for a difficult transition to college and one that is atypical of white students' experience (Solorzano et al., 2000). Some Black college males attended low-performing high schools and have unlikely ideas of what to expect in college. For some Black college males, they are the first in their family to attend college and the first time they are surrounded by a culture much different than their own. In addition to being part of a new environment, Black college males struggle with being welcomed and accepted by white faculty, staff, and peers (Solórzano et al., 2000). Even campus programs, dormitories, student organizations, and collegiate spaces are representative of the white student population and Black college males have a difficult time connecting and fitting in (Léger, 2002).

Black college males struggle to feel connected to their college environment for numerous reasons besides not feeling accepted on campus. Research suggests that many Black college males are academically underprepared for college (LaVant et al., 1997). Some Black college males are accepted to college with low reading and math scores, placing them behind many of the other students in their college courses. Black college males are more likely to enroll in remedial college courses than white students, which marks them as academically incapable of the rigors of college in the eyes of white peers or faculty (Palmer et al., 2009). This places Black male students at an academic disadvantage because they ultimately have to take more college courses than the average college student. Furthermore, Black college males sparingly interact with faculty (Palmer et al., 2009). Research indicates that Black college males do not view college professors as role models and believe college professors have low academic expectations 
for them (Guiffrida, 2005a). Social underpreparedness is another contributing factor to low retention rates of Black college males (Guiffrida, 2005a).

Black college males who struggle with integrating into the college environment and excelling academically may also struggle psychologically. Some studies have shown that Black college males report feelings of isolation, stress, personal dissatisfaction, and low self-efficacy when compared to white students (Keels, 2013; Palmer \& Wood, 2012; St. Leger, 2012). Black college males with high self-efficacy do well academically, but those who enter college with low-self efficacy tend to depart from college before earning a degree (Reid, 2013). Reid (2013) asserts that Black college males who have high self-efficacy tend to integrate into the social and academic spaces of the institution, join student organizations, take leadership roles on campus, and do well academically compared to Black college males with low self-efficacy.

Research indicates how difficult it has been for institutions to retain Black men. With lower Black male retention rates at PWIs compared to HBCUs, many PWIs are looking for ways to increase these rates through programs and initiatives (Museus, 2014). Researchers suggest there are several determinants that cause students to voluntarily depart from college: family responsibilities, economic factors, campus fit, sense of belonging, dissatisfaction with dormitory, low GPA, disengagement from faculty, and poor advising (Sedlacek, 1987). The surge of retention initiatives was created to help institutions increase retention rates. There are few colleges that promote retention initiatives for Black male students on the college website. If there are other PWIs who participate in retention initiatives for Black male students, it is not clearly visible on the school webpage. The Faculty Mentor Program at the University of Louisville pairs faculty mentors with incoming African-American male freshman to assist in connecting with the university. The Todd Anthony Bell National Resource Center for African 
Americans at The Ohio State University promotes educational and social programs to help improve Black college male retention and graduation completion. The University of Cincinnati's Black Man's Think Tank is a mentoring and leadership program that pairs Black male faculty and professional staff with Black undergraduate college males. The aim of the program is to increase Black male retention through positive relationships with college personnel. The Black Male Initiative at North Carolina State University has a living learning component that places Black college males in the same courses and in the same dormitory. One component of this program is mandatory study hall hours designed to enhance learning for Black college males. The Men of Dillard is a Black male retention program at Dillard University located in New Orleans, Louisiana. Black males participate in monthly round table discussions with Black faculty and staff, take cooking classes to learn to work as a team, and review films that deal with Black male life experiences. While there are existing Black male retention programs, there is not an exploration of student participant perspectives of retention programs at PWIs located on a rural campus. This dissertation explores a Black male retention program at a PWI located on a rural college campus and examines the participants' perceptions of this retention program as well as the perceptions of the administration in charge of the programs design and application.

\section{Conceptual Framework}

The Geometric Model of Student Persistence and Achievement (Swail, 2004) is a conceptual framework that describes the relationship between students and the institution they attend. The framework places the student at the center of the model and addresses the questions, "What can institutions do to help each student get through college?"; and, "How can institutions help integrate students academically and socially into the campus, as well as support their 
cognitive and social development?" The geometric model is shaped like a triangle, which denotes a particular force or impetus on a student. The three forces account for student outcomes: cognitive, social, and institutional factors (see Figure 1). Cognitive factors refer to what a student brings with him or her to college. The cognitive factors include the academic ability such as proficiency in reading, writing and mathematics. An important component of the cognitive factors related to student persistence is a student's decision-making and problem solving. Social factors are important to a student's stability. The social factors include integration with peers and the institution, cultural history, and personal attitudes. Research shows that social integration is important to student retention and students have a hard time persisting if they are not socially connected to the institution. The institutional factors refer to the "practices, strategies, and culture of the college or university that impact student persistence and achievement" (Swail, Redd, \& Perna, 2003, p. 77) such as academic and social support, course content and instruction, and student programming. The geometric model places institutional factors at the base of the triangle because the college forms the foundation for student success (Swail, 2004).

The student achieves equilibrium, a term to describe the mode of student persistence, when the forces from all sides (cognitive, social, and institutional) create a balance. If equilibrium is lost, students risk departing from college. The cognitive dimension relates to students' skills, abilities, and knowledge that empower them to succeed in the classroom. Swail (2004) contends that some external forces, such as peers, faculty, and characteristics that students bring with them to college are also considered cognitive factors. The social dimension relates to cultural history, family influence, financial problems, and socioeconomic status. The institutional dimension relates to everything akin to support or hinder students' ability to 
navigate and succeed in college. Such factors include financial aid, campus climate, support services, policy and practices, campus-wide facilities and diversity initiatives.

Swail (2004) discusses the process of reaching equilibrium in two stages. The first stage represents a series of variables on each side of the geometric model. Each variable has an effect on student persistence, which suggests that one variable can be equally neutralized by another variable. For example, if a student has strong social factors, but extremely low institutional factors, their ability to persist may come with some challenges. However, certain variables can combine and work with or against other variables. The combination of forces or reciprocity produces a net effect for each of the three planes of the geometric model (Swail, 2004).

The second stage refers to the continuation of reciprocity. The forces generated individually or across axes accounts for the stability or instability of student persistence and ultimately the achievement of equilibrium. The triangle does not have to be equilateral in order to reach stability. The model supports student retention when equilibrium is reached. Equilibrium of the model can be reached by an infinite combination of variables from each of the three axes (see Figure 2).

The strength of the geometric model of student persistence and achievement is helpful for understanding the multiple forces that shape Black college male experiences. The model recognizes the role of the institution, student motivation, and personal skills as well as the support of family and peers. Understanding the cognitive and social factors that influence Black college male retention brings awareness to the institution on how to improve institutional practice. Black college males benefit from this geometric model because their needs are placed at the center of the model and the institution has a responsibility to the success of Black college males. This model is significant to this research study because the primary focus is on the 
student, contrary to most student-persistent models that place social, cognitive, and institutional factors at the center. Moreover, participants in this study attend a PWI located on a rural campus and some may have entered the university in need of an adjustment period where social, cognitive, and institutional segregation was occurring. Participants discussed their adjustment, if any, to college at a PWI and if the forces (social, cognitive, and institutional) accounted for student outcome and retention. Lastly, membership in the retention initiative is common among participants, and the possible effects the initiative had on participants may help future studies address the significance of this conceptual framework as well as evoke student participant ideas in designing initiatives that serve a specific student population.

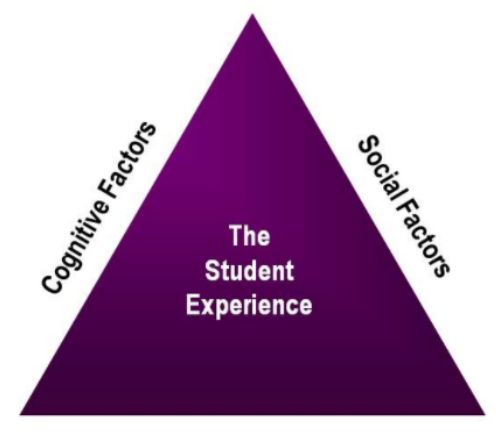

Institutional Factors

Figure 1. Geometric model of student persistence and achievement (Swail, 2004) 


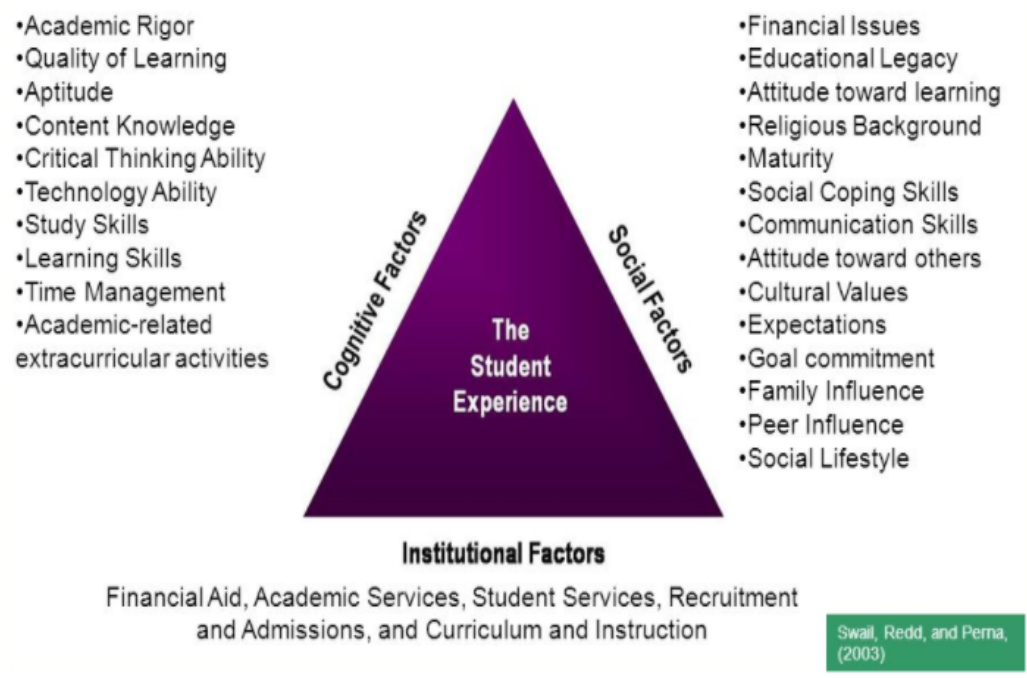

Figure 2. Geometric model of student persistence and achievement (Swail, 2004)

\section{Significance}

The retention rate of Black college males is 30\% (Palmer et al., 2014). Compared to white and other minority students, Black males have the lowest retention rate of all student groups (Palmer et al., 2014). Rarely is this phenomenon examined through the perceptions of Black males who participate in retention initiatives. Most studies have systematically examined the experiences of Black male college students who attend HBCUs, but few studies have explored experiences at PWIs. Likewise, this study is one of few to examine the experiences of Black male college students who attend a PWI located on a rural campus. Moreover, rarely have studies explored the perceptions of retention programs through the lenses of its participants. Instead, programs have been designed by educators who use conceptual models that do not reflect the demographics or student backgrounds that are unique to the institution. This research will expand the literature on Black male retention by providing insights from Black college males who participate in retention initiatives. This dissertation fills a gap in the literature by exploring the perceptions of a Black male retention initiative at a PWI located on a rural campus. 


\section{Scholarly Significance}

Campus-based qualitative research is needed to help institutions identify best practices that aid in retaining Black college men. Most retention programs lack: proven research, specific to the needs of the campus, institutionalized, a strong budget, support and student-centered (Swail, Redd, \& Perna, 2003). This qualitative research study draws on the experiences of Black college male students who participated in a retention initiative. The researcher explored the participant experiences within the retention initiative in order to comprehend student perspectives concerning the effectiveness of the initiative. The research from this study may aid college practitioners in establishing institutional programs that are specifically tailored to the needs of Black males by taking into account their perspectives. Black college males are not monolithic and without qualitative research the conversation about Black male retention continues to be too broad. Furthermore, this study may provide faculty and staff valuable insight from the Black male perspectives of their college experiences so that faculty can better assist Black men academically. Consequently, college administrators can better assist Black men by establishing educational practices that are inclusive of Black men as well as institutional programs that increase the engagement of Black men leading to higher retention rates.

\section{Definitions}

- Effectiveness - the degree to which something is successful in producing a desired result; success; a change which is a result or consequence of an action or other cause;

- HBCU - a college or university that was originally founded to educate students of African-American descent;

- Processes - a series of actions or steps taken in order to achieve a particular end; 
- Purposes - the reason for which something is done or created or for which something exists;

- PWI - Predominantly White Institution is the term used to describe institutions of higher learning in which whites account for $50 \%$ or greater of the student enrollment;

- Rural - characterized by geographic isolated area located outside of cities and town; small populations size. 


\section{Chapter Two}

We see black men as problems that our society must find ways to eradicate. We regularly determine them to be the root cause of most problems in school and society... while the society apparently loves them in narrow niches and specific slots - music, basketball, football and track - we seem less comfortable with them in places like the National Honor Society, the debate team or computer lab. (Ladson-Billings, 2011, p. 9)

\section{Review of Literature}

Black men are the least retained student group in U.S. colleges and universities (Palmer et al., 2014). For Black men who do persist in college, roughly $70 \%$ never earn a college degree (Cuyjet, 2006; Harper, 2006). There is a strong correlation between Black men earning a college degree and an increase in employment and socioeconomic status. Consequently, there is a need for programs and strategies that are proven to retain Black college men. In my study, I explore the experiences and perceptions of Black college male students who participated in an institutional initiative aimed at increasing retention among Black college males. In addition, I also examined college administrators' perceptions of the same institutional initiative and then explored the process by which the initiative became institutionalized. In this chapter, I review and discuss the history of college student retention, factors related to Black college male retention, institutional retention strategies specific to Black college males, racial identity development, and the effects of institutional racism on Black college males.

\section{Classical Explanation of College Student Retention}

Why students leave college before completing a degree has been a question that has intrigued the minds of theorists and educators for many years. College student retention is a phenomenon that poses problems for institutions and the students who attend. Institutions are 
affected by the instability of institutional enrollment, budgets, and the overall perception of the quality of the institution (Braxton \& Hirschy, 2005). College students are affected by student loans, lifetime earnings, and a loss of human capital (Braxton, 2000). According to the National Student Clearinghouse Research Center (2017), 61\% of students who started college in the fall of 2015 returned in the fall of 2016 . Asian students have the highest retention rate at $72.9 \%$, while Black students have the lowest retention rate at 54.5\% (NSCRC, 2017).

Student retention was a modest inquiry until the explosion of student enrollment in higher education after World War II (Berger \& Lyon, 2005). President Roosevelt signed the GI Bill in 1944, which provided World War II veterans money for a college education. By 1950, more than two million veterans had enrolled in higher education and by the 1960s student enrollment also increased among low income and minority students (Berget \& Lyon, 2005). The sudden growth also meant the departure of students as well. Colleges and universities across the nation were unprepared to serve fast-growing and diverse populations, and by the end of the $1960 \mathrm{~s}$ many institutions acknowledged student retention was a common concern (Demetriou \& Schmitz-Sciborski, 2011). Consequently, the rise of student retention studies increased during this era (Astin, 1977; Bean, 1980; Spady,1971; Summerskill, 1962; Tinto,1975). For the purpose of this study, student retention refers to the process that leads students to remain at the institution they first enrolled (Tinto, 1987).

Some roots or common themes related to students leaving college include student intent, adjustment, difficulty, incongruence, isolation, obligations, and finances (Tinto, 1993).

Freshmen students are the most likely to drop out of school compared to other classification ranks, and only half of an incoming class graduates within four to five years (Bean, 2001). Bean (2001) suggests there is a typical profile of students who are retained year to year; they (a) enroll 
in college following high school; (b) attend a four-year private or public university seeking a bachelor's degree; (c) are full-time students; (d) come from a white or Asian family whose parents are educated with high annual incomes; (e) attended a high quality high school; (f) received good grades in high school; (g) scored well on college entry exams; (h) intend to graduate and set career goals; (i) participate in college activities and have a positive attitude towards school; and (j) identify the campus as being a good fit (Bean, 2001). The fewer of these characteristics a student has, the more likely they will depart from college before earning a degree (Bean, 2001). The retention of students is important to institutions because without high retention rates, institutions cannot survive. For years, institutions have looked to theory to understand reasons for student departure as well as to design policies and strategies to support retention efforts. In the following section, I highlight student retention theorists who have shed light in understanding the student departure phenomenon.

\section{Student Retention Theorists}

The first study of student retention was led by John McNeely who conducted research at 60 institutions and examined how students' individual characteristics could influence retention and departure (Berger \& Lyon, 2005). McNeely (1937) focused on what he called "student mortality" or the failure of students to graduate college. He found that student retention involved several factors, some of which include time to degree, impact of college size, and student rank or classification. At the time, students' academic grades were the only predictor of retention (McNeely, 1937), but other theorists noted academic grades should not be the only variable considered (Astin, 1997; Pascarella \& Terenzini, 2005).

William Spady's (1971) model of student dropout in higher education was the first widely recognized model used in retention studies. His research findings noted that previous 
student retention studies did not use a sociological approach and lacked theoretical and empirical continuity. In addition, Spady (1971) was the first to acknowledge the differences in student attrition or departure: those who leave their first college, those who withdraw and never earn a degree, and those who are dismissed from their college or university. He proposed that the analysis of student withdrawal required a more complex model than previous models that indicated students leave institutions out of carelessness.

Spady's (1971) focus was the academic and social systems of college and how those structures contributed to student departure. His retention model, Undergraduate Process Model took shape and was inspired by sociologist and French philosopher Emile Durkheim's (1951) theory of suicide. Durkheim found that individuals committed suicide due to a lack of support by friends and the absence of values in the social system to which they belonged (Bean, 2001). Durkheim (1951) believed the number of individuals who committed suicide could be reduced if they found ways to integrate socially and intellectually into spaces within society. Spady (1971) postulated that students who withdraw from college did so because they did not fit into the social system arising out of a lack of value congruence (academic integration) or support. He proposed that academic potential, value congruence, grade performance, intellectual development and friendship support were direct factors for student departure (Spady, 1971).

Spady also highlighted that social integration would have an indirect effect on departure. His 1971 empirical study concluded that academic performance was the strongest factor for student dropout, but he also found student's social integration, grade performance, and intellectual development were indirect factors for student departure. Following Spady's work, other retention studies and frameworks were adjusted to account for the impact of studentcollege relationships on student retention (Aljohani, 2016). Using Spady's model of student 
departure as a benchmark, Tinto (1975) alleged that Spady (1971) and other theoretical models developed in the past only described the dropout process but failed to explain the process leading up to student departure.

While Tinto's (1975) model of student integration was based on the work of William Spady (1971) and agreed with Spady that colleges consist of an academic and social system that impact student success, Tinto argued that Durkheim's theory of suicide did not theoretically indicate how different students adopted behaviors to depart from their institution. Instead, Tinto believed Durkheim's (1951) theory of suicide and Spady's (1971) model of student departure were descriptive models that explained the conditions by which a generalized group of students' behaviors would lead to student departure. Tinto argued that a model did not exist to explain the individual behavior that led to student departure. Tinto suggested that a theory of student departure that would explain the longitudinal process of withdrawal as well understanding the complex behaviors that underlie student departure was necessary. Tinto (1975) posited that students come to college with pre-characteristics and commitments that affect their college success. He contended that students enter both an academic and social system that influences their ongoing goals and commitment to remain at the institution. Tinto argued that students who do not achieve some level of academic or social integration would likely leave the institution. Tinto's model (1975) was later revised to address criticism of generalized findings, (i.e., lack of identifying various student groups) and the absence of specific institutional data (Bean, 2001).

Tinto's revised model (1993) is similar in structure to his earlier ones $(1975,1987)$ with the addition of student commitment outside of the institution, plans to remain enrolled, and the identification of the unique college experiences of different student groups. Tinto identified different student groups, such as African-American students, low-income students, transfer 
students, adult students, and non-traditional students as having unique experiences that require different retention strategies than those recommended for the majority. Tinto's (1993) revised model was based on Arnold Van Gennep's (1960) anthropological rites of passage theory. Van Gennep (1960) believed that to be part of a group or community, individuals must persist through a three-phase process: separation, transition, and incorporation. The separation phase symbolizes individuals detaching from an established point in the social structure (Van Gennep, 1960). The transition phase is the period between stages, where some individuals leave a former state, but has not joined the new state (Van Gennep, 1960). The incorporation phase is the idea of an individual becoming fully invested into the culture of the society (Van Gennep, 1960). Tinto (1993) posited that the process of colleges retaining students functioned similar to individuals becoming part of communities; students would remain enrolled in college if they separated themselves from their family and peers, adopted the values and behaviors of the institution, and were committed to pursuing those values and behaviors (1993). Tinto's (1975, 1993) model on student departure revolutionized the way theorists understood student departure and has become the most widely used student departure model. Throughout the 1980 s and 1990s, literature on student retention increased as many institutions developed an interest in understanding the multiple factors that interplay with college student departure.

John Bean (1980) developed his explanatory model of student retention based on the theoretical models of Spady (1971), Tinto (1975), and Price (1977). He was influenced by the work of John Price (1977) who studied turnover in work organizations. Price (1977) developed a structural model that identified the fundamentals of employee job satisfaction and intent to leave an organization. He found that the nature of the job, participation, job satisfaction, distributive justice, and family responsibility were all antecedents of job turnover (1977). Bean believed 
student departure from college is similar to the process of employee turnover. Bean argued that individual student characteristics and student satisfaction were reasons students remained or withdrew from an institution. Bean (1980) was mostly interested in understanding the environmental factors that influenced a student's interaction with the institution and how that affected decisions to persist. He found that students are simultaneously influenced by environmental factors, such as finances, relationships with peers and faculty, and family responsibility, institutional fit, and academic capabilities. These environmental factors cause students to develop attitudes about their own proficiencies and the institution they attend (Bean, 1980). He later revised his student attrition model to incorporate a general student attrition model for traditional students within different institutional types. Bean teamed up with Barbara Metzner and developed a model of student retention (1985) for nontraditional students. This model (Bean \& Metzner,1985) was the first to address older, working students who often commuted to campus. The retention of nontraditional students was approached differently because the social integration factors were not the same as it were for residential students (Bean \& Metzner, 1985).

Alexander Astin's (1984) Student Involvement Theory is partially derived from his 1975 study on college student dropouts. The core concept of his theory includes student demographics, college environment, and student characteristics. He argued that students depart from college because of lack of involvement and failure to connect to an aspect of the institution. Astin (1984) defined involvement as the amount of physical and psychological energy a student devotes to the academic experience (e.g., academic work, participation in extracurricular activities, and interaction with faculty and peers). He believed students connected to the college through academic and social opportunities. Astin defined academic involvement by time spent 
studying and developing cognitive skills. He defined social opportunities as participation in campus activities and membership in student clubs and organizations. Astin $(1977,1985)$ showed that students' experience on campus and outside the classroom could contribute to student departure. Involvement in both academic and social activities increases student retention (Astin, 1985). In his study of college student dropouts (1977), Astin found that students, who lived on campus, held part time jobs on campus, joined social fraternities or sororities, and participated in extracurricular activities made decisions to remain on campus regardless of sex, race, ability, or family background. However, besides Astin, few theorists during this time examined and compared student persistence by sex or race. Astin found that Black students were more likely to persist at Black colleges than white colleges. In addition, white students from small towns were more likely to persist at small colleges than larger ones. Astin's (1984) approach in recognizing how multiple student groups are affected differently led to the focus of understanding retention for students of color and underrepresented populations.

Retention theorists have found many reasons why students leave before completing a degree. Howbeit, theorists during the ' 70 s and ' 80 s were not effective in explaining student departure to suit to the needs of institutions and administrators making decisions about retention efforts (Tinto, 1975). Most attempts to explain student departure focused on psychological models of student persistence, which explained student departure as a shortcoming of the individual and not an institutional shortcoming. While psychological views of student departure are warranted, it only faulted students and ignored any notion the institution and institutional environment was to blame. It was not until the 1980s that theorists began to view student departure from a sociological lens, accounting for the impact of student-college relationships on student persistence (Bean, 2001). Academic factors such as GPA, test scores, the rigor of 
college courses, and study skills contribute to student retention (Bean, 2001). Non-academic factors such as student engagement, institutional support, family and peer support, student motivation, and institutional fit also increase student retention (Astin, 1985; Kuh et al., 2008; Pascarella \& Terenzini, 1991). Presently, there are a number of retention studies and partial theories that focus on student retention (Braxton, 2000). Braxton (2000) contends there is no grand theory because differences, such as institutional types, age, gender, race, and underrepresented groups, make it difficult to propose one general theory. The lack of retention research for underrepresented groups highlights one of the limitations of retention studies. While theorists have stretched existing retention models to address new concerns, there remain a number of important areas of underrepresented student inquiry that have yet to be adequately explored. While student demographics in higher education has changed and continues to represent an increase in minority enrollment, the majority of retention studies still focus on white students (Gloria et al., 1999). Institutions must view student retention as an ongoing, campuswide responsibility in order to ensure student success for all students (Levitz, 2001).

Consequently, a second group of retention theories emerged that moved beyond addressing all students using the same retention strategies and began to place the onus on the institution to develop practices, policies, and structures that include students of color (Maldonado et al., 2005). Institutions that are reflective of diversity as opposed to pushing students of color to assimilate with white norms have restructured their policies and practices to embrace the demographic changes of college campuses (Maldonado et al., 2005). Since this shift, there have been some major studies that have examined non-white retention studies and the impact they have had on students of color. 
Dale (1995) assessed the impact of the Horizons Student Support Program on college freshmen at Purdue University. Horizons is a federally funded program that was created to increase the retention of first generation, low income, or physically disabled students. Dale (1995) compared 47 freshmen who met for five hours each week in a freshman orientation course and the mandatory support services given to 47 freshmen who were not part of the Horizons program. The support services included belonging to a social network, instruction in effective study methods, and tutoring. The outcomes showed that $85 \%$ of Horizons program participants were retained through 10 semesters while the control group retained $47 \%$ (Dale, 1995).

Schultz, Colton, and Colton (2001) assessed the impact of the Adventor program on the retention of students of color. The Adventor program at Kutztown University requires students to interact with their faculty advisers on a weekly basis through email, visits, and phone calls, to maintain consistent contact during the first year. The study consisted of 19 students and 15 faculty members who participated in the program and a control group that did not participate. The outcomes indicated that $77 \%$ of the program's participants returned to school the next year compared to $67 \%$ of the control group (Schultz, Colton, and Colton, 2001).

A Minority Retention Project (MRP) based in Northern California was created to support the retention of minority nursing majors and minority pre-nursing students (Gardner, 2005). Faculty from this California institution received a grant for $\$ 22,304$ to fund the MRP for one year. The MRP was designed to address minority students' feelings of alienation, discrimination, and difficulties with academics at their institution. The nursing faculty used a variety of strategies to promote close contact and sense of community between minority students and their peers and faculty. Some of those strategies include a retention coordinator; mentoring 
network; language partnership, family night; health care seminar; cultural competency workshop for faculty; and a minority support group. For the 2003-2004 school year, the MRP achieved $100 \%$ retention of minority nursing students (Gardner, 2005).

A new approach to student retention emerged in the mid-1990s called Student-Initiated Retention Project (SIRP). These programs are student organized, student run, student funded, and serve students of color (Maldonado et al., 2005). The University of California at Berkeley has a SIRP program that operates as a collective of five student-initiated retention centers: "the Black Recruitment and Retention Center, the Native American Recruitment and Retention Center, the Pilipino Academic Student Services, the Raza Recruitment and Retention Center, and Recruitment, Retention and Empowerment of Asian Pacific Islander Youths Considering Higher Education" (Maldonado et al., 2005, p. 10). Maldonado et al. (2005) found that members of the SIRP program reported enjoying being part of transforming institutional norms and negotiating the culture and social aspects of the college community through workshops and activities. The program develops students' cultural identity by reinforcing cultural roots and promoting challenging oppressive social and institutional norms. While there is no empirical data to reflect the success of the program, students report feeling connected to the university and have every intention to persist and graduate (Maldonado et al., 2005).

In an effort to increase retention and graduation rates for Black students attending a large Midwestern research institution, two Black faculty created the African American Student Network (Grier-Reed et al., 2008). The network is designed to address, understand and help students cope with the stressors faced at the institution. Additionally, the network includes faculty and staff who meet with students over the lunch hour. The pilot study included five students, and seven themes were identified in the students' experiences: (a) a safe space, (b) 
connectedness, (c) validation, (d) resilience, (e) intellectual stimulation, (f) empowerment, and (g) a home base. The Network also connects students to resources and leadership opportunities. These efforts have increased retention rates for Black students at this University.

Although I have presented evidence from several perspectives outlining retention studies, further discussion regarding factors related to Black college male retention will provide a contextual basis for understanding the interplay between the high percentage of Black college males who start college yet never earn a degree. In addition, the factors connect to the types of retention initiatives that have been designed for Black college males.

\section{Factors Related to Black College Male Retention}

Black college males have greater access to college than before, but many are not graduating, and an even higher number withdraw from their first institution. Nearly, 1.2 million Black men are enrolled in college and almost 50\% attend PWIs compared to $11 \%$ who attend HBCUs (Toldson \& Lewis, 2012). However, 70\% of Black college males who begin college at a PWI depart before earning a degree (Harper, 2006). Recent literature suggests that the factors related to low Black college male retention are not solely the fault of the institution but are also the result of external factors Black men bring with them to college (Harper, 2006). The narrative for each Black college male who departs from their university is different, yet whatever the reasons, the total number of Black male departures is higher than other student groups (Pascarella \& Terenzini, 2005).

Consequently, the need for PWIs to focus on understanding the challenges Black college males face is paramount. Retention models have been explored to help increase Black college male retention, but Black college men experience factors that affect retention and graduation completion that are not present variables in traditional retention models. 
Retention studies have portrayed Black college male students as disadvantaged, underprepared, and defunct (Fries-Britt \& Turner, 2002; Harper, 2009). Among the studies that have examined Black college male departure, some consistent findings have emerged. As noted by Wood (2012), Black college males were more likely to leave due to family responsibilities (26.9\%), program dissatisfaction $(23.2 \%)$, and other/personal reasons not included among the possible survey responses (21.8\%). According to Cuyjet (1997), many Black college males depart because they are underprepared for the academic rigor in higher education due to poor middle and high school systems, low expectations of teachers, peer pressure not to focus on educational attainment, financial hardships, and lack of role models. In addition, Black college males have developmental disadvantages (social, economic, and cultural) that affect their ability to navigate and succeed in college (Cuyjet, 1997). Other researchers have examined other factors, such as student engagement (Tinto, 1993; Harper, 2006), faculty interaction (Pascarella \& Terenzini, 2005), campus climate (Fries-Britt \& Turner, 2002), and external factors, i.e., family responsibility (Cuyjet, 2006; Harper, 2006) to understand Black college male departure. Most factors that influence Black college male retention can be organized into three categories: environmental, social, and psychological (Strayhorn, 2013). Environmental factors include Black college male's sense of belonging on campus, involvement in academic and social activities, campus fit, and diverse surroundings. There is a very limited Black (African American) footprint in the rural sociocultural fabric of the state in which this present study takes place. Previous studies indicate Black students experience a difficult time transitioning in campus climates that are different from their home lives and communities (Harper, 2006). Social factors include academic success, positive peer interactions, support from university faculty and 
staff, engagement in campus clubs and organizations. Psychological factors include self-esteem, self-worth, self-confidence, and grit.

In the following section, I discuss the most consistent factors associated with Black college male underachievement and low retention and graduation rates. Factors affecting Black college men are multidimensional and complex, but they need to be addressed (Harper, 2006). The factors discussed in this section are: (a) faculty-student interaction, (b) campus climate, (c) psychological factors, (d) student organizations, (e) under preparedness, (f) family and peer support, and (g) financial resources.

\section{Faculty-Student Interaction}

The relationship between students and faculty has been found to have direct effect on educational outcomes (Tinto, 1975). There are a number of significant outcomes associated with positive relationships between Black college males and their professors (Harper, 2006, Strayhorn, 2013). Tinto (1975) found that students with academic gains reported more faculty interaction in and outside the classroom. He further argued that the relationship between faculty and students has the greatest impact on student achievement and is an unequivocal part of the undergraduate experience (Tinto, 1975). According to Kuh et al. (2011) the quality of facultystudent interactions is more important than the frequency of contact. The types of contacts students have with faculty that enhance college outcomes include discussing career plans with faculty or college advisors, interacting with faculty outside of the classroom, receiving immediate feedback from faculty about academic performance, working closely with faculty members on research projects, and discussing student expectations with their professor (Kuh et al., 2011). According to Davis (1991), "Black students on white campuses who have good 
relations with faculty have never seriously considered dropping out of school and have greater satisfaction with their campus lives" (p. 154).

Black college male student interactions with faculty have been both negative and positive. According to Fries-Britt and Turner (2002), Black college males perceive faculty as culturally insensitive. Participants identified cultural insensitivity, including faculty generalizing their responses in class to represent all Black students, faculty failing to acknowledge Black history in class, and faculty refraining from discussing Black perspectives in curriculum (FriesBritt \& Turner, 2002). In a qualitative study of Black and Latino males, Dulabaum (2016) found that many Black males reported feelings of alienation in class when the professor asked them to answer a question dealing with their race. Black male students shared the assumption their professors and peers have is that they share the same perspective as other Blacks (Dulabaum, 2016). In the same study, Black males reported their professors stereotyping them based on societal influences. During a focus group session, several students shared that when they raised their hand in class, professors acted surprised and even startled to call on them. One student suggested that teachers do not expect Black men to be successful in the classroom because they assume they are attending college to play sports or they will end up dropping out after the first semester (Dulabaum, 2016). Some Black males identify faculty as being culturally insensitive as well as prejudiced (Watson, 2002). Watson (2002) found students reported professors asking them to change majors because they were not cut out for the academic rigor due to their scholastic background and home environment. Professors have low expectations and prejudices towards Black college males, which effects academic achievement and retention (Bonner, 2006; Palmer et al., 2014). Guiffrida (2005a) found that Black college students perceived faculty as less willing to go beyond their role as an educator to assist them in connecting with the college. 
Other studies have highlighted the success of positive interactions between Black college males and faculty. Watson (2002) found that Black students who reported receiving faculty support in and out of the classroom were less likely to withdraw or transfer to another institution. In the same study, students reported receiving financial support from their professors when they expressed a financial need and faculty assistance in declaring a major and creating career goals (Watson et al., 2002). Approximately $71 \%$ of Black students at the University of Michigan reported having at least one professor with a strong impact on their development (Chesler et al., 2005). Students reported the ways professors related to them in and out of the classroom as well as their curriculum strategies that helped shape their college experiences (Chesler et al., 2005). In a study exploring the relationship between Black college male athletes and faculty members, Comeaux (2008) used five measures to assess the faculty-student relationship: faculty provided encouragement for graduate school, faculty provided emotional support and encouragement, faculty provided assistance with study skills, faculty provided negative feedback about academic work, and faculty provided help in achieving professional goals. Comeaux (2008) found that the only faculty interaction variable that was significant was providing encouragement for graduate school. Student athletes who were encouraged by their professors to attend graduate school performed academically better than other students who did not report encouragement from faculty to attend graduate school (Comeaux, 2008).

In a study of Black men attending a PWI, students who had a personal relationship with faculty members reported that such a relationship had a great effect on their educational attainment (Reid, 2013). In addition, the study followed the participants post-graduation and found students who developed a personal relationship with a faculty member had greater occupational status and higher annual income than students who did not develop a relationship 
with faculty (Reid, 2013). Dulabaum (2016) found that Black male students who had been successful for at least two consecutive semesters shared similarities in their interactions with faculty. Students shared that they sought out their professors during office hours for extra help. While many expressed ambivalences of meeting with their professors, students shared professors were helpful. In addition, students also took their professor's advice by visiting the tutoring lab and meeting with classmates outside of class (Dulabaum, 2016).

It is clear that Black college male student experiences with faculty differ based on context and many other factors. However, repeated studies show that faculty-student interaction is the most important factor in addressing low retention rates for Black males (Astin, 1984; Tinto, 1993). In the next section, I discuss the effects the campus climate has on the college experience for Black college males.

\section{Campus Climate}

Prior to college, students lean on the support of their communities to get through high school. However, once students step foot on a college campus, the support they once received takes on a new form replaced with new faces, a strange environment, and the assumption that students have the skill set to properly navigate the college terrain. Feeling connected to the campus and reporting a positive campus climate increases student retention and success in college (Kuh et al., 2008). Campus climate affects the college experience for all students, but more especially underrepresented, minority students (Walton \& Cohen, 2007). According to Walton and Cohen (2007), underrepresented students on college campuses continuously gauge whether they fit or belong on campus. Acts of racism, both inside and outside of the classroom, have attributed to a stifling Black college student experience, which has traditionally been followed by high attrition rates (Fries-Britt \& Turner, 2001). A negative campus climate has 
also been connected to Black college male self-efficacy and confidence to succeed in an unwelcoming environment (Harper, 2006).

It is important for Black college males to feel they belong to the college they are attending (Hamilton, 2010). Walton and Cohen (2007) found the feeling that the campus was not a good fit, inevitably affected Black college males' achievement, motivation and persistence. Hurtado's (1992) research study found that one in four college student participants perceived racial conflict on their campus as very evident and also found that white students were less likely to perceive racial tension than Black students. Harper et al. (2011) interviewed 52 Black college male resident assistants from various PWIs and found their perceptions of racial stereotypes and microaggressions caused them to limit their involvement on campus or transfer to a different institution. Campus climate and racial stereotypes continue to be a hindrance for Black college male achievement and also affect retention (Strayhorn, 2008). Not only climate affects Black college male retention; how a student feels about their ability to achieve in a new environment also affects retention.

Cerezo et al. (2015) interviewed nine Black men attending a midsize college on the west coast about their campus environment experiences. They found that many Black men experienced frequent microaggressions, which impacted their desire to get involved with programs on campus and with peers outside of their race. Black men also reported when they did attempt to get involved in activities on campus, they were not well received and often felt hostility from staff (administration, residence hall directors) on campus (Cerezo et al., 2015). Feelings of isolation and inability to connect with the campus left many Black men with feelings of regret for attending college, which led to thoughts about withdrawing. Some participants in the study shared how they were returning to college after leaving another college because they 
felt out of place. Participants' feelings of loneliness affected their emotional well-being and the lack of campus programs that would make them feel connected to the college were lacking (Cerezo et al., 2015).

Solórzano (2000) interviewed Black students who attended three elite PWIs about the types of racial discrimination they experienced on campus. He found that the majority of the 16 Black male participants felt insecure and uncomfortable about nonverbal microaggressions experienced on campus by their white counterparts. Some participants reported that being Black on a white college campus drew negative attention from professors, students, and college staff. Other participants acknowledged avoiding interactions with whites because they did not want to experience subtle microaggressions and end up feeling the need to respond or address the situation in a negative manner (Solórzano, 2000). One student in particular noted that he felt unwanted when he and other same-race peers went to the library to study for final exams. He shared that white students looked dumbfoundedly at him and his friends as if Black students did not study or visit the library (Solórzano, 2000).

Baker (2013) examined the influence of on-campus support on academic performance for Black and Latino undergraduate students. She interviewed 27 Black and Latino college freshmen, a small number of which were Black college males. The findings indicated that the best on-campus support for Black and Latino college students was the support they received from faculty (Baker, 2013). Peer support, studying with other college students, and universityorganized study groups can improve the academic success of students, but it did not improve the grades of Black and Latino freshmen collectively. More importantly, Black college males were the only group in the study where no form of on-campus support affected their academic performance and the only group in the study whose grades declined over their first two years in 
college (Baker, 2013). Baker (2013) contends that Black college men are at a disadvantage because the campus climate does not proactively support Black men. However, the findings show that support from faculty is important for their success.

White students view groups of Black college men as racially segregated, but Black men perceive predominantly Black male groups as a valuable source of support (Ancis et al., 2000). Thus, when Black college men congregate in public places, white students, faculty, and staff view them as a threat, which continues to permeate microaggressions and an unwelcoming campus climate (Ancis et al., 2000). Ancis et al. (2000) surveyed 578 Black, Latino, white and Asian undergraduate students about perceptions and experiences of the campus cultural climate. Forty-three Black college men participated in this study. Black college men were more likely than any other group to experience pressure to conform to racial and ethnic stereotypes in regard to their academic performance (e.g., low grades and poor study habits), as well as minimize overt racial group characteristics (e.g., language and dress) in order to be accepted by white peers and faculty (Ancis et al., 2000). Black college men experienced the pressure to conform to stereotypes, accept less equitable treatment from non-Black college personnel, and racism at a significantly greater rate than other groups in the study (Ancis et al., 2000).

Reid and Radhakrishnan (2003) examined 920 undergraduate students' perceptions of a university's general campus climate. Of the 920 students, 182 Black students participated in this study. Black students reported more negative perceptions of the general campus climate compared to all other groups. In addition, Black students reported more negative racial experiences on the college campus than other groups. Furthermore, Black students perceived that the college could better support racial diversity and maintain a positive racial climate. While 
this study highlighted the experiences of Black students, it did not show the differences between Black male and female students.

Another factor that affects campus climate is the geographical location of the college campus. Many Black college males are from urban environments and the colleges they attend are vastly different than what home is like. According to Fries-Britt and Turner (2002), many PWIs are located in rural areas or small "college" towns, making the college environment less appealing for Black students due to a lack of social commodities and amenities they are used to at home. When Black students are unfamiliar with their environment, their ability to thrive in new settings is difficult. There is also a contrast between Black male students who grow up in urban environments and Black male students who come from predominantly white environments. Perhaps Black male students from predominantly white environments who attend PWIs have less difficulty fitting in to campus life than Black students from urban areas. Therefore, administrators should focus more on campus climate because it serves as a strong proponent for persistence and graduation completion (Reid \& Radhakrishnan, 2003).

\section{Psychological Factors}

From inner city school kids to the freshmen at Harvard University, an overwhelming percentage of black students simply do not believe they are as smart as whites (Green and Wright, 1991, p. 29).

An understanding of some psychological factors (self-efficacy, self-confidence, and perseverance) that contribute to the development of Black men is imperative in understanding retention. Bandura (1997) defined self-efficacy as the belief about one's capability to carry out tasks that produce desired outcomes. He believed that an individual's self-efficacy is a predictor of college achievement (Bandura, 1997). Self-efficacy has been shown to have a positive 
association between faculty and students, academic and social integration, and retention for Black males (Bandura, 1997). In a research study, Reid (2013) found high-achieving AfricanAmerican males reported having high levels of self-efficacy, which had a direct effect on achievement. In addition, Black males in Reid's (2013) study were confident they would be successful in college even after accounting for parents' education and income, high school GPA, and college major, which showed a relationship between self-efficacy and academic integration. Zajacova et al. (2005) found that Black college male students with low self-efficacy were more likely to drop out of college after the third semester. Black college males with high self-efficacy do well academically, but those who enter college with low to moderate selfefficacy run the risk of departing from college prior to graduation (Zajacova et al., 2005). Other research studies show academic self-efficacy is a predictor of college achievement (Bandura, 1997; Reid 2013). Many Black college males who have low self-efficacy may also struggle to socially integrate on their college campus, which is a predictor of student retention.

Self-efficacy has often been confused with self-esteem and self-confidence. For the purpose of this study, self-esteem is feelings of self-worth or self-value. Self-confidence is belief in one's self and likelihood of succeeding. Self-confidence is a combination of self-esteem and self-efficacy. For many years, Black college males did not consider themselves as academically astute as their white peers and their lack of self-confidence affected college retention (Cohen \& Nee, 2000). In 2004, 78\% of Black college males attending PWIs rated themselves in the top $10 \%$ academically (Harper, 2006). However, there is a large disparity between Black college males' self-confidence and the low number of Black college males who are retained each year. Black college males think highly of themselves, but research shows $70 \%$ who attend college will 
not earn a degree. Strayhorn (2014) believed that Black college males who were retained and eventually graduated possessed a psychological trait known as "grit."

Strayhorn (2014) defined grit as "the consistency of Black college male effort toward long-term goals and the stamina with which they pursue those goals over time" (p. 8). Strayhorn (2014) found that grit is positively related with Black college males' academic outcomes (grades, study habits) for those at PWIs. Strayhorn classified Black college males who show high levels of grit as "grittier." In addition, he found that "grittier" Black college males earned higher grades in college compared to peers with similar high school standardized test scores, GPAs, and educational goals. Good grades lead to retention and ultimately graduation completion. According to Strayhorn (2014) no matter where Black college males start in terms of college readiness, those who exert more grit will earn better grades in college and are more likely to be retained.

\section{Student Organizations}

Students who achieve success in college are more likely to be involved in student organizations (Pascarella \& Terenzini, 1991). This association is also true for Black college males who attend PWIs (Strayhorn, 2008). However, Black college male students participate in student clubs and organizations less often than their white counterparts (Cuyjet, 1997). Colleges must be mindful of Black males and what they bring to the institutional context. Black men do not integrate the same as their white counterparts, so it is imperative that institutions are cognizant of the social and academic integration process that Black males undergo (Cuyjet, 1997). Brown (2006) found that intramurals, athletic involvement, and student unions helped black males become acclimated to their new environment and comfortable participating in other campus organizations. Kuh et al. (1997) found that $30 \%$ of Black college men reported being 
asked or found literature on joining a club or organization. In the same study, $31 \%$ of Black college males attended a club organization at least once, and $18 \%$ worked on a school-related committee (1997). The vast majority of Black college male students are not directly being asked to participate in student organizations, which is linked to social integration, academic achievement, and retention (Kuh et al., 1997). Patton (2006) found black cultural centers provide a secondary home for Black college male students as well as assistance with adjusting to the academic requirements. Harper (2005) found campus engagement had a positive impact on black college males who attend PWIs. Black Greek Letter Organizations (BGLO) have been shown to contribute to the development of Black college male students as well as provide them a sense of belonging on college campuses (Kimbrough, 1995). BGLOs help Black college males become more engaged in and out of the classroom, which impacts their sense of self and identity and leads to retention and graduation completion. (Harper and Harris, 2006). Kimbrough (1997) found that BGLOs were instrumental in leadership development for Black college males. BGLOs are particularly important for Black men who attend PWIs (Harper and Harris, 2006) and roughly $20 \%$ of Black college males are members of Black fraternities (Kimbrough, 1997). The benefit to being involved in campus life increases students' sense of belonging on campus which leads to increased retention and graduation completion among Black college males (Strayhorn, 2008). Harper (2006) discovered that Black college males who held leadership positions in clubs and organizations had GPAs above 3.0 and were in line to graduate on time.

\section{Underpreparedness}

Academic preparedness is one of the main predictors of college success (Tinto, 1993). Black college males are adversely underprepared for the academic challenges of higher 
education (Cuyjet, 1997). Stemming from poor elementary and secondary schools, low expectations of teachers, educational limitations, and lack of role models (Cuyjet, 1997), Black college males face several obstacles prior to enrolling in higher education. Early academic problems and teachers who hold negative expectations for Black males has impinged their ability to complete high school and go to college (Palmer et al., 2009). In addition, Black college males are more apt to face suspension and expulsion than their white counterparts (Palmer et al., 2009). Black males face an uphill battle getting through high school and struggle even more in college. Few studies have evaluated how academically underprepared Black college males are when they arrive to campus. Palmer and Young (2009) interviewed 11 academically unprepared Black college males who entered an urban HBCU through a pre-college program and persisted to graduation. The study revealed that student involvement in on-campus activities was pivotal to academic success. However, Black college males were less likely to get involved in campus activities because the campus did not create activities that held the interest of Black college men (Palmer and Young, 2009). Participants also reported that faculty who displayed concern for academic success and general well-being helped to increase academic success (2009). The majority of the eleven participants also indicated that intrinsic motivation was an important determinant to academic success. Harper and Newman (2016) interviewed Black college males who were academically high performing in high school and found those who reported having a rough first-year experience expressed feeling academically underprepared for the expectations of college rigor. In addition, many of the Black college males interviewed also reported they were unprepared for the excess number of class assignments, the fast pace of each course, the enormity of academic responsibility, and the amount of time needed to devote to each course outside of class (Harper \& Newman, 2016). These obstacles call upon students' academic skills, 
motivation and preparation, which may imply that Black college males are pre-equipped to overcome these obstacles, but few are not. Not only do Black college males struggle cognitively as they face new academic challenges, but there are also some social factors that affect Black college male student persistence.

\section{Family and Peer Support}

Non-cognitive influences such as family and peer support affect Black college male achievement. Active engagement outside of the classroom provides opportunities for Black college males to establish meaningful relationships with peers. One primary benefit of engagement outside of class is that it provides a sense of belonging on campus, which leads to increased retention (Palmer, Wood, Dancy, \& Strayhorn, 2014). According to Astin (1997), the single most important influence on students' academic and social development is the peer group. For Black college males, peer groups play a vital role because it helps to encourage a sense of belonging at an institution that is different from their racial and cultural background (Bonner \& Bailey, 2006). Strayhorn (2008) found that Black college males who reported cross-racial peer interaction had a stronger sense of belonging than those who did not. Harper (2006) found that Black college male students reported that same-race peers helped to support and validate their academic success. Similarly, Palmer and Gasman (2008) found that Black college males who reported having peer support from like-minded students had a positive academic impact.

Few researchers have examined the roles of families on academic achievement and persistence on students of color (Cabrera et al., 1999; González, 2002; Guiffrida, 2004; Ross, 1998). Ross (1998) found that Black males who attended HBCUs reported relationships with parents, especially mothers, were critical to their academic success. Bronfenbrenner's (1977) ecological model identified the systems that influence human development, and he found that the 
family system has a direct and indirect influence on students' academic success. Family relationships are a central component for Black families and parental involvement positively relates to adolescent educational outcomes. However, few research studies have explored the adjustment of Black college students and parental relationships (Guiffrida, 2005). Stewart (2006) found that parental involvement indirectly impacts student achievement through involvement in activities, motivation, and perceptions of the college environment. Harper and Newman (2006) discovered that five of their 11 participants reported their home or community life had implications for their success in college. Guiffrida (2005) found high achieving Black students cited family and parental support as having a positive influence by providing emotional, academic, and financial support. While Guiffrida's (2005) study provided a better understanding of the saliency of families to the success of Black students, his study did not disaggregate findings by gender. Palmer, Davis, and Maramba (2011) interviewed Black college male participants and two major themes came out of the interviews. The first theme highlights how participants' families provided active support, encouragement and role modeling to promote academic success. The second theme stressed the importance of family dynamics and togetherness. Many of the participants' families lacked formal education, yet they remained instrumental in providing support for participants' success. Guiffrida (2005) found participants in need of financial help expressed feelings of guilt for accepting money from families that experienced financial struggle and felt pressured to drop out of college to provide financial support for their family. Research shows that the emotional and academic support needed from families is critical, but this support also transcends immediate family to include extended family and peer support (Palmer et al., 2011). 


\section{Financial resources}

Financial factors are one of the greatest predictors of departure decisions for Black college students (Palmer et al., 2014). Student loans are the primary way Black college students pay for college expenses (Palmer et al., 2014). Roughly 54\% of Black students at four-year institutions rely on loans to pay for college compared to $36 \%$ of white students (King, 1999). King (1999) also found that $62 \%$ of Black students who attended four-year institutions received grants and were the most likely of all racial groups to receive grant funding. Scholarships and grants have been linked to higher persistence and graduation rates for Black students (Palmer et al., 2014). An additional $\$ 1,000$ in grant money lowered the chances of Black students leaving college by eight percent (Palmer et al., 2014). Wei and Carroll (2004) believe policymakers have relied on loans in the composition of financial aid packages to persuade Black students to attend college, but loans are not enough to satisfy Black students' academic achievement. More research is needed to make sense of why Black students are more averse to taking out student loans than white students.

Although Tinto (1993) and Astin (1997) encouraged students working to earn money, they both suggested students work on campus and work no more than 20 hours per week. Guiffrida (2005) noted that Black college students primarily work off campus and for more than 20 hours a week. Kuh et al. (2007) found that students who work on campus have better academic success than those who work off-campus. Students contribute to their education by working and many Black students work and go to school simultaneously in order to balance college costs (Desjardins et al., 2002; Palmer et al., 2009). The inability to pay for college forces many Black college males to secure employment while in school. However, if the need is too great and their family needs financial support at home, this may force Black college males to 
work more hours, which affects their ability to do well academically. Rising college costs cause Black college males to take out more loans and work more hours. But, working too many hours can hinder their academic aptitude and possibly interrupt their decision to remain in college.

There is a growing number of colleges and universities that implement retention initiatives on campus. However, literature about the design and success of these initiatives is limited. Despite the heavy concentration of Black men in higher education, theoretical and conceptual models that explain Black college male development and achievement are largely absent from current literature. It is incumbent upon college administrators to create strategies and initiatives that attract and motivate Black male retention and college degree completion. In response to this problem, there are only a few programs to provide support and retention for Black college males. The programs that do exist do not publicly provide the success of the program or its participants. In the following section, I briefly discuss a handful of college retention initiatives and strategies aimed to increase Black college male retention.

\section{Institutional Retention Strategies for Black College Males}

The number of institutional retention strategies for Black males is limited. Previous research highlights a few retention initiatives that emerged before the millennium (Carreathers et al., 1996; Kobrak, 1992; Sherman et al., 1994). However, presently, there are few recorded institutional retention strategies for Black males. In the following section, I highlight a few of the existing ones.

The Faculty Mentor Program at the University of Louisville was initiated in 1984 to enhance the retention and persistence rates of African Americans. The idea behind the program was for faculty mentors to pair with African American incoming freshmen students in providing assistance in helping students connect with the university and to provide direction that helps 
students persist and graduate. The role of the faculty mentor includes contact by phone, email, and bi-monthly face-to-face contact with each African-American student. In the fall of 1994, approximately 129 African American freshmen participated in the mentoring program. Only 24 of the participants were African-American. Two-thirds of the African American men were retained over five semesters and nine out of 14 matriculated through their junior year. In addition, 29 African American men received minority scholarships in 1992 and only four withdrew from the university (LaVant, Anderson, \& Tiggs, 1997). In the early 1980s, the University of Louisville experienced an increase in Black freshman student enrollment, but after the first year the number of black students declined exponentially (LaVant et al., 1997). Consequently, the Faculty Mentor Program was initiated in 1984 to enhance retention and persistence among Black college students. The program's emphasis is for faculty members to be paired with incoming Black students by major. Faculty would serve as a mentor and the primary advisor for the incoming students. While student selection into the program is not based upon race or gender, the program highly recruits Black male freshman students. In the Fall of 1994, 24 Black male freshmen participated in the Faculty Mentor Program and 66\% of the students were retained over five consecutive semesters and 64\% achieved junior status (LaVant et al., 1997). Further data reveals in the Fall of 1992, 29 Black male freshmen participated in the Faculty Mentor Program and by the Fall of 1996, 17\% graduated with four-year degrees and approximately 50\% were retained and enrolled in Spring 1997.

The Todd Anthony Bell National Resource Center for African American Males is located at The Ohio State University (OSU). The Center was founded in 2004 out of a growing concern over the retention of Black male college students attending OSU. The Center promotes several educational and social programs throughout the year where Black males receive the skills 
necessary to improve leadership and increase retention and graduation completion. Other initiatives in Ohio have been developed that focus on Black male achievement in higher education. The Ohio Board of Regents discovered that the six-year graduation rates for Black males attending colleges in Ohio ranged from five percent to $47 \%$. After analyzing the data, key strategies to improve Black male graduation rates included an in-depth mentorship program, early college for Black males, and the Governor's Closing the Achievement Gap Initiative. In 2003, the retention rate of Black college male students at OSU was $80.7 \%$, but in 2008 the retention rate climbed to $89.3 \%$ (Feintuch, 2010).

Dr. Eric Abercrombie, Director of the African American Cultural and Research Center created The Black Man's Think Tank in 1993 at The University of Cincinnati. The Black Man's Think Tank is a mentoring and leadership program that pairs Black undergraduate males with Black male professional staff. The emphasis is to increase Black male retention through goal setting, balancing relationships, and giving back and serving younger Black male students (LaVant et al., 1997). In addition, the program provides a safe space for Black college males to discuss issues and concerns that face Black men in higher education (LaVant et al., 1997). The Black male professional staff assists students in overcoming challenges as well as providing skills to succeed academically. The Think Tank also has an emphasis on instilling in Black college males the need to give back to their race and serve as mentors to the youth.

The Meyerhoff Program is a Black college male program created in 1988 by Dr. Freeman Hrabowski III, President of the University of Maryland Baltimore County (UMBC). The initial design of the program was to increase the number of Black males who earn doctorate degrees. The program provides financial assistance, mentoring, advising, and research experience for Black college male undergraduate students committed to obtaining a Ph.D. in math, science, or 
engineering. The hope is that these Black males will one day join the ranks of minority college faculty in math, science, and engineering. The program has a 95\% graduation rate and boasts more than 800 graduates who have gone on to become scientists, researchers, engineers, doctors, and professors (Hayes, 2013).

The University System of Georgia (USG) launched an African American Male Initiative (AAMI) in 2002 to reach 26 of Georgia's public colleges and universities. This program is the first-ever statewide effort to increase Black college male achievement in higher education. The goal of AAMI is to recruit, retain, and graduate Black college males in the USG system through strategic interventions. The six-year graduation rate of Black college males in the USG system prior to the launch of AAMI was $28.95 \%$, but in 2011 it had risen to $40.35 \%$. In 2002, the system-wide retention rate of Black college male freshmen was $79.43 \%$ and by Fall of 2010 the number of incoming Black college male freshmen doubled, although the retention rate dropped slightly to $74.87 \%$ (Harper \& Harris, 2012).

Philander Smith College launched its Black Male Initiative in 2007. One year prior to the launch, college President Walter Kimbrough reported the six-year graduation rate for Black men at Philander College was $11 \%$. Two years after the start of the program, $23 \%$ of Black men at Philander College graduated within six years. With an annual budget of $\$ 20,000$, the Black Male Initiative had approximately 200 Black men participate in 15 events in its first year; where the total student population was 587. The Black Male Initiative events focus on non-cognitive variables like attachment to the institution, social adjustment and relationships with faculty mentors and peers and so, Black college men need to be part of supporting and nurturing environments in order to achieve success (Kimbrough, 2003). 
The Texas Higher Education Coordinating Board (THECB) launched the African American Male Initiative (AAMI) in 2009 and provided \$28 million in state and federal funding for programs to support disadvantaged students (Sáenz \& Ponjuán, 2016). Sam Houston State University used some of those funds to create the ELITE Program in 2010. This program was designed to promote the academic engagement and retention of Black college males through personal development, leadership, and service engagement (Sáenz \& Ponjuán, 2016). In addition, the program hosts national speakers, mentoring opportunities, financial literacy workshops, and tutoring for Black college males. Freshmen participants are required to maintain a 3.0 GPA and continuing students must keep a 3.25 GPA, and they are encouraged to return to the institution each year. The ELITE participants receive early course registration, access to textbook lending library, study hall rooms, and free scantrons.

LaVant et al. (1997) asserted that in order to have a strong retention program that increases retention for Black college males several things have to be considered. First, the college administration must commit to the retention program by serving as an active ambassador for the program. Second, financial resources must be allocated to support the program. Third, a spokesperson for the program should identify Black males before they step foot on campus and reach out to them prior to their arrival. Fourth, Black males should have faculty mentors from every discipline on campus to be sure that all Black college male students are being reached. Research shows that Black college males experience discrimination at PWIs and retention programs must address racial discrimination (Harper, 2006). According to Spurgeon and Myers (2010), discrimination, negative stereotypes, and a history of prejudice has plagued Black males for decades. Black males account for six percent of the total U.S. population but account for $45 \%$ of all homicides (2010). The media portrays Black men as inadequate, flawed, and 
incomplete. This deficit model obscures the success of Black men who do achieve in spite of all the pressures and obstacles they face. In addition, the risk of preserving systems of inequality by anticipating the failure of Black men is a factor that weakens Black male identity and the ways they view their own race. In the following section, I discuss how racial identity affects the success and retention of Black males in higher education.

\section{Racial Identity Development}

Few theories have been developed to understand the ways racial identity affects Black males in higher education (Cross et al., 1991; Museus, 2008). One of the first sociologists and historians to study racial identity in higher education was W.E.B. Du Bois. In his 1926 essay, Negroes in College, Du Bois chronicled the lived experiences of African Americans pursuing a college degree (Museus, 2014). Although African Americans had access to higher education, they faced challenges of racial identity, racism, and acceptance on college campuses (Museus, 2014). In his 1935 essay, Does the Negro Need Separate Schools, Du Bois wrote:

[t] here are many public school systems in the North where Negroes are admitted and tolerated, but they are not educated; they are crucified. There are certain Northern universities where Negro students, no matter what they ability, dessert, or accomplishment, cannot get fair recognition, either in the classroom or on the campus, in dining halls and student activities, or in common human courtesy. (329)

Du Bois (1935) provided a platform for critical intellectual thought related to the study of racial identity in higher education. His work challenged educators to identify coping mechanisms such as racial identity in order to mitigate student dropout and increase retention for students of color (Museus, 2014). Educators analyzed Black college males from a deficit model, which stigmatizes Black males as incapable of earning a college degree (Harper, 2012). 
Research surrounding racial identity for Black college males is lacking and more needs to be explored to understand how racial identity intersects with Black college male retention.

In a study examining the experiences of Black male students enrolled at Harvard University, Michigan State University, University of California, Berkeley, University of Illinois, and the University of Michigan, Smith et al. (2007) found participants experienced anti-Black male stereotyping and marginality on their college campus and within the surrounding city. Participants also experienced microaggressions academically, socially, and within campus public spaces. Sue et al. (2007) defined microaggressions as "brief and commonplace daily verbal, behavioral, and environmental indignities, whether intentional or unintentional, that communication hostile, derogatory, or negative racial slights and insults to the target person or group" (p. 273). Black males were characterized as being out of place and fitting the description of unsanctioned members of the college community (Smith et al., 2007). Participants at each institution reported racial battle fatigue (e.g., anger, disappointment, anxiety, and fear) and felt the campus was more antagonistic toward Black males than other groups (Smith et al., 2007). Racial microaggressive acts are many times a response to the campus racial climate (Hotchkins, 2013). The impact of racial microaggressions on Black college males impacts their academic performance, social response to the institution, identity development, and impairs the performance of these students. (Solorzano et al., 2000). In a comparative case study, Hotchkins (2013) found that high school Black males were forced to learn in an adverse and contentious school environment. Participants reported experiencing frequent racial insults, uncomfortable classroom discussions, assumptions of cheating, inability to relate to teachers, and feelings of not being liked by teachers and administrators. These feelings affected students' morale academic success (Hotchkins, 2013). Black male students are hesitant to approach faculty for help because 
they do not view them as realistic role models (Guiffrida, 2005). Black male students are more apt to seek academic help from Black staff on campus as opposed to their white faculty (Guiffrida, 2005). Guiffrida (2005) found Black students perceived Black faculty as more willing to assist them by providing them with advising and help with career goals, demonstrating a strong belief in students' abilities, and supporting and advocating for students on campus and at home. However, Guiffrida (2005) noted that Black male college students who attend PWIs also need the support of white faculty to assist them through negative microaggressions faced on campus.

Smith et al. (2011) found that as educational attainment increases for Black males, so does their environmental stress level related to racial microaggressions. Black male college graduates experience $40 \%$ more stress related to racial microaggressions and societal problems (Smith et al., 2011). Dorsey and Jackson (1995) conducted a study of Black students and found that in spite of academic achievement and success, several students reported the campus was not conducive to the success of Black students. The findings identified the campus atmosphere was not favorable to racial harmony, leading $62 \%$ of participants to report the university did not properly address issues of racism and discrimination and $46 \%$ reported the campus did not make efforts to make Black students feel comfortable in their new environment. Watson (2002) found that Black college male graduates' expectations about their future life success was rooted in their college experience. Their college experiences informed them of institutional racism, which affected their own identity and the way they viewed future success. In addition, institutions were blamed for extending bias and racism even when most institutional mission statements speak to inclusivity and diversity (Watson, 2002). 
Kanter et al. (2017) explored the college experiences of undergraduate Black students at a large university in Southern United States. In the study Black participants reported white students said negative things towards Black students. However, white participants suggested Black students were too sensitive and Blacks' perception of microaggressions were far from the truth (Kanter et al., 2017). White participants self-reported their likelihood of engaging in microaggressive acts was based on a non-prejudice nature. The results of the measures indicate microaggressive acts are subtle hostility and negative feelings towards black students. While this study could not bring truth to the white students' feelings, how Black students interpret microaggressions on their college campus and how this rudely affects their identity (Kanter et al., 2017).

Spurgeon and Myers (2010) suggested high racial identity has been linked to positive well-being and enhanced educational experiences for Black college males attending PWIs. If institutions take an anti-deficit approach to educating Black men, it helps to enhance progressive interventions developed to meet the needs of Black college men (Harper, 2012). When Black males constantly see other Black males going to prison and dropping out of school, they experience uncertainties of their own abilities and end up focusing on their weaknesses rather than focusing on strengths (Harper, 2012). If they are uncertain of their identity, the pressures of a new educational environment where many other Black men are failing or dropping out of school may be too demanding. The pressure for young Black males to follow in the footsteps of underachieving Black men is inherently overwhelming. However, instead of focusing on the negative factors that some Black men fall prey to, it is important for Black college males to strengthen their racial identities by focusing on other Black males who have successfully earned college degrees and it is vitally imperative of colleges to provide educational resources like 
academic support programs, Black male initiatives, and student orientation programs to safeguard success (Harper, 2012). In order to create campus environments that promote respect, openness, and a welcoming and safe environment, institutions must create initiatives that admonish interests, motivations, and nuances that are traditional for Black college males (Watson, 2002). Cultural, economic, and political forces have shaped how Black college males are viewed in institutions of higher education. The tradition of race goes deeper than affirmative action and race-based admission processes. Racism permeates school curriculum, the structure of departments, the hierarchy in administration, school policy, and decision making about hiring, promotion, and retention (Chesler, Lewis, \& Crowfoot, 2005). With this in mind, this study addresses the changes that need to be made in order to increase retention for Black college males. In the following section, I discuss institutional racism and how Black college males have been left out of equitable policy decisions and how racism continues to shape the higher education system.

\section{Institutional Racism}

In his book, Race Matters, Cornel West (2000) stressed the need for institutions of higher education to evaluate racism on campuses and examine how racism was ingrained in several facets of the college experience. The impetus of a student's university experience is their race (West, 2000). The university college experience has not benefited Black men (Harper, 2006). Policies created to increase access and ensure equity for African American college students exist; however, the effects of those policies have been marginal. The earliest access to higher education for African Americans took places in 1823, where Alexander Lucius Twilight earned a degree from Middlebury College (Harper, Patton, \& Wooden, 2009). In the mid-1830s Oberlin College became the first college to admit African-American students (Harper et al., 2009). In 
1862, Mary Jane Patterson became the first African-American woman to earn a college degree from Oberlin College (Harper et al., 2009). There were a few institutions prior to the founding of Oberlin College that graduated one or two African-American students. However, none of those institutions allowed African Americans to attend in large numbers (Harper et al., 2009). The establishment of Cheyney State Training School (now Cheyney University) in 1837, Ashmun Institute (now Lincoln University), in 1854, and Wilberforce University in 1856 were the United States first historically Black institutions and served as the catalyst for what would later become a surge of African Americans attending HBCUs and later PWIs (Roebuck \& Murty, 1993). For approximately 40 years, between 1823 and 1865, education policy efforts for African Americans were sparse. In 1865, the Thirteenth Amendment made it possible for churches and white missionary groups to start more than 200 private institutions for African Americans (Harper, Patton \& Wooden, 2009). The emergence of these institutions swiftly changed the demographics of higher education. Moreover, the first Morrill Land Grant Act of 1862 provided funds and 30,000 acres of land for public institutions, which was thought to increase opportunities for Black students to attend college. Following the Civil War, African Americans were still an anomaly in institutions of higher education. By this time, only 28 of four million freed slaves had earned a bachelor's degree (Roebuck \& Murty, 1993). Nevertheless, enhanced policy was on the rise to increase the number of African-American students attending college.

In 1865 , the 13 th amendment was passed, which declared that slavery, except, as punishment for crime, shall no longer exist. Following the passing of the 13 th amendment, the American Missionary Association granted monies to start over 200 private institutions for African Americans (Roebuck \& Murty, 1993). The abolishment of slavery and the surge of Black institutions on the rise provided a platform for African Americans to demand equitable 
living. However, issues of equity continued to permeate and draw a divide between Black and white institutions. White institutions received better facilities, trained teachers, and more government funding than Black institutions. It was not until the Morrill Land Grant Act of 1890 when Black institutions were taken more seriously. This second Morrill Land Grant Act mandated that government funds be distributed equally to Black and white institutions (Rudolph, 1990). In addition, the second Morrill Land Grant Act legalized the segregation of Black and White institutions. Consequently, issues of equality for students attending Black institutions continued to paralyze the aspirations of Black students desirous of the same education as White students (Rudolph, 1990).

In 1896, the Supreme Court ruled in Plessy v. Ferguson that Black and White institutions would remain segregated but had to offer equal accommodations and facilities. While Plessy $v$. Ferguson satisfied the inequitable treatment Black institutions received, white land-grant institutions were receiving state funding at a rate of 26 times more than Black intuitions (Allen \& Jewell, 2002). The notion of equal accommodations and facilities resonated in the court hearings, but states refused to grant Black institutions the same treatment as white institutions (Allen \& Jewell, 2002). For the next 50 years, the inequities continued, but many African Americans did not challenge the system. Black institutions receiving financial support seemed content, and they refrained from dissent for fear of losing any funding.

By 1950, approximately 100,000 African Americans were enrolled in Black institutions (Harper, Patton \& Wooden, 2009). In 1954, the Supreme Court ruled in Brown v. Board of Education that schools would be de-segregated and separate-but-equal facilities in public education were made illegal. While Brown v. Board of Education was immediate for primary and secondary schools, it only really profited states that were legally segregated. At the time of 
Brown v. Board of Education, 17 states and the District of Columbia had laws that enforced segregation in public schools. But in 1958, only seven states maintained segregation in public schools. The Brown v. Board decision was limited in its reach, specifically for states that never attempted desegregation. What stimulated the integration of states was not Brown v. Board of Education, but the Civil Rights Act of 1964. For the purpose of this study, the institution used was not desegregated by Brown v. Board, but instead Plessy v. Ferguson in 1896. Desegregation was forced in the institution studied because it had a graduate school, but Brown v. Board of Education urged policymakers to consider integrating undergraduate institutions as well. When President Lyndon B. Johnson signed the Civil Rights Act of 1964, Title VI of the Act restricted colleges and universities from receiving federal funds if they remained segregated (Rudolph, 1990). The Civil Rights Act of 1964 helped to increase African American enrollment in higher education, and following desegregation more African-American students were enrolling in PWIs in contrast to traditional Black institutions. Almost four decades ago, Black institutions accounted for over $80 \%$ of African American student population, but now only roughly $10 \%$ of African-American students are enrolled in Black institutions (Harper, 2006).

In 1965, U.S. President Lyndon B. Johnson signed the Executive Order 11246, which required federal contractors to employ affirmative action by increasing the number of minority workers (Rudolph, 1990). This legislation allowed African Americans to attend colleges and universities that were once inaccessible. Policy has created more opportunities for African Americans to attend college and earn degrees. While African Americans were given more access to institutions of higher education, individual and institutional racism still permeated colleges and universities. 
Individual or institutional racism is nothing new for Black men (Harper, 2006).

According to Hamilton and Ture (2011), racism is the declaration of decisions for one race for the purpose of subordinating other racial groups. Institutional racism was defined by Lea (2000) as "the collective failure of an organization to provide an appropriate and professional service to people because of their color, culture, or ethnic origin and can been seen or detected in processes, attitudes, and behavior which amount to discrimination through unwitting prejudice, ignorance, thoughtlessness and racist stereotyping which disadvantage minority ethnic people" (p. 220).

An example of institutional racism is institutional policies and practices that prohibit Black college males from participating and receiving the same benefits afforded to white students (Lea, 2000). For Black students, adequately funding their college education is one of the greatest barriers to enrolling in college, being retained, and ultimately graduating (Harper \& Griffin, 2010). One policy that is hindering Black student success is the lack of financial aid available for families whose income is less than $\$ 50,000$ a year (Watson, 2011). Many of the land grant institutions have neglected their mission to educate diverse students by recruiting and increasing aid by $28 \%$ for students whose parents make at least $\$ 115,000$ a year (Watson, 2011). In addition, similar schools award just as much financial aid for students whose parents make more than $\$ 80,000$ a year as for those whose parents make less than $\$ 54,000$ a year. According to Watson (2011) only five of the nation's 1,200 four-year colleges and universities boast a student population where approximately $30 \%$ are low income.

One model of institutional practices that promotes the success and retention of Black college males involves formal college transition programs (Harper \& Newman, 2016). Programs like summer bridge programs are designed to bring minority and low-income students to college 
during the summer to participate in six to eight weeks of college level academic work. The overall goal of these programs is to help students not feel overwhelmed and ready to depart after their first year (Harper \& Newman, 2016). Harper and Newman (2016) found Black male students who participated in summer bridge programs attributed their academic success and persistence at the university to active participation in college transition programs.

Stolle-McAllister (2011) found that summer bridge programs help to prepare Black male students for college through academic coursework, social and academic integration, and exposure to professional settings. Participants reported early academic involvement helped them gain exposure to the university. In turn, participants involved in this program had higher retention rates than Black students who did not participate (Stolle-McAllister, 2011). Participants also reported the program helped to increase self-esteem, earned them respect from others on campus, and provided a sense of belonging. In addition, participants reported forming a community with other Black students was important for retention and academic success (StolleMcAllister, 2011).

In a study of 60 Black male football student athletes, Gill and Farrington (2014) found that Black male athletes enrolled in the school's Intensive Learning Program (ILP) had higher GPAs than Black male students who were not part of the program. The ILP provides assistance to student athletes through content tutoring, assistance in developing academic skills, and oneon-one counseling. The results of the ILP indicate that Black male students benefit from structured, institutional academic practices that boost GPAs and provide a stronger academic foundation for Black males. While institutional policy and practice that reflect financial aid, early college programs, and hiring of Black faculty are important for Black males, it is advantageous for colleges to develop academic and social policy to ensure Black males feel 
welcomed, supported, and involved in the fabric of the college, which leads to increased rates of retention (Elam \& Brown, 2005; Fries-Britt, 2002).

An example of social policies inhibiting Black males' success and retention is the institution's lackluster approach to creating academic and social programs that would attract Black males (Cabrera et al., 1999). College academic and social programs need to be inclusive of all students and not just the majority (Harper \& Newman, 2016). Studies show that Black males students experience higher levels of racial microaggressions, less validation from faculty and peers, and weaker social adjustment to college than their white peers (Harper \& Newman, 2016). Harper and Newman (2016) interviewed 219 Black male students from 30 different institutions and found participants associate their poor first year performance on being academically unprepared. If college and universities recognize Black male students enter college academically unprepared, there should be institutional practices in place to assist them. In the same study, Black male students reported having unrealistic expectations about the academic difficulty of college coursework. Many participants felt they were prepared for the expectations their faculty had as well as the fast-paced nature of the courses. Institutions should have a practice in place that addresses setting achievable goals as well as ways Black male students can reach the academic rigor of college coursework. While academic practices are vital to the success of Black college males, institutional sanctioned social programs are also important.

Black students have better GPAs and higher retention rates when they participate in social activities designed by the college that focus on cross cultural peer relationships and pairing white faculty mentors with Black students (Sedlacek, 1987). However, many Black college males have difficulties integrating socially to college, particularly because the institution does not foster social activities to combat these difficulties (Harper, 2006; Tinto, 1993). Harper and 
Newman (2016) found Black males reported feelings of culture shock when they stepped foot on campus. Many of the participants did not feel they would fit in to the culture and nuances of the campus and ultimately became less optimistic about the college. Institutions perpetuate institutional racism when they do not create social practices that help Black college males feel part of campus life. In another study, Schwitzer et al. (1999) investigated the social climate experiences of Black college students. Black college students reported feelings of underrepresentedness, or less support on their campus than they felt in their high school communities, leaving them unhappy and isolated. In addition, respondents shared feelings of institutional racism, raising concerns that the institution funded white fraternities and sororities more than Black fraternities and sororities thus provoking competition between the groups (Schwitzer et al., 1999).

Institutional racism permeates policy, curriculum, pedagogy, hiring practices, recruitment, admissions, and academic and social activities. Consequently, institutional racism continues to affect the success and retention of Black college males. Rather than adjust and make changes based on the assumed needs of Black college males, it behooves institutions to evaluate best practices through informal feedback from Black college males and formal program evaluation (Elam \& Brown, 2005). To that end, institutional leaders must adapt current policy and practices to support Black college male students. Policy should help frame curriculum, support services, and social and academic practices on campus (Elam \& Brown, 2005). Institutional racism has been part of higher education for years; however, it is incumbent on administrators to safeguard the experiences of Black college male students through intentional policy and practices that increase retention and student success. This overview of institutional 
racism provides a glimpse of the need for new institutional policy and practice and an opportunity for further study. 


\section{Chapter Three}

\section{Methodology}

This chapter elaborates the qualitative single case study method that was used to explore a retention initiative designed to increase Black college male retention and academic achievement. The author offers a rationale for selecting a qualitative single case study method and presents a methodology for this study, description of participant samples, the role of the researcher, and issues of study validity. Finally, a description of data collection tools, method of analysis, strategies to increase credibility, and researcher positionality are included.

The primary purpose of this qualitative single case study design is to explore and analyze Black college male perceptions of a retention initiative designed to increase Black college male retention. In addition, I explored and analyzed administrator perceptions of the retention initiative. This study was designed to extend prior higher education practices and explore the perceptions of the retention initiative of students who identity as Black and male. To study the phenomenon of low Black college male retention rates, the researcher endeavored: (a) to explore the perspectives of Black college male students participating in a retention initiative, (b) to draw connections across the participants' responses, and (c) to identify themes of participants' involvement in the retention initiative. In order to inform the purpose of this study, the following questions guided this study:

\section{Research Questions}

1. How do Black male students perceive the purpose, processes, and effectiveness of a retention initiative aimed to increase Black college male retention?

2. How do college administrators perceive the purpose, processes, and effectiveness of a retention initiative aimed to increase Black college male retention? 
3. Are there differences in how Black male students and college administrators perceive the purpose, processes, and effectiveness of a retention initiative aimed to increase Black college male retention?

\section{Research Design}

This study uses a qualitative approach to examine Black college male and administrator perceptions of a retention initiative aimed to increase Black college male retention. According to Creswell (2007), qualitative research encompasses different strategies of inquiry and methods of data collection, analysis, and interpretation. The design of this research study investigates the essence of a small number of participants experiences about a case or phenomenon to develop patterns and relationships of meaning (Creswell, 2007). According to Creswell (2007), a qualitative study is a process of understanding a social or human problem based on building a complex, holistic picture conducted in a natural setting and then reporting with words the detailed views of participants. Qualitative research develops explanations of social phenomena and attempts to understand the world we live in and why things are the way they are (Bryman \& Burgess, 2002). Qualitative researchers study and collect a variety of empirical materials: case studies, personal experiences, introspections, life story interviews, observations, historical accounts, interactions, and anything that describes problematic moments and meaning in the lives of individuals in their natural settings (Bryman \& Burgess, 2002). According to Guba and Lincoln (2005), there are five main qualitative research paradigms: positivism, post-positivism, critical theories, constructivism, and cooperative. A paradigm is a framework of beliefs, values and methods within which research takes place (Guba \& Lincoln, 2005). A researcher's paradigm is the worldview within which researchers work. 
This researcher's paradigm is constructivist and is based on the philosophical view that knowledge is constructed and contingent on human perception and social experience.

Constructivism is a philosophical paradigm based on a subjectivist epistemology. Constructivists do not believe in on objective truth or the realization that something is true for all individuals even if they do not know it or recognize it. Instead, constructivists believe in subjective truth. A subjectivist approach concludes that knowledge cannot exist without individuals to construct it. Each individual will construct their world in a unique way based on their background and the social forces acting on them. In addition, a subjective approach assumes there are multiple interpretations and no single ultimate truth.

Creswell (2012) divides qualitative research into five categories: biography, phenomenology, grounded theory, ethnography, and case study. The design of this research study is a case study. A case study is an examination of a specific phenomenon like a program, an event, a person, an institution, or a social group (Merriam, 1988). One advantage of a case study is that it attempts to understand the phenomenon in depth-the present and past actions, emotions, and thoughts (Merriam, 1988). Case study research is a qualitative approach that explores a bounded system (i.e., setting or context) in a single case or multiple cases over time, through detailed data collection that involves several information sources (e.g., observations, interviews, documents, and reports) and informs the research through in-depth description and themes (Creswell, 2007). Case studies can be exploratory, descriptive, or explanatory and are the preferred methodology to answer "how" and "why" questions because the focus is on a phenomenon within a real-life context and the investigator has limited control over the events (Yin, 2009). The objective of finding meaning is not waiting to be discovered, but instead meaning is derived through engagement with the realities of our world (Yin, 2009). In the 
current study, the researcher is exploring a single case of using multiple sources, such as interviews, focus groups, and documents. According to Yin (2009), "how" and "why" questions are better answered through case studies because they deal with operational links that need to be traced over time. According to Merriam (1988), case studies can take on three different characteristics that illuminate the nature of the research design. They are particularistic, descriptive, and heuristic. For the purpose of this study, the researcher characterizes his study heuristically, which means the case study can explain:

- The reason for a problem

- The background of a situation

- What happened and why

- Why an innovation worked or failed to work

- Discuss and evaluate alternatives not chosen

- Evaluate, summarize, and conclude, thus increasing its applicability (Merriam, 1988).

This study developed thick, rich descriptions (Merriam, 1998) through the use of semistructured student interviews, focus groups, and document analysis of the phenomenon. The researcher plans to triangulate the data to strengthen the overall findings. Data triangulation enables the researcher to confirm or reject contradictory data found in interviews against findings from documents and other sources. Most qualitative research tends to follow a "bottom-up" or inductive approach where the data drives the development of new concepts (Yin, 2015). For the purpose of this study, the data led to the emergence of concepts and ideas.

\section{Site Selection}

The site for this research study takes place in a land grant PWI located in a rural environment. The institution is located in a homogenous environment that is built around 
agriculture and coal. The college resides in a state that has one of the oldest populations of any state. Nearly three-quarters of the state is covered by natural forests. One of the first major land battles fought between Union and Confederate soldiers in the Civil War took place in this state. Additionally, this state has one of the lowest crime rates in the country.

For the purpose of this study, a pseudonym, Mid-Atlantic College (MAC), was used to identify the research site. The MAC mission statement is: as a land-grant institution, the faculty, staff and students at MAC commit to creating a diverse and inclusive culture that advances education, healthcare and prosperity for all by providing access and opportunity; by advancing high-impact research; and be leading transformation in the state and the world through local, state and global engagement. MAC is supported by five distinct values:

1. Service - we seek opportunities to serve others and are committed to providing the highest quality of service

2. Curiosity - we ask questions, seek new opportunities and change through innovation

3. Respect - we are respectful, transparent and inclusive with each other

4. Accountability - we perform at our very best every day to create an institution this is responsive, efficient and effective

5. Appreciation - we support and value each other's contributions as we build ONE community

Based on the school's website, MAC ranks in the top percentage of public colleges and research universities. MAC has an undergraduate school population of over 28,000. The student racial composition is: $79 \%$ white, $4 \%$ Black, 3.3\% Hispanic, 1.8\% Asian, and $7.5 \%$ non-resident alien. Approximately, $87.5 \%$ of the students attend school full time and $12.5 \%$ part time. Approximately, 57\% of students graduate within six years. 
When it comes to ethnic diversity MAC ranks below average among other four-year institutions. Approximately, $85 \%$ of MAC faculty are white. According to the national average, both the student and faculty diversity population are below average. MAC boasts a 40:60 male to female student ratio, which is higher than the national average. About $47 \%$ of undergraduate students at MAC are from the same state. Approximately, 79\% of students make it past their freshman year, which is well above the national average and $57 \%$ graduate within three to six years.

The purpose of this study explores the perceptions of the case or retention program aimed to increase Black male retention. The case is located at MAC and has been in existence since January 26, 2015. This case has similarities to other institutions, however, in particular, this case was modeled after a neighboring college retention program. The recruitment of Black male undergraduate and graduate students at MAC is done through advertisements, such as flyers, emails, word of mouth, campus canvassing, large poster boards in high traffic campus spaces, and local barber shops. Student emails are obtained from the university email list-serve. To gain membership into the program, students complete a membership profile form. There is no interview, review of resume, or academic requirements for students to gain access to the program. The participants are predominantly Black men, although some Hispanic, Native American, and white males participate. The mission of the case is to focus on the development and retention of Black male college students. Each month, participants and faculty and graduate student peer mentors get together to discuss various topics (empowerment sessions) related to participants' needs and interests. Participants are assigned to a mentor to support them through their collegiate journey. The mentors and participants can meet as often as they like, but it is strongly encouraged mentor teams meet on a monthly basis outside of regular scheduled monthly 
empowerment sessions. On average, there are 35 students who participate in the empowerment sessions each month and meet regularly with faculty and graduate student peer mentors.

For the purpose of this research study, the bounded case is one institutional initiative aimed to retain Black college males. The primary investigator examined separately student participants' and administrators' perceptions of the retention initiative. Multiple institutions were not considered for this study in order to provide an element of control. Analyzing multiple institutions would be more suitable for a separate study.

\section{Sample Participants}

The researcher used a purposeful sampling technique in selecting participants for the study. Purposeful sampling is a technique widely used in qualitative research for informationrich cases (Patton, 2002). Purposeful sampling relies on the researcher's judgement when making a unit selection to be studied (e.g., people, cases, organizations, events, or pieces of data). The researcher must identify and select individuals or groups that are knowledgeable about or have experienced the phenomenon being studied (Patton, 2002). Prior to identifying and making a selection, the researcher must understand participants' willingness to participate and their ability to communicate experiences and opinions in an articulate and reflective way (Palinkas et al., 2015).

The retention initiative is a program within the Diversity Office. The researcher contacted the director of the Successful M.A.L.E. (Men Achieving Through Leadership and Engagement) Initiative to get a list of names, phone numbers, and email addresses of active participants in the initiative. Participants in the initiative range from freshmen to graduate students. In addition, the director suggested the researcher contact a few recent graduates who were also active members of the retention initiative. In sum, the researcher contacted 20 active 
members and recent graduates of M.A.L.E. and 10 agreed to serve as participants for this study. Participants consisted of 1 Graduate Student, 4 Seniors, 1 Junior, 2 Sophomores, and 2 Alumni. The researcher hoped that second semester freshmen would participate in the study, but none responded to voicemails or emails. In addition, the researcher used pseudo names in place of participant names in order to protect the identity of student participants: CW, CA, CT, ER, EW, KE, RD, JD, JM, and SA.

Furthermore, the researcher also explored the administrators' perceptions of the retention initiative. The administrators are the Chief Diversity Office and the Director of the M.A.L.E. The researcher also used pseudo names in place of participant names in order to protect the identity of administrators. The names of the Chief Diversity Officer is Dr. Grayson (DG) and the Director of M.A.L.E. is Mr. Analyzer (MA). Students and administrators received some of the same questions, so that the researcher could build a foundation of how students and administrators perceived the retention initiative. Administrators provided the concept of the initiative and students provided the inception or thoughts of being part of the initiative. The sample pool included classification rank: sophomores, juniors, seniors, graduate students, and recent graduates. Each of the participants must have served at least one full year in the initiative. My intent was to understand the collection of perspectives from students in different grade levels. It was important to understand the perceptions of this retention initiative from both the student and administration viewpoint, so that one group did not influence the other. Moreover, purposeful sampling was important for this study in order to make sense of how the retention initiative was perceived from participants of the program.

According to Patton (2002), qualitative methods emphasize saturation or a comprehensive understanding of a phenomenon by continuing to sample until no new 
information is obtained (Patton, 2002). In addition, qualitative methods are used to attempt to ensure that the knowledge acquired is representative of the entire sample. Unlike quantitative methods, qualitative methods base the number of participants sampled on the type of analysis proposed. This research study methodology is a case study, which yields itself to a homogenous sample, requiring smaller samples, that are analyzed in great detail and depth (Palinkas et al., 2015). Homogenous sampling is chosen when the sample shares the same characteristics or traits (e.g., group of people who share the same race and gender) and the research question is specific to the particular group being examined (Patton, 2002). Within a qualitative research design, more than one type of purposive sampling technique can be used (Palinkas et al., 2015). The researcher selected a form of purposive sampling called critical case sampling. Critical case sampling is useful for exploratory, single case research with limited resources, but is decisive in explaining the phenomenon. According to Patton (2002), a decisive case is one in which when the unit studied is having a problem, then the researcher can be sure all the same groups elsewhere are having the problem.

The homogenous unit selected for this research study was Black males who were part of an institutional initiative aimed to increase Black male retention. In addition, the other unit consists of administrators who were in charge of implementing the institutional initiative. This research is guided by the purpose of gathering of Black college males who attend MAC, so that each male could clearly articulate and reflect on the perceptions of their experiences being part of the institutional initiative. Furthermore, this research was also concerned with the perceptions of administrators in positions that oversee the initiative.

Patton (1990) suggests that sample size is best determined by the time allotted, resources available, and study objectives. This research study needed to produce enough data where 
additional participants did not provide any new insights. The idea of participants not providing additional insights is called saturation. According to Guest et al. (2006), saturation in a homogenous group occurs around 12 participants. For the purpose of this study, saturation is likely to occur between six and 10 Black male participants and one to two lead administrators. Data saturation is reached when further coding is not needed and when the researcher cannot obtain additional new information (Fusch \& Ness, 2015). A large or small sample does not guarantee data saturation, rather it is the data collection methods that do (Guest et al., 2006).

\section{Data Collection}

The data for this study did not commence until the approval from the Institutional Review Board (IRB). Following IRB approval, the researcher conducted semi-structured interviews. The researcher conducted 10 separate interviews with student participants. In addition, the researcher also conducted 2 separate interviews with both administrators. Qualitative interviews are the chief method the researcher used to collect primary data. The principal method of data collection was semi-structured interviews. Semi-structured interviews with participants averaged to be one-hour in length. The researcher conducted semi-structured, open-ended interviews to engage discussion around promoted themes driven by the research questions and conceptual framework. Students and administrators were interviewed, so the researcher could explore how students and administration perceive the case. The researcher asked students and administrators similar questions, so that parallels could be made about the purpose, process, effectiveness, and influence of the case. Open-ended follow-up questions were asked in addition to the semistructured questions to give depth and expression to participants' voices. Semi-structured interviews were completed in one setting. The researcher conducted 12 semi-structured interviews over a three-week period. Semi-structured interviews were each one hour in length. 
Semi-structured interviews with each student participant were conducted in a private quiet room reserved in the library. The same room was used for each of the 10 student participants. Semistructured interviews with administrator participants were conducted in their college campus office. The researcher conducted the interview with DG, the VP of Diversity, in his office. In addition, the researcher conducted the interview with MA, the Director M.A.L.E., separately on another day. Of note, the Diversity Office is not located on campus, which makes it hard for students to know where it is located.

This exploration adds depth to the description of the case and both groups are able to provide different perspectives. Semi-structured interviews were selected so that the researcher would remain open to emergent themes and ideas within a thematic structure. Semi-structured interviews are a series of open-ended questions or broad questions to ask which inherently defines the topic under investigation. The researcher explores themes and ideas to understand their experiences and assist the researcher in understanding the "what" and "how" of the experience (Kvale \& Brinkmann, 2009). This method gives the researcher the ability to probe the participant in several different ways based on how the participant is responding. The method also works best when the researcher's topic has a number of areas to be addressed. The researcher recorded the semi-structured interviews with audio recording equipment and assure participants of confidentiality (Kvale \& Brinkmann, 2009).

The researcher also used document analysis to give voice to the phenomenon. Document analysis is an example of secondary data. Document analysis is a form of qualitative research that gives voice and meaning around a particular topic (Bowen, 2009). The most common text used for document analysis is written documents (Bowen, 2009). Bowen (2009) suggests that a wide array of documents is important although researchers should also be concerned with the 
quality of documents rather than the quantity. For the purpose of this research study, document analysis had the potential to provide contrasts between the administrators' perceptions of the retention initiative and the written documents prepared by the administrators. In addition, the documents helped contextualize the case study and offered opportunities to probe both administrators and students about activities and events pertinent to the retention initiative.

The researcher met with the Director of the Retention Initiative to discuss getting access to helpful documents related to the initiative. The Director of the Retention Initiative emailed the researcher documents that were helpful for the study. Documents were sent to the researcher over a one-month period. It took the Director of the Initiative one month to collect and compile documents related to the research study. Overall, 15 documents related to initiative functioning were analyzed. These included guidelines and planning materials (e.g., Guidelines for How to Plan An Empowerment Session, M.A.N.-Goals Linked To Mission-MA-2014, M.A.L.E. Initiative-Goals Linked To Mission-2014, M.A.L.E. BROCHURE, M.A.L.E. Leadership Breakfast 2017, Mentor Guidelines and Responsibilities Form-Basic Roles), meeting notes (e.g., M.A.N.-Notes \& Questions for Future Planning-2014, M.A.L.E. Initiative Planning Notes), advertisements (e.g., Flyer for M.A.N Leadership breakfast, Flyer for Monthly Empowerment Session), schedules (e.g., "M.A.N. Schedule of Activities-2014-2015-REVISED, Successful M.A.L.E. Fall \& Spring Calendar 2015-2016, Successful M.A.L.E. Invitation-Peer Mentors \& Empowerment Leaders-TEMPLATE-Fall 2016), and other documents (e.g., M.A.L.E. InitiativeMembership Profile Form-2016 Shorter, Newspaper Article_Black Men at WVU).

In addition, when evaluating documents, the researcher should not consider the data as "necessarily precise, accurate, or complete recordings of events that have occurred" (Bowen, 2009, p. 33). Bowen (2009) suggests the researcher explores the content of the documents by 
using an interview technique. Similar to how the participant provides the researcher with relevant information, the researcher approaches the document asking questions then highlighting the answers within the text (Bowen, 2009). Document analysis can be useful for painting a broad, overall picture that provides the researcher a way of identifying meaningful and relevant content (Bowen, 2009).

Finally, the researcher used a focus group method to elicit perspectives about the meaning of truth (Fusch \& Ness, 2015). Focus group interviews lead to different types of data not accessible through individual interviews (Merriam, 1998). Focus group interviews are typically flexible, unstructured dialogue between the group and the researcher (Fusch \& Ness, 2015). Focus groups were a good way to reach data saturation for this present study because semi-structured interviews take place with the same participants as those in the focus groups. Focus groups add a group perspective about the phenomenon that semi-structured interviews do not.

To participate in the focus group, student participants were invited to the Diversity Office on a Saturday afternoon. All student participants carpooled together. The focus group met for two hours. The researcher (facilitator) provided food for student participants. The facilitator effectively facilitated a small group of six participants and asked good follow-up questions. The facilitator also played the role of the scheduler by confirming participation through email, text messages, and phone calls. Nine participants confirmed, but only six participants showed up for the focus group. The recorder assisted the facilitator by capturing in writing what participants were saying and produced an effective summary shared with the facilitator. 


\section{Data Analysis}

The case study analysis method requires the researcher to use varied qualitative data sources including individual interviews, document analysis, and focus groups to gain the perceptions of the study participants. Stake (1995) defined analysis as "a matter of giving meaning to first impressions as well as to final compilations” (p. 71). Merriam's (1998) definition of analysis is an application of constructivist epistemology. She defined analysis as "the process of making sense out of the data by consolidating, reducing, and interpreting what people have said and what the researcher has seen and read, which is the process of making meaning (Merriam, 1998, p. 178). Stake (1995) suggested that researchers should conduct data collection and analysis at the same time.

For the purpose of this research study, the researcher took an exploratory perspective in analyzing data through thematic analysis. Thematic analysis is a method for identifying, analyzing, and reporting themes (Braun \& Clarke, 2006). Thematic analysis is not tied to a preexisting framework and can be used with different theoretical frameworks. Through thematic analysis, the researcher is able to collect data in relation to the research question. Thematic analysis introduces patterns or themes through examination and recording repeated phrases that are important in describing the phenomenon within the data. The researcher examines and records patterns for the semi-structured interviews and focus group. This approach focuses on the participants perceptions and experiences related to the phenomenon. The most widely used thematic analysis was developed by Braun and Clarke (2006), who created six steps of thematic analysis:

1. Familiarize yourself with the data

2. Generate initial codes 
3. Search for themes

4. Review themes

5. Defining and Naming themes

6. Producing the report

The process of reducing data comes in three stages: the free line-by-line coding of the findings, the organization of codes into related areas to construct descriptive themes, and the development of analytical themes (Aronson, 1995). Coding is the process of organizing a large amount of data into smaller segments (Bailey, 2009). Initial coding or open coding is term for breaking up multiple pages of text into more manageable sections that can later be grouped for the analysis stage (Strauss \& Corbin, 1990). During this stage, the researcher reads data or listens to the recordings and in turn writes down initial thoughts. Once the researcher has become more familiar with the data, it is important to identify preliminary codes. This can be from direct quotes or discovering common ideas and then paraphrasing them. The researcher reads every line of data, while understanding some codes will be deleted later and new ones may emerge. The further reduction of data is called axial coding, which is the process of reducing the data by identifying and combining the initial coded data into larger categories (Strauss \& Corbin, 1990).

After numerous codes have been found, the researcher will identify all data that relate to the classified patterns. In conjunction with coding, the researcher also participates in an iterative process called memoing. The researcher "creates, defines, and refines conceptual categories, makes tentative notes about links between concepts, and draws a sketch-often literally as well as metaphorically — of features important for understanding the setting” (Bailey, 2009, p. 133). 
When memoing it is important the researcher asks questions, pose hypotheses, and sees answers grounded in the data (Bailey, 2009).

After coding and memoing, the next step is to combine the related patterns into subthemes. Themes are derived from patterns like what people say, meanings, feelings, and conversation topics (Aronson, 1995). Themes are meaningless when standing alone but emerge from participants' stories to form a comprehensive picture of their collective experience (Aronson, 1995). When patterns emerge between themes, the researcher will obtain feedback from participants to gain a clearer understanding and establish other questions for the participant.

The study used a qualitative data analysis software, NVivo 8 (QSR International) to evaluate the semi-structured interviews and focus group. The software helps make sense of the transcripts from the interviews and focus group. NVivo software (QSR International) classifies, sorts, and arranges the information from the transcript to assist the researcher with the analyses. To analyze data from semi-structured interviews and a focus group, the researcher used a thematic analysis approach (Braun \& Clarke, 2006), which allowed me to bring preexisting research questions to the analysis of the data while also investigating entirely unanticipated themes. Thus, deductive and inductive codes, respectively, were identified and used in the analysis. The questions from the interviews were used to create initial, deductive codes. Then, the transcripts were reviewed to identify themes emerging from the text to create inductive codes. Together, these codes comprised the codebook. Specific text passages relating to the codes were compiled into code reports for analysis. In the results presented here, the participants' quotes are used to illustrate the findings. This data analysis was used to analyze the content of the data collection. Patterns or themes relevant to the participants' experiences and perspectives were identified. 
Once the patterns have emerged, the researcher must build a valid argument for selecting the themes. The researcher formulates theme statements and clear working definitions that describe the essence of each theme to construct a story line. The interpretable pieces of writing using extract examples that relate to theme and research question are what makes up the descriptive storyline (Aronson, 1995). Thick, rich descriptions provide strong, visual images for the reader as well as insights into the research questions (Bailey, 2009). Descriptions should be sufficiently detailed, so the researcher engages the reader into the setting and phenomenon (Bailey, 2009). During the final analysis, the researcher will develop a report presenting the interpretation of results, participant and researcher insights, limitations and generalizations.

\section{Validity of Research}

This research study employs multiple research techniques to ensure validity and reliability of the research. Patton (2002) indicated that studies that use only one method are more vulnerable to errors linked to that particular method (e.g., loaded interview questions, biased or untrue responses) than studies that use multiple methods (p. 248). The researcher uses triangulation to help assemble emerging theories (Creswell, 2012). In addition, the researcher employs member checks. Participants can review their responses (member checking) to confirm the findings of the research. Participants receive their transcript as a document and are asked to review and reply if there are any discrepancies. Member checks makes sure the researcher captures a true and honest representation of the participants experience (Creswell, 2012). Furthermore, the researcher completes field notes of each interview. According to Groenewald (2004) field notes are descriptive and analytical while avoiding judgement. Field notes provide summaries of the interviews and are used to reflect, organize, and improve the study. 


\section{Researcher Positionality}

It is important to acknowledge the researcher's positionality. I am an African-American male who grew up in a metropolitan city. As the eldest of four boys I have always encouraged my brother's aspirations and educational pursuits. Comparing our academic struggles to that of our white peers who received an education in better school districts, taught by highly educated staff and personnel, an abundance of technology and resources, mandatory test preparation, among many other benefits, caused me to question if we had been afforded those same advantages, would we too have earned advanced degrees and maintained competitive employment. As a Black man, earning a college degree was an incredible feat because I had to navigate a new world without the mentorship and guidance of university faculty or staff. But, I watched many of my white peers gain access to the community of help from white faculty that many of my Black peers and I never received

In addition, I served as a graduate student mentor in this same retention initiative from 2014-2016. In qualitative research, bias is inevitable and can affect the validity and reliability of findings. Recognizing bias made me take strides to reduce it during my interviews, focus groups, and write-up of my results. My personal experience and desire to see Black males excel in college proved to be beneficial in connecting with participants and administrators who can help with the study. While Black college males have challenges in retention, these obstacles can be worked through, but it takes a community of support to overcome the challenges and persist to graduation. 


\section{Evidence of Trustworthiness}

Credibility. The researcher sent each participant the transcription from their interview to be sure the participant's point of view was accurately portrayed.

Transferability. The researcher did a thorough job of describing the research context and the assumptions central to the research. The results of the qualitative research can be generalized or transferred to other PWIs in rural settings.

Dependability. It is important to account for the ever-changing context within which the research occurs. The setting remained constant. Students met in the campus library for semistructured interviews and the office of diversity for the focus groups. The experiences of each student participant varied, but it did not affect the way the researcher approached the study.

Confirmability. The researcher documented the procedures for checking and rechecking the data throughout the study. Researcher kept a journal throughout the study in order to frame any biases. 


\section{Chapter Four}

\section{Findings}

This chapter presents data collected through interviews and a focus group with students and administrators from a land-grant PWI located in the Appalachian region. The primary purpose of this qualitative single case study was to explore and analyze Black college male perceptions of a retention initiative designed to increase Black college male retention.

More specifically, it focused on the following three questions:

1. How does the initiative in place help to retain Black college male students attending a land-grant PWI located in a rural environment?

2. How do Black college male students perceive the purpose, processes, and effectiveness of a retention initiative aimed to increase Black college male retention?

3. How do college administrators perceive the purpose, processes, and effectiveness of a retention initiative aimed to increase Black college male retention?

Prior to presenting the findings, it is important to emphasize the methodological approach and organization of the findings discussed in Chapter Three. The design of this research study investigates the essence of a small number of participants' experiences about a single study case to develop patterns and relationships of meaning. Generally, qualitative research develops explanations of this social phenomena and attempts to understand the world we live in and why things are the way they are (Bryman \& Burgess, 2002). In the current study, the researcher's paradigm is based on the philosophical view that knowledge is constructed and contingent on human perception and social experience. Through the use of semi-structured interviews and a focus group with emphasis on the participants' subjective experiences and their perceptions of the retention initiative the researcher sought to develop "thick, rich descriptions" (Merriam, 
1998) of the phenomenon. The researcher allowed the data to lead to the emergence of concepts and ideas.

\section{Structural Organization of the Chapter}

This chapter (a) introduces the participants, (b) describes the environment of the college campus, (c) outlines the retention initiative, (d) emphasizes the emerging themes and sub theme from the semi-structured interviews and focus group in relation to the research questions through examination of the data thematic analysis, and (e) concludes the findings from a holistic view of the college retention initiative. It is the researcher's hope that the data provided, through the voices of my participants, provides an articulate conversation about the experiences of Black college male students who attend a PWI in a rural environment. This chapter is dedicated to presenting the results of this study, in an attempt to bring awareness to college retention initiatives and the students they serve. At the conclusion of this chapter, it will be apparent that the student perceptions of a retention initiative aimed to increase Black college male student persistence should be properly examined and compared to the perceptions of the administrators overseeing the retention initiative. The aforementioned experiences do not fully illustrate a representation of all retention initiatives nor do they characterize the voices of all Black college male students.

\section{Student Participants}

The student participants for this study were purposely selected so that the researcher could guarantee information-rich data (Patton, 2002). Each participant selected for this study identified as an African-American college male who has been an active part of the retention initiative for at least one year. Two participants transferred to MAC from other institutions, while the remaining participants enrolled at MAC immediately following high school. Relevant 
findings from the demographic survey completed by participants are provided below. Table 1 includes participants' responses to general demographic questions. Table 2 highlights participants' self-reported challenges of attending a PWI and how they were introduced to the retention initiative. Importantly, what emerged from how students were introduced to the retention initiative was the pressure from being the first in the family to go to college. Eight participants self-reported they were first-generation college students. For example, RD grew up in an environment surrounded by drugs and violence and his athletic prowess opened doors for him that were not open for many of his friends. RD reflected: "For me, college was the stereotypical way out. Luckily, I had scholarships, so it was an easier access point for me." SA also noted that as a first-generation college student, even his friends were less likely to see the benefits of attending. SA noted: "College was a way out. It's your only option kind of thing. No one else went to college." $\mathrm{CH}$ grew up in an area similar to RD and no one around him desired to attend college and did not recognize any benefit it could provide. $\mathrm{CH}$ shared: "My parents didn't graduate college and even through struggling found ways to take care of us. I am the second person from my block in the last 15 years to go to college."

Two students who participated in the study were not first-generation college students. KE recalled: "For me, college was automatic. Not as much as my mom having graduated from college, but the people in my school, all of them were focused on college. That's, literally, all I heard since middle school." Similarly, JM grew up in a household where both parents attended college and attending college after high school was his only option. JD shared:

I grew up in a household with both my parents who were college graduates, so it wasn't really an option for me. Early on, I remember even freshman year of high school, we 
were already looking at schools. It wasn't really if college was an option, it was which one you're going to.

Research shows that African-American students who come from families whose parents have a college degree, arguably are likely to have additional resources and a support system that are not available to many African-American students who are the first in their family to go to college. Participants in this study each expressed a strong desire to attend college, but many lacked the social and cultural capital to properly navigate the new college terrain. In the section below, a short participant profile provides more context about each of the student participants.

\section{Student Participant Profile}

Ten Black college males were selected and interviewed for this study. The researcher contacted 20 Black college males who were part of the Successful M.A.L.E. Initiative, but only 10 participated. The experiences and stories provided by the participants in this study represents a rich variety of data from multiple subpopulations and backgrounds.

A. CW was a Maryland stand-out high school football player. He received several D2 scholarships and a few D1AA, but his brother was not comfortable with the options and felt CW needed to attend a school that would give him an academic edge and give him the best shot at a career after college. MAC University was not originally on his radar, but MAC provided him money to attend and he was interested in their pre-pharm program. CW grew up in a very high Black and Spanish community, and when he arrived at MAC, he felt an immediate culture shock. However, as a member of the Academic S.T.A.R.S. he arrived on campus five weeks before school started and was able to enroll in summer classes for credit, meet other Black students, and mingle with campus professors and administrators. 
2. CA is a first-generation college student from Washington DC who first enrolled in an HBCU on an athletic college scholarship. His college football coach left the school after CW's freshman year and many of the scholarship players ended up losing their scholarships or wanted out of their scholarships to attend other colleges. CW's high school best friend attended MAC and encouraged CW to start fresh and come to MAC. CW and a teammate at the HBCU transferred to MAC together and coming to MAC as a transfer student did not feel foreign because he had a connection with the campus although he had never visited it. CW would later transfer from MAC during his senior year because of family responsibilities and lack of institutional support.

3. CT is from Virginia and applied to one college in his home state: James Madison. He felt the other schools in Virginia were more academically challenging and he did not want to place those pressures on himself as a freshman in college. CT applied to other colleges outside of his home state (Morehouse College) and when he did not get into those colleges a friend from his high school had been accepted to MAC and told CT he should apply. During the summer following his senior year, CT visited MAC and fell in love with the campus and felt comfortable with the six-hour car ride from home. His dorm and roommate experience his freshman year in college made him feel at home and he quickly became involved in campus activities. He is a recent graduate from MAC University and remains heavily involved in student organizations he served in.

4. ER is from Washington, D.C., but ended up going to high school in a small city located in the eastern panhandle of West Virginia. He is the son of a military man and he and his family moved around often until his father retired in West Virginia. 
ER was used to diversity and being around other students of color, but when he arrived at West Virginia was one of few Black students in his high school and wished he lived in the next district over that had a larger proportion of Black students. His parents instilled in him the importance of going to college and the influence of attending MAC University came from all of the direct and indirect messages he received from school peers, restaurants, and billboards. He is a recent graduate from MAC University and remains heavily involved in student organizations he served in.

5. EW is a first-generation college student from Miami, Florida. He attended an HBCU for undergrad and found out about MAC University in his search for a graduate school experience that would be fully funded. EW never intended to move so far north, but the opportunity to finish a fully funded hybrid (online and face-to-face) Master's program in 2 years appealed to him. He accepted a position as a graduate assistant to offset student fees and pay for housing and it was his graduate assistant advisor who told him about the retention initiative for Black college males. EW desired to be part of a community of Black men similar to the community he belonged to during his undergraduate tenure.

6. $\mathrm{KE}$ is a first-generation college student from Washington DC and made a list of colleges he wanted to attend. MAC was number four on his list, behind University of Delaware, Pace University in New York, and Babson College in Massachusetts. When he didn't get into his top three colleges, it was evident he would strongly consider option four. Because MAC is a public institution, as a DC resident, KE received $\$ 10,000$ towards his tuition. He didn't know much about the social structure of the college and attended MAC without visiting the campus. 
7. $\mathrm{RD}$ is a first-generation college student from Columbus, Ohio and was recruited to MAC to play football. MAC was not his first choice and he had other scholarships, but due to credits and grades his options were limited. He narrowed his school search to five schools and the Sunday before high school athletes "signing day" he committed to attend MAC. While he is from a rural area of Columbus, his home community consisted of predominantly rural Blacks and so navigating a predominantly White rural college campus was an adjustment. His first semester was rocky due to family issues at home, but his teammates, college coaches, former players who still lived in the area, and connections with a few Black male mentors helped in his adjustment.

8. JD is a first-generation college student from West Virginia and attended a predominantly white high school. His first college choice was to attend a HBCU, but due to his family's limited exposure to the college process he decided to look at colleges some of his high school friends had been accepted to. JD went on a campus tour of MAC through a special weekend hosted by the admissions office. He listened to Black student panelists talk about their experiences at MAC and he instantly felt a connection with the university. Later that summer he attended a bridge program at the university for Black students and was able to develop friendships before the start of school.

9. JM is from Montgomery County, Maryland. He admits that he had no choice but to be a college graduate. Both his mother and father are college graduates from NC A\&T and since birth he knew A\&T was his top choice. JM's parents are season football ticket holders, so there was heavy pressure to attend the college. His other 
college choices were, LSU, Auburn, Western University, and MAC. JM served as a student manager for his high school football team and MAC recruits came to his school to recruit players. JM inquired about the need for student managers and MAC students shared they had a few slots open. While, JM knew his parents wanted him to attend A\&T he wanted to experience something different, and MAC offered him a partial scholarship to attend and work as a student manager for the football team. When he visited the campus, he had a feeling he would fit in well and would find comfort in attending such a large university.

10. SA is first generation college student from New Jersey. He is a transfer student from a two-year college. Initially, MAC was one of his top choices, but when he was not accepted to any of his top choices. His 2-year college has a direct pipeline to MAC and many students who are not accepted to MAC initially will attend this small college to increase GPA and become more college ready. SA was a student athlete at his first college, but when he transferred to MAC he focused on his academics and no longer pursued playing sports. MAC was not an immediate culture shock because his two-year college was more of a culture shock and helped to prepare him in navigating the college terrain at MAC. 
Table 1

Participant Demographics

\begin{tabular}{|c|c|c|c|c|c|}
\hline Name & Gender & Race & Class Rank & $\begin{array}{l}\text { Home } \\
\text { Community }\end{array}$ & $\begin{array}{l}\text { High } \\
\text { School }\end{array}$ \\
\hline CW & M & Black & Senior & Rural & $\begin{array}{l}\text { Pred. } \\
\text { Black }\end{array}$ \\
\hline $\mathrm{CA}$ & M & Black & $\begin{array}{l}\text { Senior/Transferred to } \\
\text { HBCU }\end{array}$ & Urban & Mixed \\
\hline $\mathrm{CT}$ & M & Black & Alumni (2017) & Suburban & $\begin{array}{l}\text { Pred. } \\
\text { White }\end{array}$ \\
\hline ER & $\mathrm{M}$ & Black & Alumni (2017) & Rural & $\begin{array}{l}\text { Pred. } \\
\text { White }\end{array}$ \\
\hline EW & M & Black & Grad Student & Urban & $\begin{array}{l}\text { Pred. } \\
\text { Black }\end{array}$ \\
\hline $\mathrm{KE}$ & M & Black & Junior & Urban & $\begin{array}{l}\text { Pred. } \\
\text { Black }\end{array}$ \\
\hline $\mathrm{RD}$ & $\mathrm{M}$ & $\begin{array}{l}\text { Black/Native } \\
\text { Amer/Syrian }\end{array}$ & Senior & Rural & $\begin{array}{l}\text { Pred. } \\
\text { White }\end{array}$ \\
\hline JD & M & Black & Senior & Suburban & $\begin{array}{l}\text { Pred. } \\
\text { White }\end{array}$ \\
\hline JM & M & Black & Sophomore & Suburban & Mixed \\
\hline SA & M & Black & Sophomore & Suburban & Mixed \\
\hline
\end{tabular}


Table 2

Participant Response Summaries

Name Challenges at PWI M.A.L.E. Years -

M.A.L.E

CW Small network of Black peers; does not Outreach from the CBC\&R

4 feel like home

CA Small network of Black, like-minded
peers; Professors had little to no
understanding of the make-up of the Black
family

Worked for the CBC\&R

CT Small network of Black peers;

Approached by another

student

ER Fragmented - urban black students stay

Academic S.T.A.R.S. together and rural black students stay together

EW Lack of cultural awareness and history

Graduate Assistant

Supervisor

KE Hard to access things that are available in urban cities

RD Pressure that Black men have to be strong Former WVU Athlete at all times

JD No Black representation in the classroom and administration

JM Lack of programs for Black students; does Academic S.T.A.R.S 
SA Pressure to assimilate to white culture and not be himself

University Announcements;

\section{Administrator Participants}

The administrator participants for this study were purposely selected so that the researcher would guarantee information-rich data (Patton, 2002). There were two administrators selected, one of whom was the creator of the retention initiative and the other the chief diversity office for the institution. The purpose in selecting administrators to participate in this study was to compare the findings to student participants as well as the archival documents related to the retention initiative. The administrators provided rich-detailed information concerning the retention initiative, the students they serve, and the understanding of why this retention initiative is of importance. The two administrators agreed that the retention initiative was imperative to the success of African-American college males. However, they contrasted in their views of the way the program should be run. Both administrators identified as African-American male. DG serves as the Vice President of the Diversity Center and the sole Chief Diversity Officer. His involvement in the retention initiative spans from his more than 20 years of experience in law, advocacy, and diversity. He is the direct report for the retention initiative. MA is the Director of the retention initiative. As a former student and assistant director from a Midwest college, he brought the idea of starting a retention initiative for men of color to MAC University. He created the program in one department at the University, but later when he changed roles and moved to a new department on campus, he renamed the retention initiative and expanded its reach from Black males to men of color. While the retention initiative is open to all men of color, $90 \%$ of the initiative consists of Black college male students. The results of the semi-structured 
interviews with administration participants are shared later in this chapter. In the section below, a short administrator profile provides more context about both of the participants.

\section{Administrator Participant Profile}

The researcher only contacted two administrators because they were the only ones in charge of the creation and implementation of the retention initiative. While other campus administrators participate in the program, they were not part of the planning and design of the initiative. Other campus administrators meet with student participants once a month during empowerment sessions and, on occasion, with students outside of monthly empowerment sessions. The experiences and stories provided by the participants in this study represents a rich variety of data from different backgrounds.

1. Dr. Grayson (DG) has a doctorate jurisprudence and his background as a trial attorney opened the doors for him to serve in Diversity Office. He is the first chief diversity office at MAC and prior to his appointment there was no diversity office. DG spearheaded the transition of the social justice office, which included student accessibility services to now include affirmative action and diversity initiatives. In the early years of his tenure, he made the case throughout the state for the need for more diversity work and one single unit on campus to oversee the ancillary diversity work such as the Black Culture Center and the LGBTQ Center. However, the institution decided not to place all units under one department and the diversity work on campus remained fragmented, without being systematized, measured, and tracked with a high degree of responsibility. After serving six years as Chief Diversity Officer, DG has recently stepped aside into a more advisory role to the university president. 
2. Mr. Analyzer (MA) is a current Ph.D. student at MAC University. He began his professional career at a Midwest college and accepted a position at MAC in June of 2012 to serve as an assistant director for the Black Culture Center. He quickly discovered there was not any type of targeted program or initiative specific to African-American students, specifically African American males. In his experience at his former Midwest college, he worked closely with the Black male initiative there. His experience working with the Black male initiative and becoming a member of Alpha Phi Alpha Fraternity Inc., a Black Greek Letter Organization, stoked his desire to start a Black male initiative at MAC. In 2012, he formed a Black college male program called M.A.N. (Male Achievement Network) that was to deal with the notion of achievement of Black men achieving in all facets of their lifeacademically, professionally, socially, culturally, and personally. Two years after this appointment, MA changed positions and took a job at the Diversity Office. M.A.N. did not continue at the Black Culture Center and so with the approval of his new supervisor, DG, he started a new initiative for males and called it The Successful M.A.L.E. Initiative. The acronym for M.A.L.E. stands for Men Achieving through Leadership and Engagement, which soon became a MAC support initiative for MAC men of color. MA recently stepped aside as Director of M.A.L.E. to focus on his doctoral studies. He still serves as an advisor for the initiative.

In the following section, the case or the retention initiative is described to provide context for the findings that are discussed later. 


\section{The Case: The Successful M.A.L.E. Initiative}

The Successful M.A.L.E. Initiative or affectionately known as M.A.L.E. was created under the Diversity Office by MA. It was modeled after the first initiative, M.A.N., which was founded by MA in June of 2012. However, the first initiative did not gain the traction that it needed to be supported by the institution at large. MA and DG enlisted the support of the university president to repurpose and relaunch an initiative for men of color on campus. This new initiative would focus on two main tenets: retention and graduation completion. The other components of the initiative would support the retention and graduation completion for men of color. M.A.L.E would be the first retention initiative built into the fabric of the institution for male students of color. In other words, MAC did not have an institutional history of retention initiatives for men of color. The researcher worked closely with one of the university head librarians to research if the university had other programs that supported male students of color, but after looking through the archives for weeks, we did not discover any documents related to programs for male students of color. This does not suggest that there were not informal programs for male students of color, but there were no documented cases.

With the support of the University President, M.A.L.E was supported by professional mentors, administrators, campus departments, and the Office of the President. Although this retention initiative was not established within the university's strategic plan, the college President has publicly supported the initiative and has been an active participant in monthly empowerment sessions. With the expansion of the M.A.L.E. initiative, the responsibility was now a campus wide effort, receiving support from other departments such as Student Life, Housing and Residence Life, and the Black Culture Center. The M.A.L.E. initiative has 
struggled to be a data-driven program, yet the interviews with students indicate it has been effective aiding in both retention and graduation completion.

M.A.L.E. meets monthly for empowerment sessions and periodically throughout the year for special events and mentor-mentee outings. These sessions are normally run by MA, professional mentors, and graduate student mentors. The active student participants range between 25-30 for monthly empowerment sessions. There are five to 10 active professional and graduate student mentors who attend the monthly empowerment sessions. In addition to the monthly empowerment sessions, the professional mentors are assigned five to seven students and are encouraged to meet with them on a monthly basis. Graduate student mentors are also encouraged to meet with professional mentors on a monthly basis to discuss potential at-risk students and prepare for monthly empowerment sessions.

\section{Other Initiatives Supporting Black College Males}

The researcher identified M.A.L.E. as being the only direct program on campus that supported the retention and graduation completion of Black college males. However, during the semi-structured interviews with student participants what was discovered was there was a separate program on campus that was indirectly geared to support the retention and graduation completion of Black college males. Four of the 10 student participants were part of a summer bridge program for incoming freshmen called Academic S.T.A.R.S. (Students Achieving and Reaching Success). S.T.A.R.S. was created by the Black Culture Center on campus and is a five-week program that helps African-American students build an academic foundation, develop cultural self-awareness, and enhance leadership capability. The program offers a three-credit course during the five weeks where students are introduced to the academic rigors of college, meet one-on-one with a professor, and become acclimated to working in groups to complete 
tasks. In addition, the program enlists periodic, student development workshops for students.

S.T.A.R.S. accepts approximately 20 students each academic year.

Participants who were part of S.T.A.R.S. were contacted about the program by the Black Culture Center. To be eligible for S.T.A.R.S. students must: (a) be a first-year African American student who is carrying at least a 2.75 in their high school program, provide evidence of extracurricular activities or proof of community service, submit high school transcripts, include three letters of recommendation, and write an essay. The participants in this study who were also part of S.T.A.R.S. each expressed the impact this program had on their success in college and M.A.L.E. was another more ongoing support system for them. Participants who were part of S.T.A.R.S. and M.A.L.E. had advantages that other participants did not. They were able to build relationships with other students, faculty, and administrators prior to the start of their first Fall semester. They did not struggle in navigating the campus terrain like many of the other student participants. In addition, the successful completion of a college course prior to the Fall semester gave students momentum in their academics as well a feeling of success in their academic journey.

The Diversity Office and the Black Culture Center are two separate departments that both focus on the retention and graduation completion of Black students on campus. M.A.L.E. focuses on Black college male students and their challenges and successes they find attending a PWI. However, while S.T.A.R.S. does not focus solely on Black college males, it does offer Black college males a support prior to coming to college. This support is important to discuss because 4 of the 10 participants expressed the importance of being part of S.T.A.R.S. and the impact and influence S.T.A.R.S. has had on them. In addition, all four participants were introduced to M.A.L.E. through their involvement in S.T.A.R.S. 
In the following section, the college environment in which M.A.L.E. is located is described.

\section{The University}

The college campus is located in a state in the Midwest, nestled between the Appalachian Mountains and has pristine views of the natural landscape. The state was formed in contention with a neighboring state during the American Civil War. The majority of the counties in the state are designated as rural. It is known for logging and coal mining. Roughly, three-quarters of the state is comprised of forests. It is one of the least diverse states in the nation with $93.1 \%$ of the state being white (National Center for Public Policy and Higher Education, 2008). In addition, it ranks 37 th out of 50 of African-American inhabitants. Of its inhabitants, 18.7\% have a bachelor's degree or higher (2008). The state is challenged by retention, degree completion, attainment gaps, and enrollment in higher education. This challenge is heightened by the number of high school students who do not enroll in post-secondary schools following graduation.

Subsequently, $18.3 \%$ of the state population lives in poverty (2008). Historically, the mining and coal industries have been the state's main source of production, and it is also known for outdoor activities, including skiing, whitewater rafting, fishing, hiking, and hunting. The state's population is also aging faster than the U.S. national average. It has a median age of 40 which ranks as the oldest population in the United States (2008). Despite the economic challenges the state experiences, the city where the college is located for this study is ranked by Forbes (2017) as one of the top 10 best small cities in the nation to conduct business. In addition, the college is ranked in the top 150 public universities and in the top 202 best value colleges (Forbes, 2017). 
In the following section, the findings are discussed. The themes and sub-themes that emerged from the study are explained in detail. More specifically, the themes and sub-themes are derived from the following three questions:

1. How do Black male students perceive the purpose, processes, and effectiveness of a retention initiative aimed to increase Black college male retention?

2. How do college administrators perceive the purpose, processes, and effectiveness of a retention initiative aimed to increase Black college male retention?

3. Are there differences in how Black male students and college administrators perceive the purpose, processes, and effectiveness of a retention initiative aimed to increase Black college male retention?

In addition to the M.A.L.E. initiative, another initiative (S.T.A.R.S.) is referenced because student participants shared this program served as separate support to help retain Black college male students. The researcher only addresses the M.A.L.E. initiative in the findings because it is the only campus initiative that is designed specifically for Black college males. However, both M.A.L.E. and S.T.A.R.S. initiative(s) are intertwined throughout the findings because it is impossible to highlight some of the participant experiences as it relates to M.A.L.E. without addressing their involvement in the S.T.A.R.S. program. 


\section{Findings}

The findings in this study provide a framework for understanding the need for retentionbased initiatives for Black college males, the organizational structure of such initiatives, and how the vision and implementation of the initiative align. These findings support the research questions in this study. In the following section the themes from the study are discussed. In addition, the researcher analyzes differences of opinion held by students and administrators. This approach details the common themes within the study as well as any differences shared so that a complete picture of the findings are shared.

Themes. The identified themes originated from predominant motif coding and were organized in three groups reflective of the components in the research question 1 and $2-$ purpose, processes, and effectiveness: Group One (Purpose) - Needs and Obstacles: External and Internal; Group Two (Processes) - Support: Through the Program and Outside the Program; and Group Three (Effectiveness) - Organization: Sense of Family/Community and Ways to Improve the Program. Figure 3 illustrates all themes in this study.

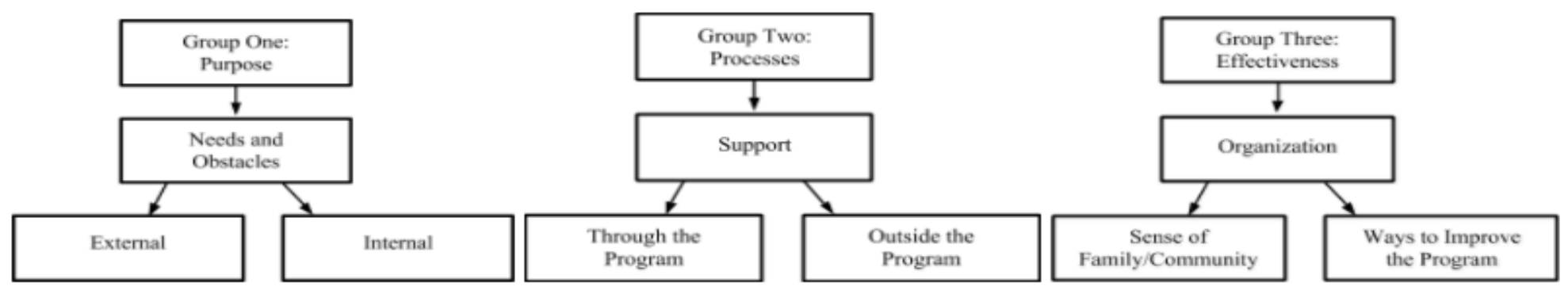

Figure 3. Themes and sub-themes

Common themes and sub-themes. Within some of the theme are sub-themes that further narrowed and detailed how the participants understood the nature of their respective experience. 
These were also identified by a careful analysis of the predominant motifs within the experiences of the participants.

Needs and Obstacles, External Needs and Obstacles, refers to broader cultural and institutional challenges that black students face while attending college. They detail the nature of the circumstances of the individuals' outside world such as interactions with others, the institutional environment and family problems. Internal Needs and Obstacles, expand upon the nature of the inner-self and subjective and personal lives of the individuals as they go through college experience.

Support, Support through the Retention Program, expands on how the program in place is perceived by both students and administrators. Support outside the Retention Program, describes resources that students identified as available outside the targeted retention of the initiative designed to increase Black college male retention.

Organization, Sense of Family/Community, details students' reaction to the community that was formed because of the initiative and reasons why they remained members. Finally, Ways to Improve Organization of the Program, details students and administrators' perceptions about the logistics that can make the program to function better and any unmet needs an improved program should address. Figure 2 illustrates these themes and sub-themes.

\section{Group one (Purpose): Needs and obstacles.}

External needs and obstacles. External Needs and Obstacles, refers to broader cultural and institutional challenges that black male students uniquely face while attending college. For example, participants reported that they felt as "odd men on campus," which made it difficult to connect to the majority white student population. CW said: "Most classes were Caucasians students and roommate was Caucasian (felt alone in class [])." CA noted: "Black male 
population is very small." CT echoed: "three black males on my entire (dormitory) floor." Participants shared an overwhelming need to connect with other Black males. They were not visible in their dorm rooms, classrooms, or even in public spaces like the student union and cafeteria. For some participants, the lack of other Black males on campus was new and entirely different than what their home communities and school districts looked like. RD expressed: I think the challenge of fitting in on this campus because, as a predominantly white institution, year-round cultures is different from what you're used to, what you grew up in. [ ] You hang around people that don't necessarily have the same culture beliefs or views of certain things that you're used to and it's just different [ ] Adapting to new people, different cultures.

KE agreed with RD's expression of the lack of Black students on campus. He said: "As far as me being here, I wish there was more black students, at a [basic] level, I wish there was more black students, that's all." There is a need for Black college male students to be around and interact with other Black college males. While the number of Black college males on campus is small, there is still a visible number. However, many Black college males are spread out on such an enormous campus leaving rare opportunities for them to connect. MA shared because Black college males have rare opportunities to connect it was important to create a program that brought them all together. MA shared:

So, having this opportunity, I think for people at a predominately white institution creates this safe, this comfortable space for students of color to be able to debrief, to be able to talk about their experiences, their struggles, their concerns, their issues, their successes. The participants further elaborated on race related, cultural issues that affected them while in college. They talked about working through the cultural differences, fighting "Black Male" 
stereotypes, dealing with white privilege, as well as about general difficulties with finding appropriate support from family members. Below are examples that illustrate each of these issues.

Participants talked extensively about the necessity to work through cultural differences and obstacles that affected the Black community as opposed to the white student population. KE reflected:

I think that is the case, a lot of times we think that [as Black males] college isn't for us. But I also think one the flip side of that, with Black males, we see all these other ways to make it. The primary ways and sometimes our primary role models are actors, rappers and ballers. So it's like, 'I don't know how to act so I'm going to gear towards rapping and balling." It's easier, these days, to get your stuff out there.

Many of the first-generation participants also expressed how many of their high school peers took jobs out of high school instead of attending college. The idea that "college is not for us" was a reoccurring theme among some of the participants. Culturally, they were not raised in a community that pushed attending college. While some of them were encouraged by their parents, many of their peers did not subscribe to the thought that college would be beneficial. Instead, the chased dreams of becoming athletes and rappers, which is entirely different from the cultural upbringing of their white counterparts. KE further explained:

The black community, especially for black men, has become obsolete or non-existent to the fact that black men often find different ways (other than college) to secure and find their own niche not centralized in our community of black resources.

JD remarked: 
A lot of black males come from high schools that are inadequate and don't prepare them the best for college. It's a natural thing that happens based on the way our laws and things like that are set up. They don't know they're behind and they come in thinking with a good attitude, “I'm ready to do this." But really, they're already 10 steps behind. They're going to be working hard, harder than the man next to them, when they get here.

Participants shared that when they arrived at campus they realized that their Black community had not properly prepared them academically and socially for college, especially a PWI. When they spoke with their white peers about the communities in which they grew up in, they quickly realized that culturally Black males entered college lacking the academic and social support their white peers received. In addition to cultural obstacles, participants expressed the need to work hard to live outside the "Black Male" stereotype. There are a number of Black stereotypes that participants expressed and some are: all black men are athletes, all black men are not intelligent, and all black men are aggressive and competitive. CT explained:

They [whites] could start taking down some of those stereotypes. Because all these students come from different backgrounds. They don't know what black people are like, they haven't been around black people. If their first experience with them or interaction with them, is them dressed nicely, and carrying ourselves the right way, that can help knock down some stereotypes and make for a better campus overall.

CT alluded to the notion that Black men enter college with these stereotypes. They step foot on campus and immediately they have been judged and marginalized. This reality is an uphill battle for Black men as they attempt to navigate the terrains of a PWI. RD agreed with CT about being placed in a stereotypical box as a Black man on a predominantly white campus who is seeking the same experience as his white peers. RD shared: 
I think, as athletes, they put us in this box of, "you're just a stereotypical black athlete." Trying to live outside of that is definitely a challenge. They weren't really accepting towards the fact that I was a black person looking for extra help. I was kind of tossed to the wayside. And I was also a football player, so a lot of the flack that I caught was "you guys have everything over there so you don't need it." So whether I caught flack because I was on the football team or because of my skin tone, I'm not sure.

The stereotype of being an athlete does not help Black men navigate the campus environment. White peers and faculty do not take Black college men seriously because they assume the majority of Black men are accepted to college to play a sport. Black college males who are not athletes are treated as if they were athletes, and not taken seriously in the classroom. Thus, the stereotype to be aggressive and compete emerges. This "double-edged sword" rudely affects the Black male experience on campus. KE commented on RD's experience as an athlete: The fact that it's a double-edged sword as far as motivation and healthy competition. I think we also- we try too hard to impress each other. Sometimes, this crabs in the barrel mentality, people have it but, man, black people is crazy this crabs in a barrel mentality that we have. How we feel the need to [say:] "You went to Miami last year? Alright, I go three times a year. They like to flex with the '03 Benz just because it got the emblem on it. It's like a flip to the axis. How do we successfully compete versus just competing and bringing each other down at the same time?

One reason Black college males have to work harder than their white peers is because of the new college culture they have yet to learn, the number of white peers and faculty who do not take their college aspirations seriously, and as KE echoed, many Black males feel they have to compete with one another in order to be successful. This idea of having to "flex" in all accounts 
perpetuates aggression and competition. KE alluded to how unhealthy having to "flex" is. There is so much heavy lifting that needs to take place in order for Black college men to compete at similar levels as their white peers. Black college males are not doing as well academically as their white peers and institutions have to be mindful of the barriers that stand between Black college males and academic success. And once those barriers are defined, the proper measures need to be in place to aide Black college males in their success.

MA echoed:

And I think it's very important because of the data, the graduation rates of black students, the persistence rates compared to their white counterparts is not up to par. It's not what it should be. They are often pretty dismal and bleak numbers in comparison to their white counterparts. So we have to begin to think about as an institution, what do we do, what do we provide our students with in order to properly serve them, to best develop them, to make sure that there's this idea of holistic development that's happening for the academic, the social, the professional, the cultural and the personal.

The obstacle for Black college males to convince others they desire a college degree is different from their white peers. And yet, in order to be taken seriously, Black college males need white peers and faculty to encourage their academic pursuits and leadership positions on campus. Black men are much more than the stereotypical athlete who provides entertainment, but instead resilient and goal-oriented men who yearn for the same college experience as their white peers.

Participants also discussed that white privilege was an obstacle they faced on the college campus and the design of the retention initiative helped them see that white privilege was not a thing of the past, but simply something present and systemic. Participants agreed that M.A.L.E. 
helped them see how real institutional racism and white privilege were and provided them the tools to be resilient and strive for success despite any challenges. RD shared:

It's literally built into the system for them to, in any system, any institution, for white males to be pushed forward. I feel like we all, as black men, we come in to college with weights on our shoulders. We are always fighting to make it. So many people are against us. We are technically an anomaly. Whereas, a white person, it's expected them to go to get their bachelor's then get their Master's, get Doctorate's degrees. Their path is already paved for them. Whereas, we got to make our own.

KE echoed RD's sentiments and expressed:

Things like that that are definitely going to come into play. People bragged on Bill Cosby about this at one point, talking about, stop talking about institutional racism. Just get the job done. Or just do this, do that. We know the system is built against you. That's not the only factor that goes into whether or not you get a job. You can't keep bagging on that as to why you didn't get a job. Be the best you that you can be kind of thing. This pull yourself up by your boot straps mentality, which is so problematic to some people, that kind of thing.

KE and RD acknowledged the "system" is not built to help Black men succeed, but they both agreed that in order for Black men to be successful they must be willing to work hard and fight to create a path that has not been laid out. SA agreed and shared: "There's definitely a privilege but I have the mind set you can't ignore stats. If I'm doing better than someone who is privileged, you can't ignore that. I will work harder to surpass what I need to. You just can't ignore certain things." SA discussed how it is hard to ignore stats, and if Black college males are performing well in the classroom, regardless of white privilege, it is hard to ignore the numbers. 
Some participants acknowledged that when they are doing as well as their white peers, they are still at a disadvantage. CA summarized:

There is a constant feeling of having to compete. We are battling white privilege constantly. It feels like connections are more important than resumes. Due to this, I think I have to work harder to be sharp in so many areas. I have to be able to blend socially and academically with multiple types of people.

$\mathrm{RD}$ expressed similar thoughts as CA:

This internal battle we always have with white privilege versus us, creating the competition with white people and they don't even know the competition exists. I just had to explain white privilege to a white person two weeks ago. They just don't understand it. [ ] We're always told, you got to work twice as hard or be twice as smart to be as half as good as a white person. That's a negative pressure on us. We have this battle going on, left and right, in everything we do, to be half as good as white people, rather than trying to be just good for ourselves. Being the best we can for ourselves rather than our white counterparts.

These examples emphasize a unique set of social and cultural obstacles that black students have to resolve during their time in college. Note that the same issues are recognized by first generation college students and by those who came from families with parents with a college degree. Such issues clearly have to be addressed by a successful retention program.

Further, within the sub-theme Family Environment, participants reported that they often have additional responsibilities to their families that takes time away from college coursework. They also indicated that these special circumstances were not recognized by the school 
administration, and they rarely received any help or support. RD told a story about very difficult times in his life when he needed but did not receive support from the university:

It would have to be the death of my cousins. I had two cousins murdered last year. They were like, "You can go home for the funeral but after that, everything else is expected." Still got to go to practice, still got to go to class, still got to study hall, all these pressures of the day are still on you even though something that's so traumatic has happened. There was no, “Take your time, do you need counseling, do you need this or that?" It was like, "You've got the weekend off but make sure you come back ready to go." [] Lost another family member recently to gang violence; thought about leaving the school and going back home.

CA noted that black students tend to have more responsibilities to their families than white students typically do:

Black men are also realizing the importance of experience in the work force as opposed to class time. This is a proven necessity. Many students have responsibilities to their families. [ ] In my second year at WVU Grandmother developed dementia. At the time it was just I and my mom taking trips to NC every weekend to take care of her; could not afford to hire a nurse; told professors the dilemma but professors did not understand; I lost a passion for school because of all the things that were happening; felt it was important to get a job and help take care of family and start in career in graphic design which I did not need a degree for.

These participants' lived experiences suggest that Black college males have a great responsibility to family and many times as the "man" in the household, the responsibility of family needs falls on them. Participants expressed that white college males typically do not 
leave college to go home to take care of family nor do they work jobs to send money home to family. JD expressed:

During my senior year, I'm looking for colleges, I really wanted to go to a Historically Black College. And I am a first-generation student, so that guidance alone was cumbersome. It was intimidating. And I started this journey to do campus tours. Of course, I couldn't necessarily travel anywhere, just because of family issues and family limitations, so I thought it best to attend a school in the same state even though I did not get to attend the school of choice (HBCU).

Participants shared that family responsibilities impact their ability to focus on academic work as well as keep them close to home. MAC University was not the number one college choice for any of the participants. Some wanted to attend smaller, private colleges but did not get accepted. Other participants wanted to attend an HBCU, but MAC University was closer to their homes and families then were the HBCUs. Retention programs need to account for special circumstances related to the students' family lifestyle, since many African-American students come from economically, disadvantaged communities. Participants discussed their external needs and obstacles and they also mentioned their internal needs and obstacles that impacted their college experiences.

Internal needs and obstacles. Internal Needs and Obstacles details the inner-self and subjective and personal lives of the participants as they go through their college experience. Two closely related major points emerged within this theme: Lack of Motivation and Lack of Role Models.

Participants repeatedly addressed the sub theme Lack of Motivation as an important problem. For instance, SA noted that "some black males come to college without a clear focus." 
He then continued: "I kind of think of it as it's a lack of motivation. What ya'll are saying how it's a competition, I think we need that more in our communities, so it keeps us all intrinsically motivated because that way, it's something we pursue." KE echoed SA and shared:

That intrinsic motivation thing you said before was so valid. I'm not saying an 18 year old or a 19 or 20 year old is irreversible as far as their attitude. But once you've been doing stuff that has been built into you for over 15 years it's hard to change that in a few weeks of talking to somebody.

Participants mentioned that Black males have a lack of motivation because they do not see other successful Black males graduating from college. In addition, there are few Black men working in higher education who would inspire and motivate Black men to do well. So, the need for intrinsic motivation is imperative, and if Black males do not develop it or bring it with them to college, they run the risk of dropping out. But the how to develop intrinsic motivation is why retention initiatives are important for Black males. DG shared:

I think a little bit of a problem with this (retention initiative), is that it was a little social, a little academic. As opposed to being kind of a mandatory. So you had self-selection. And what so often you have with self-selection you have the most motivated that will do it and many times those that need it the most really don't realize it until they're in it a couple or three years down the road.

The majority of the participants in this study expressed having intrinsic motivation.

While this is positive, they represent just a small percentage of Black males on campus. Because of the obstacles that Black college males face on campus, having a retention initiative that is not mandatory usually attracts students who are intrinsically motivated. However, the many Black college male students who have not developed intrinsic motivation are left out of the retention 
initiative. Moreover, the initiative aides the students who self-select to be part of the program, but it does not help those who may need it the most. Similarly, S.T.A.R.S. assists Black college students who have at least a 2.75 high school GPA accompanied by an essay and letters of recommendation. DG expressed: "The challenge I think with the S.T.A.R.S. program is that there's so few people involved in it." Self-selection has a limited number of Black college males involved in both M.A.L.E. and S.T.A.R.S. and in order to help Black college males develop motivation to do well, it is paramount that the initiative find ways to reach more Black college male students. Aside from lack of motivation, participants agreed the lack of mentors and role models in their lives made their involvement in M.A.L.E. purposeful.

Participants' journeys to college did not come from mentors or role models from home. CA explained: “There was no real mentorship and our parents didn’t graduate college and even through struggling, found ways to take care of us." JD agreed: "Mentorship is a common thread here at WVU. It doesn't really exist in the black community as a whole. [ ] They tend to not be able to find mentorship through core development processes of college." MA expressed:

A big part of the initiative is to create community among other men of color, to allow for strong and genuine networking and role-modeling and mentoring with professional staff. All of those pieces are important because most men of color have not had this prior to the initiative.

Participants explained that one of the purposes of the initiative was to provide mentors and role models that would help Black college males reach success in college. EW expressed: Without this initiative, the university would have a hard time retaining African-American males or African-American students, period. This initiative, gives students mentors and 
role models. And for many of us, this is the first time we had a mentor who looked like us guiding us.

SA echoed:

Some of us don't come from the best situations. It's tough for a lot of people, but the M.A.L.E. initiative worked with me where I was and gave me the support I needed. It's tough. People have the emotional support of their families, but it all depends on the type of support they get in college that makes all the difference.

JD agreed:

As a first-generation student, the guidance alone was cumbersome. It was intimidating to think about. So, stepping foot on campus, I was fortunate enough to do a program called Academic Stars program, which is sort of a transition program for first-generation African-American students on campus. You spend six to eight weeks on campus, really learning the campus, figuring out what your place is here at WVU, figuring out what your place is here at WVU as an African American, and connecting with mentors that guide you along the way.

JM was also a member of S.T.A.R.S. and shared:

That first week on campus, I didn't feel nervous or scared. Because I was involved in S.T.A.R.S., I already had a group of maybe $25+$ friends, a couple mentors, older students, on campus, and faculty that I've already met that it was like, "I'm comfortable here, this is home, I really like this place."

Each of the themes include discussion about S.T.A.R.S., which are revealed even more throughout this chapter. Participants external and internal needs properly align with the purpose of the retention initiative. They shared obstacles they faced prior to college and after stepping 
foot on campus. Thus, the creation of the retention initiative helped to mitigate some of these obstacles and guide students to the proper resources. The next theme that developed was Support, which properly aligned with the processes of the retention initiative.

Group two (processes): Support through the program. Support Available Through the Retention Program, reflects students' and administrators' perspective on what the program was able to offer Black males on campus. All participants recognized that the retention program at the very least is aiming to address the common obstacle of low retention and graduation rates of Black males on campus.

JD explained: "For me, it was a breath of fresh air to have people that look like me and wanted to have the same amount of success or same type of experiences while they're in college or after college."

SA agreed:

I like the M.A.L.E. initiative because, at the simplest form, it's motivational. You see people that's similar to you and really excel and be the best man they can be. You don't get to see that many places, especially on this campus. Seeing other black men close to your age out there trying to make a name for himself academically, whatever the case may be. It's empowering, honestly.

KE echoed the support the initiative provided:

It's definitely given me an avenue to some of the professors and administrators, faculty and mentors that I still have and I still keep in contact with to this day. The good thing about it is it's nice to see all those black guys there (empowerment sessions). It feels good. More people to talk to. And if it's a small group, it's more intimate, so you can have those tougher conversations. 
RD commented:

That (retention initiative) gives you a sense of belonging, especially for a lot of people. Most of us are first generation college people, to have a sense of belonging to an organization or a group who make you more comfortable here and your experience a lot better.

Participants agreed that the initiative provided them support in several ways. Although, all participants come from different backgrounds and have different needs, the common theme was they all felt supported through the initiative. For some, sitting in room with other Black college males every month was the support they needed. And for other participants, the initiative was the only space on campus where they felt a sense of belonging and a safe space to be themselves.

CW described the monthly meetings as "sessions away from school where men could meet up and talk about things that affected the lives of Black men." He also thought that this was where the program was the most efficient. "the initiative is extremely effective for what the initiative was to do: Discuss personal issues; Black male students on campus personal relationships with black faculty and staff (because most faculty students I have are white). [ ] It was great to connect with other African American leaders on campus."

Sometimes the discussions addressed frustrations and challenges that students faced. Participants mentioned that M.A.L.E. was the only safe space on campus to discuss sensitive topics without feeling marginalized and most importantly accepted. CT referred to initiative meetings as times when "group members coming together to voice opinions, frustrations, challenges..." to be "very effective". 
ER characterized the program as "enlightening (always learning something), opportunistic (always faculty and leaders there to speak with), fulfilling (seeing other brothers who care about the future of their lives)."

EW agreed with other participants:

I was looking to observe the program to pour in to others and be part of a sense of community or brotherhood to express ideas and concerns. The initiative was a community! It was a support group of men who could challenge my thinking and I could challenge their thinking. The initiative provided opportunities to provide support and a safe place for Black college males.

JD thought about the support within the initiative as a "Place to vent; place where he could make jokes and others understand," where people are "Looking after you as a person." KE highlighted the support of the initiative was "to create a safe space for men of color to discuss all topics and academics, [ ] to facilitate growth, [and provide the] support system." RD also saw the program as giving an "opportunity to black men on campus (students and non-students) to network, come together and talk in a safe environment."

SA described the initiative as a "help group (support group), [where you can ] remain true to yourself." It gives "support through speakers brought from the outside," and "events (once/month) provide extra motivation."

All participants agreed that one of the greatest strengths of the initiative was that it provided support for Black college males. The initiative served as a haven for many participants and the only space on campus where they could intentionally be around other Black college males and discuss topics that were of interest to them. Members of the administration also 
emphasized that creating a strong support system for Black college males was one of the main goals.

DG saw the main initiative functions as "structured to be a place where it was a social outlet and grooming for leadership; [a place to] come together and see other successful people. MA shared:

The initiative was formed to create community among other men of color, to allow for strong and genuine support, networking, role-modeling and mentoring with professional staff. I'm a strong believer that when you support students by connecting them to something on campus that they can be involved in (outside of the classroom) then they become passionate about school and the likelihood to retain them increases.

The support within the initiative encouraged participants to remain active members of M.A.L.E. and receive the type of support they needed in order to persist. Participants also mentioned receiving support outside the program, which aided in their persistence and academic and social pursuits.

Outside the program. Support Available Outside the Program, reflects students' perceptions of broader institutional resources that they found to be useful outside the retention program. The participants commonly referred to select teachers who went out of their way to help and support their students beyond the academics. Yet, most of the participants shared that teachers were not as active as their high school teachers. Many participants felt like another number in the classroom. In addition, participants involvement in bridge programs like Academic S.T.A.R.S, student leadership positions on campus, intramurals, and Black Greek letter organizations provided additional support they needed. 
Participants shared how easy it was to speak with their teachers in high school. Their teachers showed concern about their academic achievement and would have one-to-one conversations with them about the importance of doing well academically. Participants shared that the one-to-one approach of professors was not as visible, and not only should it be more visible for Black college males, but there should be a relationship between professors and Black college males that is evident of support in and outside the classroom for Black college male students to be more successful. JM shared:

Professors should be somebody that we could see as not intimidating and when you think of the super unapproachable guy that's just gonna fail you and tear up your paper...But if it's somebody that you connected with and you end up having a class with them and you're looking down the lecture hall at somebody that I know on a first name basis that I could stop by his office and we could have lunch and not only talk about what's going on in class but let's talk about what's going on in life. And conversations about the Black family back home.

SA echoed:

Class sizes and getting to know my professors were my biggest obstacles. I think it depends on the type of teacher though. Some teacher's main focus is to really help you. Other's it's just to get the job done. I feel like, if they care about you, they will come out and tell you "You're falling behind." Otherwise, it's up to you as a student if you really want to achieve you have to take the extra step and go talk to the instructor. It all depends on the teacher. Or the situation.

Some participants expressed getting to know professors was an obstacle, but the responsibility of doing well in class was up to the student. They did not suggest that if the 
professor did not go out of their way to get to know each student then all would be lost. Rather if the student did not put in the time to get to know the teacher or the understand the class material, the student would be the one at fault. Not all participants felt this way and several expressed that college professors were more hands-off than teachers in high school. The hands-on approach had helped Black male students know that the teacher was invested in them, which would lead to them doing well in class. RD expressed:

For me, it was always- I was an athlete. My teachers (high school), they hound your back to make sure that you're good so you can go to college because it makes the school look better. I don't think there was one teacher that didn't come up to me, "You got this done? Is this done? Do you need help with this?" They always had my back. I wasn't a kid that didn't pay attention in school or anything. I got my work done. I did it by my own hands. They always made sure I was good though.

There was one African-American male professor who attended M.A.L.E. regularly, but he did not teach a subject area that many of the participants majored in and so the vast majority never took his class. Yet, his perspectives in the meetings about how to get to know professors helped participants feel more comfortable about approaching professors. Participants who were part of S.T.A.R.S. shared they were able to get to know their professors during the five-week program in a more intimate way than other participants who were not part of S.T.A.R.S.

KE was not part of S.T.A.R.S, but he had a positive relationship with one of his professors that inspired him to remain at the University during a difficult time. He shared:

I think that when I got shot, the school reacted pretty well. They got notified because otherwise, how would they have known? Because I got shot back home. One of my teachers is my friend on Facebook. My mom posted about it and tagged me, so she 
(teacher) saw it and she reached out to me, I don't know what it's called, a department...but yeah - they (department) dedicated to student help or something like that. They helped me out and excused me for a week of classes, stuff like that. I said that's all I really need before I can come back. [ ] I had a good relationship with that teacher because I took the class. And they are someone I look up to. The teachers here push you, they encourage you and stuff like that is what made me want to stay at this university.

Most participants had good things to say about their interactions with faculty and those who did not share a whole lot indicated that it was the responsibility of the student to seek out the professor if they needed additional help. One participant in particular did not have a good relationship with one his professors, which ultimately led to him deciding to leave the university. CA shared:

I had a journalism teacher who literally... This was two weeks in advance. I told her two weeks in advance, I'm gonna have to go to North Carolina because my grandmother is ill. And she couldn't give me my exam early. I ended up getting a D in that class. Because it's one of those classes where every exam matters. So, my GPA dropped and never got high enough for me to qualify for all of my financial aid and without that I couldn't maintain. Then I lost the passion for school and had so much stuff going on in my life. And so, I started applying for jobs and eventually dropped out of school to work. Relationships with professors were of utmost importance to participants, but many of the participants did not have prior experience on how to approach professors for extra help or even how to develop great student-teacher relationships. Those participants who had a jump start on how to establish relationships with faculty were part of the bridge program, Academic 
S.T.A.R.S. The S.T.A.R.S. program was another support Black male students were able to receive outside of the M.A.L.E. initiative. Four of the 10 student participants received an invitation during their senior year in high school to apply for S.T.A.R.S. JD shared he received an invitation from the Black Culture Center to attend a five-week bridge program prior to the start of school. JM explained:

But, one thing that helped convince my parents of me going here was the S.T.A.R.S. program and that was a program where you come, let's see, early June and you stay until the end of July and it really just honing in on teaching you what life is gonna be like as a black student at PWI [] And that program really helped me gain a lot of friends helped me ease into my first couple of weeks. I met my roommate, who I'm still roommates with the guy now, we're pretty good friends. Lifelong friends, I would say.

ER shared:

I was extremely lucky my first semester because of the S.T.A.R.S. Program prior to my first semester. The S.T.A.R.S. Program was that five-week program basically offering a three- course credit on African-American history, and also taking you into a deeper mindset of African history, and African-American history in the diaspora. It just was an overall knowledge and sense of African-American self-worth and then through that program, I found a small group of friends that we all went through that, which also made us closer. That's why I say it was extremely lucky because I wish I had a Stars Program leaving college, going into the real world. Having that program and introducing me to a set group of friends before college, I definitely had a leg up of social life, of academic and it definitely started me on the right foot being a black student at WVU. 
This idea of having a "leg up" or a jump start is what participants echoed throughout this study. Most participants felt academically and socially behind their white peers and had to work harder to catch up. But, those who were part of S.T.A.R.S. felt better prepared for their first year in college than those participants who were not part of the program. CW expressed:

I received an email (about S.T.A.R.S) and I was asked to complete ... I think it was an application and I applied to it. They said the way to find out about S.T.A.R.S. is if you basically mark you're African American you automatically get added to their email blast, so you get everything that comes from them.

The Black Culture Center had an email list serve of African-American students who were admitted to the university. They used this list to narrow down students to reach out to who had a minimum of a 2.75 high school GPA. For this reason, CW believed that students who were part of S.T.A.R.S. were more focused and driven than other African-American males on campus.

CW further explained: "Everybody that came to S.T.A.R.S. was pretty much driven. I personally say that because this is a time like ... the way S.T.A.R.S. is set up you have to forget about five weeks of your summer hanging with friends back home before you go to college so it's either, you're gonna make that decision to focus on your future or just try to have fun. I know most people would have chose to stay home and have fun. Not me, I was determined."

When I probed all participants why they were not part of S.T.A.R.S., several shared they had never received an invitation and the only way they heard about it was after they arrived on campus. By that time the S.T.A.R.S. program was already complete. ER explained that over 450 African-American males attend the University, roughly 15-20 are part of the S.T.A.R.S program each year. CA expressed: “Everyone doesn't do the S.T.A.R.S. program, everyone 
wasn't able to do that. So for people that transferred like me, being part of M.A.L.E...that's a big deal."

These discoveries suggest that retention programs should be very sensitive to the backgrounds African-American students came from. They have to pay a special attention to the first generation to go to college because they have to overcome additional challenges due to the lack of motivation and the lack of role models. In addition, some of the participants shared they first heard about the M.A.L.E. Initiative through the Black Culture Center and other participants did not mention the Black Culture Center. It is clear there is a disconnect between the Diversity Office and the Black Culture Center. While the S.T.A.R.S. program does not come under the Diversity Office, GA expressed his thoughts about the program:

But the challenge I think with the S.T.A.R.S. program is that there's so few people involved in it. You might have 25 students or so that are invested in pretty heavily but as the institution continues to grow with 1,200, 1,400 African-American students which means that you probably had a least 350 African American male students, new students coming in from an African American background that there was not really any designated designed program for them. So it became a thing that those who have the great opportunity to get in that, receive services, but we really didn't have a way to offer those services to a large group.

If both departments work to aid Black college males in retention, it is not clear that there is a partnership, but rather each department seems to work in a silo. The participants who were part of Academic S.T.A.R.S and the M.A.L.E initiative expressed they felt a deeper sense of belonging on campus and were more likely to join student clubs and organizations, hold student leadership positions on campus, build relationships with faculty and develop a community of 
friends prior to the start of school. The Diversity Office and the Black Culture Center are not connecting with a large number of African-American male students. However, the ones they have reached have expressed the initiative being beneficial. And at the same time, there is a shared recognition that the program is far from ideal, and more work needs to be done. This is discussed below.

Alongside M.A.L.E. and S.T.A.R.S., some of the participants participated in additional programs that proved to help them connect more to the University and increased their likelihood of remaining on campus. JD shared:

So, freshman year, I was appointed co-president of NAACP. Sophomore year, I became an RA, a diversity ambassador, and still held a position with the NAACP, so I became president that year. Junior year, I became a university ambassador, so, dealing with social media, dealing with the brand, dealing with recruitment. I became an executive within SGA, sat on the student conduct board for the university. And then my senior year, I became a student senator for SGA, still held all the ambassador positions, our university ambassador, diversity ambassador. Was still an RA for three years, so from sophomore to senior year. I think that's it. I was probably on some additional committees and stuff. CW echoed:

A few leadership positions I've served here. I'm personally gonna say that I've learned myself here, who I am, the type of person I am here. I also pledged Kappa Alpha Psi, Fraternity (Black Greek Letter Organization) which has allowed me to be supported from Black male students my age and older. [] I was involved in intramurals since I did not end up playing football for the school. 
ER's involvement on campus was vast and is similar to the shared experiences of many of the other participants who were part of M.A.L.E. and S.T.A.R.S. ER shared:

I was president, secretary, and treasurer of the Pi Mu Chapter Alpha Phi Alpha Fraternity Incorporated (Black Greek Letter Organization). I was also a Student Diversity Ambassador for the Diversity Office. I was also a student worker for the Black Culture Center. I was also a student leader for the ... what is it called? Society for Human Resources Management. What else? I know I was involved in a couple more other things. I was a Student Mentor for the Academic Stars Program, and also the Male Initiative Program. Let's see. What else did I do? Senior year I applied for, ran, and ultimately won Mr. Mountaineer. That was a major, if not the most major accomplishment, and arguably one of the greatest accomplishments of my entire life. I was also nominated for Student Leader of the Year Award through NAACP Image Awards, then obviously graduation. Only two participants who were not part of S.T.A.R.S. joined Black Greek Letter Organizations and other served in leadership positions on campus. The majority of participants who were heavily involved in initiatives outside of M.A.L.E. were also part of S.T.A.R.S. Participant involvement in both initiatives seems to be a trend for student involvement on campus, persistence, and graduation completion. CT is a recent graduate and was actively involved in M.A.L.E., his fraternity, and president of a student organization within his content area. CT mentioned:

I knew about Greek life before coming to college and I knew I wanted to join a black fraternity in college. I knew about it a little bit about it. I had my uncle's ... I had an uncle that's an Alpha. My aunts are Delta's and AKA. So, I knew a little bit about it. So when I got on campus I just started noticing the buzz on the campus and just the way they 
dressed. They use to wear a suit and looking sharp on campus. Then they start putting on step competitions and party walk competitions. "Oh, man. That's" They're about the Greek Life, but they also have juice on campus. They got clout. That really sparked my interest. Then when I found other people that were interested as well, I started to bond and connect with them. That really helped push my interest for the fraternity and involvement in other leadership positions on campus.

While CT is the only participant in this study who graduated and was not part of S.T.A.R.S., his active involvement in M.A.L.E. and his fraternity ignited the passion to become more involved in student leadership positions on campus. The other graduate, ER, was part of M.A.L.E. and S.T.A.R.S. and he became the first African American to win the Mr. Mountaineer award - an award given to the most exemplary senior on campus.

The experiences outside the initiative reinforce the need for targeted support programs for African-American males on campus. M.A.L.E. is a great resource and a program that Black college males need. However, other support programs on campus are imperative to increase the likelihood that Black college males return year to year, ultimately leading to graduation. Heretofore, the researcher has discussed the findings related to the purpose and processes of the retention initiative. In the next section, the final category (effectiveness) is discussed.

\section{Group three (effectiveness): Organization.}

Sense of family/community. Sense of Family/Community was a sub-theme out of the organization of the initiative. Participants were asked to describe their perceptions of the effectiveness of the program. Participants shared that the retention program was a home away from home. There was a sense of familial belonging and participants relied on the community built within the initiative. Most participants expressed looking forward to coming to the monthly 
empowerment sessions, yet, those same participants equally expressed the initiative did not meet often enough. For example, CA referenced the program as "great for us, but we need to meet more [] we are all we have on this campus, so we should be around each other more."

EW stated:

When I moved here, I moved here to go to grad school, as well as to be a graduate assistant in the integrated marketing communications program. I knew absolutely no one. Although I was nervous about that, I was just hopeful that I would come across either someone, something, or some program that will build a community for myself and help me, I won't say assimilate, but help me kind of immerse myself in the area. You know, build a community that it's actually being somebody who is totally new, and a total outsider, who had never heard of this state, let alone set foot in the state.

EW is the only graduate student participant who enrolled in MAC University having already attended and graduated from an HBCU. His experience about the M.A.L.E. initiative was important because he was familiar with support programs for Black college males and he was able to provide a perspective none of the other participants shared. SA presented:

It's very supportive when you can have someone of your own race who's been through it and then can just come back and give you words of wisdom and just keep pushing. That right there is the push and support I need and the reason why I feel connected to this initiative - we are a family.

CA noted: "It just was like family and we developed that here. Our school is known for football and the athletes are looked at as being a family, but it's not just athletes. We are a family too." CT suggested: 
The black community in the dorms was really what first connected me [] even if we were all in the same crew in a sense, we all was cool. We didn't have no problem with each other. We would all go out and party together. We looked out for each other. A nice black circle within the university. I'm not saying that we were trying to distance ourselves from each other. You just connect with people that look like you. And that is also what I found in the M.A.L.E. initiative. We are family.

The sense of family or community was apparent and while the mission of the retention initiative does not suggest students creating a tight knit group, it is important to consider. Other than t-shirts, participants of this initiative do not have paraphernalia like Black Greek fraternities and this idea of having some may help the program stand apart and provide more visibility. Graduate and undergraduate students alike are looking for a support system — a "family" who they can connect with. CA talked about how members of this initiative should be looked at as being a "family" much like the college football team. He shared that the initiative meeting more often and doing non-academic related things would help to increase the visibility of the program and encourage other Black college males to be part of the program. He goes on to explain: "Becoming part of M.A.L.E. was like a team. We're like a team. We had shirts that had M.A.L.E. Subconsciously, we would even sit in one section of the student union with our shirts on."

Participants shared that being a "family" was a great reason for many of them to feel comfortable at the University, which inspired reasons for them to stay. The feeling of "family" was important to their success. However, participants discussed ways in which the family would be a tighter and more effective unit. As the researcher, I asked participants to design a retention initiative for Black college males and be sure to include everything that you would do different 
from the current initiative. Participants provided great feedback and the results are in the next section.

\section{Ways to Improve the Program}

Both students and administrators recognized that the existing retention program is work in progress. For example, DG referenced creating and managing the program as "building the plane as we flew it." He admits that the organizers "just scratched the surface - this initiative was a test model." The program went through a series of transitions, including a change in management. All of these changes affected the program. Both students and administrators had a series of suggestions on how to improve it.

Administrators talked about how to incorporate the program into institutional fabric better and how to provide a more effectively organized structure. Specifically, MA said: "This new program was built into the fabric of the institution rather than from one single office." MA also noted that the university "need[s] a staff person (WVU) who is responsible for Black Male Initiative and Black Woman Initiative (work more closely with students in a support capacity)," and that the program needs "more \$\$." DG agreed that "funding streams were low."

He also noted that he "went into it to provide some resources and look back after the first few years (believes it takes 4-6 years to completely measure), [but] the institution did not pour a lot of money to do certain things." DG admitted that this try "felt like more of a test case and [he planned] go back and show the institution the need." He also said that "you needed statistics on your side to show the institution the need, [and the] overall hope was having a strong cohort do the analysis and come back for specific funding."

The Initiative went through a series of changes during the last several years. DG detailed some of them: 
When program started he had a coordinator working on program $100 \%$, but then the coordinator went back to work on his Ph.D., and the momentum shifted. Good programs take 5-7 years to get acculturated in the institution, continuity is very important. This lack of thought through organization was recognized by most students. Even though they did not know about the full story behind it, they repeatedly commented that better organization will significantly improve the effectiveness of the program.

JD stated:

The consistency from the initiative and the community is not there. We meet once per month and then wait to gain more people at the next meeting 30 days from the last. The bridge building of support is lacking and doesn't truly take advantage of the full opportunity to truly support men of color on campus.

SA noted:

[There is a]] lack of awareness about the initiative. Some people either just don't know about it or they don't care until they actually attend an event. Some people don't care to really better themselves and see what we have to say. They don't care about the power we can have if we stick together.

Several participants talked about how many Black college males do not know the program exists and those who do know the program exists do not want to attend the monthly meetings because they assume it has a strict academic focus, which is not what they are looking for. But addressing the awareness of the initiative and the need to let more Black college males know about the opportunity is something most of the participants discussed. SA commented: When I first got here, the Resident Assistant, Gary worked in my dormitory. As soon as I hopped out the car he handed me a M.A.L.E. flyer - boom. Just like that. [ ] So I would 
just set up a booth and have some people come. Maybe we can do something similar, like an early move in day for black men, or early move in day for students of color, something like that. Maybe a week, maybe a few days. Just to get them into the fold and maybe they get some type of perk for coming early. Or they complete this week- long thing they get a certification. I don't know.

The idea of inviting Black college males to campus before school starts was echoed by other participants. Many felt if Black males had a chance to come to campus before school started they would have an opportunity to meet faculty, learn where their classrooms were, register for classes, and meet other Black college males. SA further elaborated:

I think the approach has to be a little more attractive [], we have to, at the end of the day, stay true to the male beliefs but virtue off. Essentially, even something like a barbecue, having a male initiative barbecue for all black students. Come and hang out, we could talk, we still have the same sessions that we need to but come grab something to eat. Grab a bite, something to eat.

CA suggested:

I would probably make [recruitment a] part of the orientation classes. I would try to get a pipeline going so that students of color have an option besides the S.T.A.R.S. program. This way students that didn't excel in High School are afforded the opportunity to learn skills and are rewarded for being a minority pursuing a degree.

The S.T.A.R.S. program is only for those students who have a 2.75 high school GPA and write an essay and collect letters of recommendation. Several participants agreed with CA and echoed the need for a program to exist where all Black college males were admitted to it. They shared the program needed to be mandatory instead of self-selected. KE proposed: 
This needs to be somebody's main project. It's no one's main project. I don't mean to take it that deep, this is no one's baby. It was [MA's] baby. He took care of it as such. Somebody has to view M.A.L.E. as a full- time job!

The initiative is not a full-time program. In other words, one individual does not spend all of their work schedule on activities for M.A.L.E. Both administrators agreed that the initiative requires a person to work on the initiative full time. Student participants were not privy to these thoughts from the administrators, but they all agreed that the program should be run like a full-time job. In addition to how the program is fun, a few of the participants discussed there were no measurement tools to show how successful the program is. The number of active students is not recorded anywhere and the number of students who successfully graduated from the university serving as an active member of M.A.L.E. was not recorded either.

EW noted that "no measurement tool of how the program is successful." MA explained how the initiative was an enormous undertaking and he did not receive the proper personnel nor budget to successfully run it. MA shared:

No, I didn't really get any help with the program. I think if I can remember back then, I think what I used at the time was just an excel sheet to keep track of the students that participated from semester to semester. A few would fall off due to graduation, then they would be removed, they would be taken off the list if they graduated. There were a couple students each semester that we would lose, but it was just a few, maybe just a handful, and that was only due to a class restriction or a job restriction that hindered them from being able to attend the empowerment sessions on Monday nights. 
There was not a clear system of who was leaving and who was joining. MA mentioned that a couple of students here and a handful of students at other times, but there are no records of the exact reasons students left the program. MA continued:

That was an area, and I think even moving into the new initiative that I had always wanted to do better at, was some of the tracking beyond my excel sheets. But I think given the enormous amount of responsibility I had with other programs in addition to that made it a little bit difficult for me to be able to give that area that kind of attention.

MA shared how he was spread thin between this initiative and the other responsibilities he had for his job. It became overwhelming and he knew the initiative needed more attention, but he did not know how to go about it with limited budget and personnel who volunteered. MA expressed:

Not many places that I know of have someone that is hired specifically for the purposes of running a male retention program or an African American male initiative. I do think that it is needed to have someone, a staff person, even a program coordinator role or capacity, who could be responsible for something like that of a black male initiative to work more closely with those individuals in a support capacity by meeting with them on a more consistent basis, to have sort of academic meetings, academic check meetings to talk about some of the specifics going on with their lives, with their worlds. Participants agreed that more awareness about the program was needed as well as the administration spending more time developing the program. There was too much turnover and the program fell through the cracks at times because it was too enormous of a responsibility for one individual who could not focus solely on the program. Aside from more Black college males becoming aware of the program, student participants had other suggestions on how the 
initiative can address specific needs that African-American males have during their college years as well as teach them life-long skills.

Some participants thought that the program did not address most issues raised by participants and some students thought that the topics received enough attention. But generally, students felt that there is a wide range of personal, emotional, and everyday problems that the initiative could address through individual mentorship and more personal relations with black faculty, staff, and more advanced students of the university. Many of them suggested to put more emphases on their long-term goals and life-long skills, rather exclusively focusing on college years. They believed that this would provide a better motivation and help to form the "right" mind set. Individual mentorship and availability of role models could be especially effective in that. For instance, CA suggested that the initiative needs to find the way to "discuss personal issues," which can be done through "personal relationships with black faculty and staff (because most faculty students have are white)." He also felt that it is important to teach AfricanAmerican males to "serve as a leader."

CA also felt that the program has to "offer more emotional support. [It is [ too academically structured. [That] retention is an issue but there is a need for emotional support. [For instance,] had a friend Brian transfer back to Morgan because he didn't "feel" loved by the school." CT suggested that initiative needs to give more "tips on how to be a successful student," and also provide additional “opportunities of professional development, [prepare for] job interviews, [and help to] formal dress (dress for success).”

ER agreed that "entering into the real world coming from college revealed a lot of ah ha moments. He also felt that it is important for the initiative to provide leadership opportunities to black students. "M.A.L.E. initiative always looked at him as a role model so he carried that with 
him to his career." He felt that even more emphasis needs to be placed on other Black college male to serve as leaders. In addition, ER felt M.A.L.E. did not put enough emphasis on real life skills: "what are the things black men do not know" (politics, finances, taxes), things that aren't taught at home or in the classroom, [including] respect of womanhood (how do you date, find a wife, what is your idea of a family, how do you get there)."

Similarly, EW thought that the program needs to help the students to answer broader and longer term questions of "what does development of Black Male look like? How do we help participants achieve personal goals?" He believed that this could be done through "more active engagements from all institutional leaders.” Among specifically suggested topics were “navigating difficult conversations, professional development, and business acumen."

JD agreed that the program needs to put more focus on "helping [students] develop holistically." He felt that Black men define themselves by the media or by how the white population views them. The initiative needs to have a component that helps Black men know who they are and what great things they are capable of achieving. RD professed that many Black men shy away from conversations and support that could benefit them. RD shared: "Mental health services and education on sexual orientation are things Black men do not participate in because our black communities teach us that we do not need counseling or that Black men are heterosexuals."

Black men are not a monolithic group. There are vast differences among Black men, reflected in their diverse professions, religious and political views, and sexual orientations. If Black college males are not careful it is easy to subscribe to the stereotypes of Black men as opposed to being true to self. Participants acknowledged that M.A.L.E. should be a place where Black men from all backgrounds should be able to come and intermingle without questioning 
why they are the way they are. The safety in being comfortable with who each other must first be established in mentorship groups that meet outside of the monthly meetings. Some participants expressed the importance of a more robust mentor program that helps Black college males in every facet of their lives. JM felt the "Initiative can do more to mentor, [including] mentorship opportunities." He also said: "Mentors have to reach out to students more. Mentors [have to] meet with students between the monthly sessions. [They should have] heavy presence during new student orientation, before school starts [and on the] first day of school."

KE and other participants echoed the claim that more mentorship is needed. He stated that the initiative needs to "carefully select a system where mentors are invested, don't just put people in place because of their title." He continued, "Get old students who left back involved. [ ] Groom students to be leaders on campus, [so] University [can go] to these students for speaking, programs.” JD suggested:

Establish mentorship from the beginning. Use the participants as mentors and use the professional staff as mentors as well. The key component on M.A.L.E. is to provide support. That is the mentorship component that needs to be emphasized and provided when freshmen students come to campus and throughout their time on campus. With, the network on campus of black people wanting to succeed we should not, should not, be losing so many black students per semester, or per year.

Both first-generation student participants and those who came from a family with parents with a college degree, agreed that individual mentorship and a focus on life-long development would significantly improve effectiveness of the program. 


\section{Difference of Opinion: Students and Administrators}

Student participants and administrators agreed the M.A.L.E. initiative was a program designed to help Black male students navigate their new college terrain as well as introduce students to campus resources that would aid in their success. Albeit, while many of the participants expressed the need for the initiative, some of their experiences were different from how the administrators perceived the program and participant involvement. In this section the researcher discusses student and student differences, student and administrator differences and finally the differences between administrator and administrator.

Student and student differences. Each of the students discussed how impactful the program has been for the college experience. They mentioned the initiative serves as a pinnacle component to their academic success and retention. However, some of the student participants perceived the effectiveness of the program differently, although everyone was glad to remain part of the initiative. EW shared:

There is not a measurement tool to show how successful the program is. It feels good to be part of the group, but what exactly is the goal related to retention and graduation completion. Black men across the country have low retention and graduation numbers, so how does this initiative show how well it is working. Because of some of the things are not working it is smart to pivot and try something else that works. Another thing that doesn't seem to be working is student follow-up. Each month we get new students who attend the monthly meetings, but then I never see them again. Did they not like it or did we drop the ball in not reaching out to them again? 
Other student participants never mentioned the assessment of the program. When the researcher probed them about the number of students who participate in the program, some reported it was a good or consistent number. ER felt:

M.A.L.E. had the most Black men I ever saw in the same space at one time on campus. Each month we attracted a really good number of students and faculty. Roughly, about 25-30 students and 5-10 staff came out each month. We were a real tight group and we spent time with one another outside of the monthly meetings. Had it not been for M.A.L.E. and S.T.A.R.S. I would not have thought about entering a master's program following graduation. I owe so much to those programs and I would not change much about them.

Many student participants expressed the need to increase the number of student participants while a small few felt the number was small enough to get to know everyone on a personal level. Those students who participated all felt compelled to be part of the program, however, this study also highlights differences in student and administrator perceptions of the initiative.

\section{Student and Administrator Differences}

CA is the only student participant who transferred to another institution. He left the semester before this research study began, but he was part of the M.A.L.E. initiative since the program started and he remained an active participant through his junior year. CA initially thought the concept of the M.A.L.E. initiative was different than how the administrators described it:

The concept of M.A.L.E. seemed corny at first because I saw this same program at my previous school [HBCU]. M.A.L.E. was run like a group meeting instead of student organization or student club. At my last school we met more regularly on campus and 
other Black men on campus wanted to be part of our group because we were different. We were popular kids on campus, athletes, scholars and everyone in between. Everyone on campus knew about us, but here no one really knows about us.

KE also noted the initiative did not catch the attention of those who needed it the most: Black students were not completely hooked to M.A.L.E. because we did not meet often enough. Once a month is not enough time for students to be hooked. We saw the same 15-20 faces every month. M.A.L.E. needs to be something students are excited to go to and not just focus so much on getting everyone together to just sit and talk about who is struggling in what class or things like that. At times it felt like a TED talk series instead of a club or organization. M.A.L.E. was extremely helpful for me to find my way around campus. I ended up joining a Black fraternity to get that brotherhood feel.

The Director of M.A.L.E., MA, thought the initiative was well advertised and attended:

The M.A.L.E. initiative is a University sponsored initiative. The President has endorsed the program on several occasions and periodically he comes to our monthly empowerment sessions. To gain the attention of men of color on campus, we set up information tables during welcome week, host a student diversity mixer and partner with the campus partners throughout the year. The entire University knows about our program and we have had great support. As far as participation, we have a good number of regular attendees each month.

Many of the student participants felt the initiative was good for their student morale and connection to the University, they did not feel the initiative had a broad reach. Several student participants suggested the initiative did not meet often enough, but the director of the program felt the monthly empowerment meetings were organized and structured enough to capture the 
needs of the attendees. In addition, student participants felt more Black students should be part of the program, but the design of the program was not enticing enough to draw and sustain students who were not already part of the initiative. While the initiative supported those participants who attended regularly, students and the administrator differed regarding the effectiveness or the reach of the actually program. Contradictorily, the VP of the Diversity Office, DG, pointed out that Black student applications increased by $99 \%$ in 2016 - the largest and most diverse class the University had received. DG shared:

Being able to list the increase in Black student applicants on the school website made the University an acceptable place to apply. Many students do their research and if they do not see support systems on school websites they will end up applying elsewhere. The fact there was an initiative [M.A.L.E.] in place may be reason why some students applied to the school. We do not know those exact numbers, but I strongly feel initiatives like M.A.L.E. is why many applicants are interested in the University.

Albeit, there was an increase in Black student applicants to the University, but according to student participants M.A.L.E was isolated and did not draw many of the Black male students who attended the University. Many of the student participants felt the University did not do a good job of extending the reach of the program to the entire campus. However, the administrators felt the University strongly supported the program and the influx of Black applicants was partly due to the initiative. This is an example of student participants and administration interpreting the scope and reach of the program as limited versus generous. Other examples of where student participants and administration perceived the initiative differently include: structure of program is too academic, not mandatory for incoming freshmen, lack of organizational structure, institution is less diverse than advertised, animosity between the 
M.A.L.E. and S.T.A.R.S. program, etc. Moreover, student participants and administration were not the only vested shareholders who disagreed on the nuances of the program.

Administrator and administrator differences. The administrators of the program also disagreed on certain aspects of the program and how it should be run. In the following section, I describe some of the administrators differing thoughts on the program.

DG suggested the M.A.L.E. initiative was not designed solely for Black male students:

The initiative was for underrepresented students at the University. It so happens the majority of the initiative is made up of Black students. There is a great number of minority and underrepresented male students at the University and this initiative was designed to support these students because historically they receive the least amount of support on college campuses. As the University's first chief diversity officer, I was tasked to create an infrastructure for disability, affirmative action and diversity initiatives. I hired the director of the initiative to implement a program to support students of color and he ended up leaving prematurely to pursue another graduate degree. We lost him in the middle of strengthening our initiative and designing measuring tools to define the program's success.

DG referenced the need to cater to all underrepresented students, however, MA created the M.A.L.E. initiative with Black male students in mind. He recognized the low retention and graduation rates of Black male students across the nation and had experience being part of a Black male initiative at another institution. His hope to create an initiative for Black males were met with challenges from his supervisor.

GA was gracious to bring me on board from a previous position at the institution. In my former role I created an initiative for Black male students and in my new position I 
encouraged GA to allow me to continue as long as I created a new name for the initiative. I was part of a male initiative program for Black students at a previous institution and my involvement in my black Greek letter fraternity helped me develop a program that would focus on the achievement of Black male students. When I joined GA's office he asked me to focus on underrepresented students and students of color. Because I had already built the program (before changing the name) the same students who were with me helped me continue running it. So, the vision GA had for the program was slightly different than the program I had in mind. Research shows that graduation and persistence rates of Black students is not even close to their White peers, so I knew that was the population we had to start with.

Not only did the administrators not completely agree on the nature of the program, but there was also differing views on how the program should be run. MA shared:

M.A.L.E. is a support system for students and helps connect them to institutional programs and organizations that help to increase retention and graduation completion. Research shows that Black students need to develop personal, social, leadership, and cultural capital in order to be successful on college campuses. My aim was to also help students with racial identity development and provide ample opportunities for students to connect with Black faculty, staff and campus partners. This approach would provide Black students with a wholistic view of what success looks like from their own community. My hope was to provide more apparel for students to wear. I was thinking ties, blazers, polos, and lapel pins. This would make students feel part of something larger than a few monthly meetings. In addition, I wanted to create a reading literacy 
program that pertained to student culture. Lastly, internships and etiquette seminars would be important for male development.

DG thought the initiative would be better served if there was less focus on the social aspects and more focus on the academic infrastructure. He shared:

The initiative did not focus enough on the social aspect, but instead a lot of social activities surrounded the initiative. I did not hear any conversations about student GPAs or the number of students who had to withdraw or defer a semester. Academically, underrepresented students do not do as well as their peers, so it is important to create a stronger academic support system. I would have liked to see a classroom environment where you helped students develop stronger math and writing skills based on cultural defunct. In addition, I wanted to see academic departments (schools) on campus collaborate with our office and provide extra academic support for underrepresented students. This program should be mandatory for incoming freshmen and DG felt the students should self-select for the program. However, I think students need to have some sort of investment and the current model does not have students give anything up [investment] so I think there is a lack of participation because students are not selfmotivated and have not made any personal investment.

Both administrators recognized the need for the program, but it seems that how the program should be implemented differs. This ambivalence could also lead to any ambiguity about the program from both the macro and micro level. Students also shared differences about the effectiveness of the program and that may have come from the differences between both administrators. 
The researcher also employed document analysis to provide more context around student and administration perceptions of the retention initiative. Document analysis requires the researcher to look at data from different angles to appreciate the holistic issue from all perspectives. Review and summation of qualitative inquiry is certainly imperative when it comes to understanding the lived experiences of an individual. The following section outlines the document analysis and interpretation of information collected for this research study. The general process of document analysis for qualitative studies involves five steps summarized by Creswell (2012): Organizing and preparing the raw data (i.e. transcripts, notes, images, etc.) for analysis, reviewing the data to develop general ideas, overall meaning, and making sure the information given has depth and credibility intact, coding the data by labeling with key words and phrases to categorize the data, generating descriptions of the setting and people involved, then finally making interpretations of what those descriptions mean.

Document analysis. Interestingly, word count analysis of the documents used by the Initiative revealed that a list of 20 most used words included students, initiative, male, black, college, school, support, empowerment, academic, campus, university (see Table 2 and Figure 2). It did not include words such as mentorship, networking, family, community, sense of belonging, connecting, safe environment, motivation, and long-term goals. This may reflect inconsistency between intuitive understanding that became apparent from interviews with both administrators and student participants, as well as from a focus group, that in its current state the initiative primarily attempts to address the common obstacle of African American Males of being "odd men on campus." That is, probably, why student participants believed that advertisement and recruitment is not done effectively by the Initiative (i.e., stated focus did not 
match the actual focus). Data suggest that the program was planned and promoted more as another academic program, which may limit its ability to reach the targeted audience.

Finally, the apparent disconnect between the language used in the planning documents and the perceived goals and main activities of the Initiative also may reflects that the important needs that student participants articulated are not in the focus of the current Initiative. For instance, commonly stated need for individual mentorship and help with long-term planning, motivation, and life-long skills development are not among the 20 most used words.

\section{Conclusion}

The primary purpose of this qualitative single case study design was to explore and analyze Black college male perceptions of a retention initiative designed to increase Black college male retention.

More specifically, it focused on the following three questions:

1. How does the initiative in place help to retain Black college male students attending a land-grant PWI located in the Appalachian region?

2. How do Black college male students perceive the purpose, processes, and effectiveness of a retention initiative aimed to increase Black college male retention?

3. How do college administrators perceive the purpose, processes, and effectiveness of a retention initiative aimed to increase Black college male retention?

The results of the analysis suggest that the existing program is a project in process, a testrun, that appears to address the most visible issue of African Americans of being "odd men on campus" through creating a safe place to network with other black students, faculty members, and administrators. Being able to connect to members of the university community appears to help with retention of black students. However, no objective measure of the program success has 
been developed yet. Thus, it is difficult to claim the program to be successful. Additionally, the apparent lack of objective evidence of success prevents the program administrators from applying for more support from the institutional.

African-American students who participated in the program did recognize the lack of structure and organization of the program but believed that it provides "a safe place" for them to interact and connect and provided a "family" away from home. They suggested that the program puts more focus on long-term goals and personal development, life-long skills, and a general drive to succeed rather than on short term college-related problems. They generally agreed that this should be done though well-structured individual mentorship from black faculty members and more advanced black students who participated in the program for several years. They felt that it is very important to provide members of the initiative with leadership opportunities, as it is one of the most important life-long skills that often lacks among African-American students.

College administrators perceived the program at this point as a test run. Originally, they aimed to address the achievement of men of color comprehensively: academically, professionally, socially, culturally, and personally. For now, they saw it as a support system for students and a way to connect them to the broader university community and to various institutional programs. They recognized the lack of organization and the lack of objective measures of the program success. This did not allow administrators to improve the program in a data driven way, and also did not allow them to apply for more comprehensive institutional support.

Chapter Five will report these themes and sub-themes, conclusions, as well as the implications of this study for, methodology, theory, and practice.

Table 3 
Twenty Most Commonly-used Words in the Initiative Documents

\begin{tabular}{|c|c|c|c|}
\hline$\#$ & Word & Count & Weighted Percentage \\
\hline 1 & students & 151 & $1.23 \%$ \\
\hline 2 & initiative & 135 & $1.10 \%$ \\
\hline 3 & male & 119 & $0.97 \%$ \\
\hline 4 & black & 117 & $0.96 \%$ \\
\hline 5 & like & 116 & $0.95 \%$ \\
\hline 6 & college & 112 & $0.91 \%$ \\
\hline 7 & school & 98 & $0.80 \%$ \\
\hline 8 & student & 88 & $0.72 \%$ \\
\hline 9 & people & 85 & $0.69 \%$ \\
\hline 10 & just & 70 & $0.57 \%$ \\
\hline 11 & support & 70 & $0.56 \%$ \\
\hline 12 & empowerment & 69 & $0.51 \%$ \\
\hline 13 & going & 62 & $0.50 \%$ \\
\hline 14 & interviewer & 61 & $0.47 \%$ \\
\hline 15 & first & 57 & $0.46 \%$ \\
\hline 16 & think & 56 & $0.42 \%$ \\
\hline 17 & academic & 52 & $0.42 \%$ \\
\hline 18 & campus & 52 & $0.42 \%$ \\
\hline 19 & program & 52 & $0.42 \%$ \\
\hline 20 & university & 51 & $0.42 \%$ \\
\hline
\end{tabular}




\section{Chapter Five}

\section{Summary, Limitations, Implications}

This study examined the experiences of participants who are active members in a retention program specifically for African-American college male students. The purpose of the study was to understand the perceptions of the purpose, process, and effectiveness of the retention program for African American college men. A review of the literature highlighted a gap between African-American college male involvement in retention programs and their perceptions of the retention programs in which they participated. Previous studies have not accounted for the active role students play in programs that have been designed for them. This study helps close this gap by listening to the voices of active members of a retention program, addressing their experiences and promoting their needs in such a manner where programs begin to petition the lived experiences of students prior to implementing any student initiative.

This study employed a qualitative design to interpret the perceptions of active members within the retention initiative. There were 10 student participants and two administrative participants in the study. Student participants' classification ranged from sophomores to recent graduates. The researcher decided to recruit two recent graduates to examine if the retention initiative supported the students in reaching graduation. Document analysis was conducted to aid in the gathering of themes for the results of the study. Document analysis utilized the word count analysis to discover the frequently used words by the participants in their university experience. The themes derived from the study were needs and obstacles, support, and organization. Two sub-themes were derived from each of the major themes. The theme Needs and Obstacles had sub-themes: external and internal. Second, the theme Support had subthemes: through the program and outside the program. Finally, the theme Organization had sub- 
themes: sense of family/community and ways to improve the program. These themes contributed to the participant involvement in the retention initiative. However, the administrator participants were not made aware of the student participant reactions to the program. The student and administrator participants answered research question one: "what initiative is in place to retain Black college male students?" In addition, the student and administrator participants also shared their perceptions of the purpose, process, and effectiveness of the retention initiative. The researcher asked both student and administrator participants to answer research questions one through three to examine the contrasts and similarities of the responses. Later in this chapter, the researcher will highlight the differences in response to questions one through three.

The purpose of this chapter is to explain what was found in this study and present a discussion from the data findings. This chapter shares points of tension and consensus between the student and administrator participants. Following this, the alignment of findings with the literature and conceptual framework are explored. Finally, limitations and implications for practice and future research are addressed, followed by a personal conclusion.

\section{Consensus: Students vs. Administrators}

Students and administrators believed the Successful M.A.L.E. Initiative was a program that served unmet needs of Black college male students. All students acknowledged that they were not properly prepared for college, and the benefits they received in high school were not visibly present in college. Some of these benefits included college counseling, caring teachers, culturally relevant activities, and a climate that was diverse and welcoming. Unfortunately, according to students and administrators, these benefits were not part of the college culture. This finding is affirmed by the document analysis. The most commonly used words of the participants 
did not really talk about the benefits or the mentorship system in the university. Rather, the college culture consisted of microaggressions, lack of diversity, culturally inept faculty, and racially repressed social activities. Students were aware that Black college males were a minority in college and acknowledged more Black female students discussed attending college than Black males. Students stressed the influence of the media and Black athletes and rappers as reasons why Black males were not considering college and why many Black males dropped out of college. The administrators of the initiative recognized the perils of Black college male retention and so they created an initiative that would increase retention and graduation completion numbers on campus. Moreover, the design of the initiative was based on a program from a neighboring institution as well as what the administrators believed were factors that enhanced the Black college male experience. Therefore, the importance or purpose of the retention initiative was mutually agreed on by students and administrators. Additionally, both agreed that the process by which the retention initiative was administered was helpful.

Students and administrators believed the monthly empowerment sessions were an important part of the retention initiative. MA, the creator of the retention initiative, adopted the once-a-month session from his former institution. He believed that students meeting once each month was important for continuity and relationship-building and gave the professional mentors and students enough time to schedule to be at each session. Students shared the consistency in the monthly sessions was something they looked forward to each month. Because the campus was so large, students mentioned they would only see many of the active members during monthly sessions. The lack of mentorship or the infrequent mentorship was also affirmed by the document analysis. In fact, mentorship did not even appear as one of the most frequently used words by the participants. In addition, the professional mentors and administrators would also 
only see one another during the monthly empowerment sessions. So, the empowerment sessions became a space for both Black students and administrators to collaborate and a safe environment for private and personal discussion. Administrators shared some of the student generated discussions, which included topics on insensitive faculty, school policy, feelings of being home sick, and academic rigor. Students professed that the empowerment sessions were the only space on campus where they could be transparent about their feelings of being a minority attending a PWI. In addition, students shared that the monthly sessions helped them feel a sense of community, in place of the other spaces (dormitory, classroom) on campus that made them feel alienated. While students and administrators agreed that the monthly empowerment sessions were meaningful, there were other procedural components that they did not agree upon. The researcher will share some of those areas in the next section. Furthermore, both students and administrators agreed the initiative was effective in certain measures.

Many students shared that the retention initiative was one of the motivators that kept them coming back to campus each year. They looked forward to the monthly sessions and the periodic activities outside of the university. Based on the results of the document analysis, the students indeed wanted to have sufficient motivators in order to perform well in the university. Several students referenced taking a trip together to the Black Male Summit in Akron, Ohio. This was a rare off-campus trip, but the students who attended all mentioned how close-knit the experience was, and it encouraged many to spend time together outside of the monthly empowerment sessions. The administrators sponsored the trip to the Black Male Summit for two consecutive years, but they have not been back since. When the administrators were asked why they did not continue taking students to the Black Male Summit, DG shared that changing of the guards led to the trip not being funded. Not only was the initiative effective in encouraging 
students to return back to campus each year, but the initiative also opened doors for students to take part in other campus activities. ER, CW, JM, CA, CT, EW, and JD all joined a Black fraternity. Consequently, seven out of 10 student participants joined a Black fraternity after they were members of M.A.L.E. They credit the retention initiative in helping them find other student clubs and organizations on campus to join. These students shared that, had M.A.L.E. not influenced them, they probably would not have learned about or considered joining any student organizations. JD and ER were exceptional students, and both were part of four or more student clubs and organizations on campus. Equally, there were parts of the initiative students and administrators agreed on and areas that were contentious. Some of these areas are discussed in the next section.

\section{Tension: Students vs. Administrators}

Students and administrators agreed M.A.L.E. was the retention initiative in place to help retain Black college male students (RQ1). However, students mentioned another initiative, Academic S.T.A.R.S. that was helpful in retaining Black college male students. S.T.A.R.S. is an initiative open to all Black incoming freshmen students out of the Black Culture Center. Four of the 10 student participants attended the five-week S.T.A.R.S. program and all participants shared that this initiative was also in place to help retain Black college male students. Albeit, M.A.L.E. is specifically for Black college men, but participants expressed they received even more attention and guidance during S.T.A.R.S. than they did as active members of M.A.L.E. ER shared that S.T.A.R.S. helped him to feel comfortable approaching faculty during office hours and introduced him to M.A.L.E. CW acknowledged that those who were part of S.T.A.R.S. were more focused and driven because they gave up five weeks of their summer to come to campus and take classes. DG expressed that S.T.A.R.S. was a good concept, but poorly designed and 
managed. Chief Diversity Officer, DG, shared that S.T.A.R.S. only admitted a small percentage of the Black college male community each year and that M.A.L.E. was open to all Black college male students. Students who were part of S.T.A.R.S. only had positive things to say about the program and made mention that S.T.A.R.S. also prepared them to seek out other student clubs and organizations for social camaraderie and leadership positions. The researcher thought the only initiative on campus that promoted Black college male retention and graduation completion was M.A.L.E.. However, students made it clear that S.T.A.R.S. and M.A.L.E. were two programs doing the same thing but located in different parts of the campus and under separate management. The emergence of another initiative that supported Black male retention brings to question why the two programs are working against each other instead of in conjunction. It is important to merge partnerships between both entities in order to increase program budget, reach of program, and remove any doubt that one program is better than the other. M.A.L.E. was not the only initiative on campus to aide Black college males, so it is paramount to examine if there are differences in the procedural components.

While students and administrators agreed there were procedural components of the initiative that worked well, they also disagreed on other procedural elements (RQ 2, 3). Students acknowledged the importance of the monthly empowerment sessions, but many expressed the initiative does not meet often enough. The researcher probed each student and asked how many more times they desired to meet. Some responded that they would like to meet weekly, while others expressed two to three times more each month. There was not a consensus as to how many more times the initiative should meet, but students expressed meeting more times would encourage other Black males to join and would help to increase the number of times active members participated. Students shared they wanted to meet more because they felt isolated in 
their classrooms and public spaces on campus. Meeting more often would give students energy and motivation to continue going to class and complete assignments without feeling any real connection to the university. In addition, students expressed that the administrators selected monthly meeting times that did not benefit all participants. Students understood that the days and times fit the schedule of the professional mentors and other staff, but students were not asked what days and times would best fit their schedules. Students felt their opinions about meeting times and topics of interest were not taken into consideration during the planning times of the initiative. MA shared he facilitated a retreat before the start of the year to create a plan of action for the year. The participants in the retreat consisted of professional mentors and peer mentors. However, the participants did not include student participants of the program. A survey was not administered to active participants asking what topics of interest or best available days to meet would be most suitable. The lack of student input about topics and meeting days were not the only areas students felt left out of the planning of the initiative. Students also felt the monthly empowerment meetings were too academic.

Students felt like some of the meetings reminded them of being in class and their interest in the initiative was to be part of a community that allowed them to express themselves as Black men without feeling like they had to be academically engaged. There was also some tension between both administrators in regard to the academic component within the initiative. MA shared, "the academic side, you know, it is for some people, it is a touchy spot and some students are not performing well academically. However, M.A.L.E. never set out to be solely based on academics." Although MA stressed that the initiative was not supposed to focus solely on academics, many students feel that it is. Due to the low national average of Black men who persist and graduate from college, if the focus of the initiative is to increase those numbers, it 
may be that the initiative was created in an academic manner. DG agreed that the academic component was important and suggested the initiative be more academic and less social as well as mandatory versus self-selected. Students expressed needing more social outlets within the initiative. Even though both administrators did not agree with each other about the initiative's self-selection process, they agreed the initiative needed to serve more students. While the initiative is active, it is still being planned out and needs more structure. Another point of contention between students and administrators is how well the program is doing (RQ 2, 3).

The need for the initiative was evident from both students and administrators. However, students expressed not knowing how well the program was actually doing. EW shared, "I have not seen, any measurement tools or understanding how we're measuring the success of the program. I'm a data guy. I have not seen what the thing is that are identifying success and failure." The researcher probed the administrators about the program's success and DG shared, "We were building the plane as we flew it. Because we were already up in the air and we needed to do some things, many times without having a lot of funding." MA added, "I think that the way I knew that the initiative was a success at that time was based upon what I saw from the participants, the students that we worked with, who were moving to the next level." MA admitted that he planned to create measuring tools to gauge the program's success, but he never felt he had enough time because his job was too demanding and his decision to return back to graduate school also impacted his ability to properly measure the program's success. EW also expressed, "What is the graduation rate of African Americans at WVU now? What was the goal for us to move? Or was this program trying to address that?" JD added, "What are professional and peer mentors doing to retain these brothers on campus, making sure that they're okay in their day to day lives, and what have you." Administrators did not have a measurement tool in place 
and students recognized that. This lack of structure and organization may have an indirect effect on student's participation, but a direct effect on the University involvement, especially if asked to provide monies for the initiative and a direct effect on faculty who are not aware of the importance of this program. There are both initiatives that lack structure and organization and ones that are polished with a firm foundation. Throughout the literature, there are discussions these types of initiatives as well as the theories to create a firm foundation for research studies. In the next section, the researcher aligns the research study with the literature to examine if there are similarities.

\section{Literature}

Why are only $30 \%$ of Black college male students retained each year? And of those who do persist, why do $70 \%$ never earn a college degree? These disparaging numbers make the argument that there is a need to retain and graduate Black men. In this study, the researcher examined the factors that led to Black college male students' persistence and graduation completion. These factors were derived from semi-structured and focus group interviews probing student perspectives concerning a retention initiative aimed to increase Black college male retention. According to Bean (2001), there is a typical profile of students who are retained and graduate each year. That profile includes (a) enrollment in college following high school; (b) attending a four-year private or public university seeking a bachelor's degree; (c) being a full-time student; (d) coming from a white or Asian family whose parents are educated with high annual incomes; (e) attending a high-quality high school; (f) receiving good grades in high school; (g) scoring well on college entry exams; (h) intending to graduate and set career goals; (i) participating in college activities and have a positive attitude towards school; and (j) identifying the campus as being a good fit. Of the 10 criteria that Bean (2001) suggests are a benchmark for 
student retention and graduation completion, the student participants in this study, collectively, meet more than half of these criteria. However, when the researcher asked the participants why some of their Black peers dropped out of college or never enrolled, many shared that that those students lacked a solid family foundation, did not have good enough grades, did poorly on entrance exams, did not get into their college of choice, forcing them to attend a community college, and particularly being unclear how to set goals in college. All of the student participants enrolled in college following high school. When the researcher probed them to see how many of their peers did not attend college right away, most of the participants shared at least $75 \%$ of Black peers stayed home and worked following high school. Nine of the 10 participants enrolled in a four-year public university. One single student started at a two-year college but transferred to MAC University after his sophomore year. Many Black college males enroll in community colleges following high school (Harper, 2006). All of the student participants came from Black households and categorized themselves as working to middle class families. Two of the 10 participants attended affluent high schools, one private school and the other a public school located in an affluent school district. Six of the 10 participants shared they graduated high school with a 3.0 GPA or better. All of the participants were involved in at least one college activity, with many participating in two or more. The participants in this study fit many of the criteria Bean (2001) suggests are factors that improve retention and graduation completion. However, the students in this initiative are students who voluntarily signed up to participate. The initiative is self-selected and students do not go through a rigorous or mandatory screening selection. So, the participants have some level of drive to seek out an initiative that will improve their success (RQ1). The participants who are missing from this study are those who have less than half of the criterion Bean (2001) offered. Based on research question one, "How does the initiative help 
retain Black college male students," all student participants shared the retention initiative served as a reason for their retention and success. Both recent graduate participants expressed if the retention initiative was not in place they would not have graduated as quickly as they did. The researcher probed the graduates about whether the initiative was the sole reason for their success, but it was not. They shared that being involved socially on campus as well as being invited to participate in Academic S.T.A.R.S. were also reasons they remained at the school. The other eight student participants acknowledged that M.A.L.E. helped guide them on campus as well as provide resources that were not made available to them in other spaces on campus. Additionally, the Director (MA) of M.A.L.E. felt strongly that the initiative helped to retain Black college men. He shared, "the initiative provides a support system for students and connects them to institutional programs and organizations to help retain and graduate students." All of the student participants agreed that M.A.L.E. was a great support system and acknowledged they felt part of a family. MA expressed the initiative is also "a safe space for students to discuss successes and concerns in order to receive support that leads them to retention and graduation." Lastly, MA believed one strength of the initiative is the role-modeling between students and staff, which provides inter-generational perspectives. M.A.L.E. helped participants in three areas that Swail's (2004) geometric model suggests is imperative for retention; cognitive, social and institutional. M.A.L.E. helps students cognitively by connecting them to academic resources on campus. The initiative helps students socially by encouraging them to be student leaders and join black fraternities. Additionally, the initiative helps students with academic support set up through the institution. However, the University lacks consistent faculty support for students, lacks a welcoming campus environment for students, lacks financial aid assistance for students, and student services that reflect the culture of Black college males. The literature on retention 
suggests that the factors related to low Black college male retention is in part because of the institution, but also the external factors Black men bring with them to college (Harper, 2006). The researcher in this study discovered external factors that student participants brought with them to college and compared them to factors found in pre-existing literature.

Some of the factors that influence Black college male retention include institutional factors such as student engagement (Harper, 2006; Tinto, 1993), faculty interaction (Pascarella \& Terenzini, 2005); and campus climate (Fries-Britt \& Turner, 2002), as well as external factors that include family responsibility, peer influence, and psychological factors (Cuyjet, 2006; Harper, 2006). All of the participants acknowledged feeling "homesick" and missed some of the amenities they found at home that the campus did not have access too. CA and SA talked about how important public transportation was for them at home, but the University did not offer anything like it. RD shared how close his family is and to be hundreds of miles away from them affected his ability to transition into the university setting. He expressed, "There were times I wanted them (family) here or I go to them." JD and SR went to high schools that had a racially mixed student body and they agreed that having a racially mixed student body in high school helped them to fit in with racially mixed peers in college. Most of the participants grew up in predominantly Black communities and found it difficult to connect well with white peers and faculty. CA shared, "sometimes I feel like we (blacks and whites) have nothing in common." Aside from the inability to connect with white peers and faculty, Black college men struggle with psychological factors like self-esteem, self-worth, self-confidence, and grit (Cuyjet, 2006, Strayhorn, 2013). CA discussed feeling helpless, with no one to turn to when his grandmother was ill. RD shared two of his family members were killed during his freshman year in college and while he had confidence and grit to get through it, he discussed not having an outlet to deal 
with his emotional pain. KE disclosed he was shot one weekend home visiting his family and one of his professors found out about via social media and immediately contacted the department to offer assistance. KE was genuinely moved by this gesture and said it had a direct impact on his desire to stay at the university. KE was the only participant who expressed a college professor went out of their way to provide assistance. He also admitted his self-worth increased because of his professor's personal attention to his life. All participants agreed they possessed grit, an important attribute in being a successful Black college student. They defined grit as the ability to push through life's obstacles to reach your goal. For Black men who do not possess grit or a strong sense of self, it may be a liability that affects their ability to do well in college. All participants in this study have goals to graduate from college. Presently, two participants are recent graduates, one student participant is a graduate student, and one student dropped out of MAC and transferred to a four-year public college close to his home. The other six participants are active students who are on course to graduate. In addition, the criteria used to gauge students' likelihood of persisting and graduating come from extensive research. The criterion that Bean (2001) developed came from existing student retention theories. Most researchers gain knowledge from existing research and theories in order to further the cause. The researcher in this study also looked at several theories to guide his limited understanding of student retention. In addition, the researcher paid special attention to Tinto's $(19975,1993)$ model of student departure and Swail's (2004) geometric model of Student Persistence and Achievement to further explain the obstacles and needs Black men face in college as well as provide recommendations for educators and policy makers as they progressively address the unmet needs of Black college male students. 
Tinto's $(1975,1993)$ model on student departure revolutionized the way theorists understood student departure and has become the most widely used student departure model. Tinto (1993) believed that the process of colleges retaining students is similar to how people become part of communities. Particularly, students would remain enrolled in college if they separated themselves from family and peers and adopted the customs, values, and behaviors of the institution (Tinto, 1993). This research study illuminates the difficulties for Black college men to voluntarily separate themselves from family and peers. Considering Black college men have difficulty separating from family, it may be an impossible feat for Black men to accomplish this. In this research study, several participants shared that family and family responsibilities were important to them. RD expressed, "That first semester was really about getting acclimated and get my foundation set in place so I could navigate through. The first semester was really adjustments and adapting to one, my surroundings and being so far away from my family." CA added, "Most of my family is in North Carolina - my grandmother, my mom is a single mom, and I've been having to work a few jobs to help my family." Moreover, adopting the customs, values, and behaviors of the institution is another hard stretch, specifically for Black men who are not from a similar environment.

Tinto (1993) identified different student groups, such as African-American students and low-income students, as having unique experiences which require different retention strategies than the ones recommended for the white population. While Tinto acknowledged Black college students as having unique experiences compared to white students, he did not provide readers with a solution that caters to Black college students. Generally, no theorist has developed a theory specific to the retention of Black students. SA shared, "I read somewhere, the white population has a higher graduation rate than Black students. Something needs to be done about 
that." Participants recognized that Black students were at a disadvantage in college. Their hope in the initiative was because they felt it was the only program on campus where participants felt someone cared about the state of Black men in college. CW felt, "This initiative has been extremely effective from what I understood the initiative was supposed to do. But I have zero black teachers, nobody that is black teaching me. This makes it hard for students like me." Participants have unique experiences compared to their white counterparts and these experiences have required Black to students advocate for themselves and seek opportunities to connect with the campus. While Tinto (1993) did not have a retention or graduation solution for Black college males, he recognized that work must be done in order for Black college males to increase retention percentages. The researcher also paid special attention to Swail's (2004) geometric model of student persistence and achievement to further explain the obstacles and needs Black men face in college.

The geometric model of student persistence and achievement is the conceptual framework the researcher used to guide the study. The model is shaped like a triangle which denotes a particular force on the center of the triangle. The center of the triangle represents the student and the outside of the triangle account for student outcomes: cognitive, social, and institutional factors (see Figure 1).

In this study, the researcher discovered by placing participants in the center of the triangle, participant outcomes were varied, but had similar themes. All participants were Black men, but the communities and school districts they attended were vastly different. Previous research has promoted the Black college male experience as similar or monolithic, but this study demonstrates how different Black men are and how their needs are diverse. During the semistructured and focus group interviews, the participants disclosed the cognitive, social, and 
institutional factors that influenced their decision to become part of the retention initiative as well as thoughts behind their decision to remain at the university.

The study used document analysis to analyze the data collected. Document analysis utilized the data with word count analysis to determine which words are mostly used by the participants and which words are seldom used. Based on the results, the 20 most used words included students, initiative, male, black, college, school, support, empowerment, academic, campus, university. It also bears noting that the mostly used words did not reflect positive words and phrases such as networking, mentorship family or sense of belongingness. One possible interpretation of this is that the participants did not really feel any sense of belongingness or effective mentorship. On the other hand, it is also possible that using the word count analysis, the participants did not use these specific words but actually chose to expound more using other words or sentences. A good response to the results of this document analysis is o ensure that the Black college male students would be able to experience positive experience during their university education and actually be able to articulate and relay this positive experience to others.

Some of the cognitive factors that emerged in this study were academic rigor and critical thinking ability. RD shared, "I had no idea what to expect. My teammate, Terrell, helped me out a lot as far as understanding my role as a football player and the hard academics as a student." CW echoed, "I wanted to play football here, but my brother advised me to focus on my academics. Had he not gave me that advice, I would have come here to play football." The influence of trusted people in the lives of these participants helped them make critical decisions about their college career. In many instances, participants were not cognitively ready for college, but the influence of family, friends, and the retention initiative helped them strengthen their cognitive abilities, ultimately representing a factor that increased persistence. 
Parallel to cognitive factors, this study also introduced social factors that participants shared were important in their development and reason to join the retention initiative. Some of the social factors that emerged in this study were financial issues, cultural values, and family influence. SA shared, “A really good friend of mine (here) didn't have the best focus with school. It was tough for him. He ended up having a baby and barely could afford school. He ended up dropping out." Black college males have great intentions of doing well in school, but finances and family obligations continue to be an obstacle for Black men who enroll in college. If Black college men come from families of low socioeconomic status, paying for school is a significant challenge that their affluent, white counterparts may not experience. In addition, participants spoke about cultural values that impeded their ability to remain focused on school. Some of those cultural values centered on participants would respond in certain situations. Participants expressed that if they got someone pregnant, the first thought would be to drop-out of school and get a job to provide for the baby. Other cultural responses involved interactions with others who shared different cultural values. SA continued, "My first roommate was a white student who I hung out with until I was able to find my core group. It's just...you know, be able to stay true to yourself and be who you are, but it's difficult with people who don't understand your culture." This idea of culture emerged several times throughout the interviews. Socially, participants felt their peers and faculty did not embrace their culture and oftentimes made them feel marginalized on campus. There were no campus activities that represented their culture and many times participants felt it was hard to fit in. The retention initiative provided the cultural context participants needed to feel like they were part of the campus. 
Akin to cognitive and social factors were institutional factors that influenced participants' decisions to be part of the retention initiative. Some of the institutional factors that emerged in this study were academic services and student services. JD shared:

The S.T.A.R.S. and M.A.L.E. programs empowered me in being an RA, being an SGA senator, being a university ambassador, where a lot of those faces were white. And I was the only black man sitting at the table. So it was sort of like, if I don't do it, who will? Being part of the retention initiative helped participants find their voice and encourage them to take their voice with them in spaces on campus where there was no representation of Blackness. Albeit, the absence of Black representation in spaces on campus may add to the disparaging number of Black men who drop-out of college before earning a college degree. CT acknowledged:

Once I joined a Black fraternity that's really what got me to become a part of M.A.L.E. because a lot of my older fraternity brothers were a part of M.A.L.E., which then pushed me to be a part of other things on campus.

Participants were introduced to institutional academic and student services through the retention initiative. There was a level of trust the retention initiative provided the participants, which in turn helped them open up to the many offerings the University provided. Some participants joined fraternities and others became resident assistants. No matter the number of services participants were part of, they all expressed how M.A.L.E. and S.T.A.R.S. encouraged them to take part in these services.

The cognitive, social, and institutional factors proved to be meaningful for the participants in the study. Swail (2004) suggested that if students did not connect cognitively, socially, or institutionally, it would be a hard feat for them to remain at the college. However, 
Swail (2004) also made mention to the notion that all three factors carry different weight for students. For instance, a student could connect well socially and institutionally, but not connect as well cognitively. In this instance, the student may persist and eventually graduate, but the presence of all the factors increase the likelihood of a student persisting and earning a degree. Participants in this study valued the retention initiative and acknowledged it helped them develop social and cognitive skills to navigate the terrain of a PWI.

\section{Limitations}

This dissertation investigated the perceptions of a retention initiative aimed to increase Black college male retention and graduation completion. During this study, I provided descriptive accounts about the lived experiences of a retention initiative based on the stories and reflections of the participants. The data collected was beneficial and I was able to take into account the influence the initiative had for Black college male students. Further, this study advanced the knowledge of the Black college male experience by addressing the unmet needs of Black college males and acknowledge ways to aid them in their pursuit of excellence through retention and graduation completion. As I reflected on the entirety of this research study, I am extremely pleased with the results, experience, and knowledge gained. However, while reflecting on the enormity of this project, I recognized a few limitations that should be addressed.

Although I do not consider myself a limitation, I recognize that as a Black male researching Black male students, I am privy to cultural nuances and lived experiences that could influence my connection with the data. In my attempt to maintain the integrity of the data, I constantly checked in with my participants to be certain I provided an accurate account of their stories. While, my presence as a Black male does not discredit the study, it would be meaningful 
to know what the outcomes of the study would be if a white man or woman served as the researcher.

It bears noting that the study also used document analysis using the word count analysis to analyze the responses from the participants. It can be taken as a limitation since the words uttered by the participants may not necessarily reflect the entirety of what the participants wanted to mean. Thus, it may also be taken as a limitation if some of the data analysis in this study pertained to the word count of the responses from the participants.

In addition, this study was bounded geographically and demographically. The location of this study took place at a land-grant PWI located in a rural environment. The experiences of the participants in this study are specific to this school. However, it would be important to examine the experiences of Black college males who attend PWIs located in suburban and urban environments. Some of the cultural artifacts that participants revealed were not accessible to them in this rural environment would be available to them in other geographical locations. Thus, the outcomes of the study may be different. Furthermore, the demographic of the study included Black college men attending a PWI, but if the study included Black college men attending a HBCU, this may show deeper comparisons between Blacks at PWIs versus HBCUs.

Furthermore, one of the research questions asks, "How does the initiative in place help to retain Black college male students attending a land-grant PWI located in a rural environment?" When I started this research study, I was only aware of the M.A.L.E. initiative. However, the participants mentioned another program entitled Academic S.T.A.R.S. While S.T.A.R.S. is not solely designed for Black college males, it is a summer-bridge program for newly admitted Black college students. The impact and influence S.T.A.R.S had on Black college males was just as profound as the influence M.A.L.E. had on participants. It is impossible to tease the two 
apart. In a future study, it would be interesting to see how the S.T.A.R.S. program influences the retention of Black college male and female students.

Additionally, all of the participants were active members of the retention initiative. Their participation helped the researcher construct a better understanding of the purpose, process, and effectiveness of the initiative. However, it is important to know the experiences of Black college males who do not participate in the initiative. How are they able to persist year to year without being part of the initiative? And if these men are at the brink of departing from the college, what do they need in order to persist and graduate? These limitations were not intentional, but they are important to highlight. The next section discusses the implications for practice and future research.

\section{Implications}

This study highlights the experiences of Black college male students who attend a PWI located in a rural environment. While this study is not a representation of every Black college male students' story, the data provided identifies knowledge beneficial to Black college male development. This timely study is about self-awareness, purpose, processes, effectiveness, adaptation, and development. The researcher attempted to explain the experiences of Black college male students without deviating from their raw accounts and personal stories about college, retention and programs. This study outlined the importance of programs for Black college males that aimed to help them develop and grow in unfamiliar spaces. Based on the data provided, educators, faculty, and administrators should discuss ways to engage Black college males in multiple spaces on campus that promote their well-being, academic aptitude, social integration, and retention. This dissertation should also prompt parents to engage in 
conversations with institutions about ways to aid Black college males in addition to ways parents can best support them from afar.

\section{Conclusion}

As this dissertation comes to a close, it is paramount to acknowledge the conversation about how to provide Black males a college experience that promotes growth, retention and graduation completion is just getting started. This dissertation was a project that began based off of my personal journey through higher education and later gained momentum and support from scholars who research student injustices and the outcomes of those injustices as experienced by students and the institution at large. Through this study, the researcher had the privilege of sharing space with Black college male students who not only aspire to earn a college degree but have ambitions to return to their communities and inspire other Black males to consider college as a realistic, attainable option.

This study does not provide all the answers to the plight of Black men in higher education. Nor does it provide a new theory to help educators create intentional programs or practices that would lead to increased retention efforts for Black college males. Rather, this study is an in-depth analysis of the phenomenon - retention initiatives aimed to increase Black college male persistence. The hope is that the creators of retention initiatives recognize that Black men are not monolithic, and their voices are imperative in designing programs that are tailored for them. In addition, retention initiatives serve as incubators of opportunity and in these spaces are Black males influenced to embrace the culture of the institution, join student organizations, partner with other peers, and develop positive, working relationships with faculty. The impact and influence retention initiatives have on Black college males is essential for their success. 
It is my hope that I held your attention long enough to compel you to advance this conversation and scholarship. The knowledge is now in your hands and the promise of Black male success lies in the voices of the those who believe in social justice, equity, and inclusion. To my participants, may you forever strive to allow your voices to be heard and may this work compel you to pave the way for those in your rearview. 


\section{References}

Aljohani, O. (2016). A comprehensive review of the major studies and theoretical models of student retention in higher education. Higher Education Studies, 6(2), 1. http://doi.org/10.5539/hes.v6n2p1

Allen, W. R., \& Jewell, J. O. (2002). A backward glance forward: Past, present and future perspectives on historically Black colleges and universities. The Review of Higher Education, 25(3), 241-261. http://doi.org/10.1353/rhe.2002.0007

Ancis, J. R., Sedlacek, W. E., \& Mohr, J. J. (2000). Student perceptions of campus cultural climate by race. Journal of Counseling \& Development, 78(2), 180-185. https://doi.org/10.1002/j.1556-6676.2000.tb02576.x

Aronson, J. (1995). A pragmatic view of thematic analysis. The Qualitative Report, 2(1), 1-3. Retrieved from https://nsuworks.nova.edu/tqr/vol2/iss1/3

Astin, A. W. (1977). Four critical years. San Francisco, CA: Jossey-Bass.

Astin, A. W. (1984). Student involvement: A developmental theory for higher education. Journal of College Student Personnel, 25(4), 297-308. Retrieved from https://www.middlesex.mass.edu/ace/downloads/astininv.pdf

Astin, A. W. (1985). Involvement the cornerstone of excellence. Change: The Magazine of Higher Learning, 17(4), 35-39. http://doi.org/10.1080/00091383.1985.9940532

Astin, A. W. (1997). How "good" is your institution's retention rate? Research in Higher Education, 38(6), 647-658. https://doi.org/10.1023/A:1024903702810

Bailey, C. A. (2007). Coding, memoing, and descriptions. In A guide to qualitative field research (pp. 125-142). Thousand Oaks, CA: SAGE Publications Ltd. https://doi.org10.4135/9781412983204.n9 
Baker, C. N. (2013). Social support and success in higher education: The influence of on-campus support on African American and Latino college students. The Urban Review, 45(5), 632-650. http://doi.org/10.1007/s11256-013-0234-9

Bandura, A. (1997). Self-efficacy: The exercise of control. Macmillan.

Bean, J. (1980). Dropouts and turnover: The synthesis and test of a casual model of student attrition. Research in Higher Education, 12, 155-187. http://doi.org/10.1007/BF00976194

Bean, J. P. (2001). College student retention-defining student retention: A profile of successful institutions and students: Theories of student departure. Education Encyclopedia-State University.com.

Bean, J. P., \& Metzner, B. S. (1985). A conceptual model of nontraditional undergraduate student attrition. Review of educational Research, 55(4), 485-540. http://doi.org/10.3102/00346543055004485

Bloor M., Frankland J., Thomas M., \& Robson K. (2001) Focus groups in social research. London: Sage Publications.

Bohrnstedt, G., Kitmitto, S., Ogut, B., Sherman, D., \& Chan, D. (2015). School composition and the black-white achievement gap. NCES 2015-018. National Center for Education Statistics.

Bowen, G. A. (2009). Document analysis as a qualitative research method. Qualitative Research Journal, 9(2), 27-40. http://doi.org/10.3316/QRJ0902027

Bonner II, F. A., \& Bailey, K. W. (2006). Enhancing the academic climate for African American men. In M. J. Cuyjet (Ed.), African-American men in college (pp. 24-46). San Francisco: Jossey-Bass. 
Braun, V., \& Clarke, V. (2006). Using thematic analysis in psychology. Qualitative Research in Psychology, 3(2), 77-101. http://doi.org/10.1191/1478088706qp063oa

Braxton, J. M. (Ed.). (2000). Reworking the student departure puzzle. Vanderbilt University Press.

Braxton, J. M., \& Hirschy, A. S. (2005). Theoretical developments in the study of college student departure. In A. Seidman (Ed.) College Student Retention: Formula for Student Success, (pp. 61-87) Westport, CT: Praeger.

Bronfenbrenner, U. (1977). Toward an experimental ecology of human development. American Psychologist, 32(7), 513-531. http://doi.org/10.1037/0003-066X.32.7.513

Brooks, M., Jones, C., \& Burt, I. (2012). Are African-American male undergraduate retention programs successful? An evaluation of an undergraduate African-American male retention program. Journal of African American Studies, 17(2), 206-221. https://doi.org/10.1007/s12111-012-9233-2

Brown, C. (2006). The impact of campus activities on African American college men. In M. J. Cuyjet (Ed.) African American Men in College, (pp. 47-67). San Francisco, CA: JoseyBass.

Bryman, A., \& Burgess, B. (Eds.). (2002). Analyzing qualitative data. Routledge.

Bush, E. C., \& Bush, L. V. (2010). Calling out the elephant: An examination of African American male achievement in community colleges. Journal of African American Males in Education, 1(1). Retrieved from http://journalofafricanamericanmales.com/wpcontent/uploads/2010/02/Calling-Out-the-Elephant.pdf

Butler, S. K., Evans, M. P., Brooks, M., Williams, C. R., \& Bailey, D. F. (2013). Mentoring African American men during their postsecondary and graduate school experiences: 
Implications for the counseling profession. Journal of Counseling \& Development, 91(4), 419-427. https://doi.org/10.1002/j.1556-6676.2013.00113.x

Cabrera, A. F., Nora, A., Terenzini, P. T., Pascarella, E., \& Hagedorn, L. S. (1999). Campus racial climate and the adjustment of students to college. The Journal of Higher Education, 70(2), 134-160. https://doi.org/10.1080/00221546.1999.11780759

Carreathers, K., Beehmann, L., Cootie, R., \& Nelson, W. (1996). Three exemplary retention programs. New Directions for Student Services, 74, 35-52. https://doi.org/10.1002/ss.37119967405

Cerezo, A., Lyda, J., Enriquez, A., Beristianos, M., \& Connor, M. (2015). African American and Latino men's recommendations for an improved campus environment. Journal of College Counseling, 18(3), 244-258. https://doi.org/10.1002/jocc.12018

Chesler, M., Lewis, A. E., \& Crowfoot, J. E. (2005). Challenging racism in higher education: Promoting justice. Rowman \& Littlefield Publishers.

Chronicle of Higher Education, Aug. 29, 1997 (in vol. 44, no. 1).

Cleveland, D. (Ed.). (2004). A long way to go: Conversations about race by African American faculty and graduate students (Vol. 14). New York, NY: Peter Lang.

Cohen, C. J., \& Nee, C. E. (2000). Educational attainment and sex differentials in African American communities. American Behavioral Scientist, 43(7), 1159-1206. https://doi.org/10.1177/00027640021955801

Cole, D., \& Griffin, K. (2013). Advancing the study of student-faculty interaction: A focus on diverse students and faculty. In M. B. Paulsen (Ed.), Higher education: Handbook of theory and research (Vol. 28, pp. 561-611). New York, NY: Springer. 
Comeaux, E. (2008). Black males in the college classroom: A quantitative analysis of student athlete-faculty interactions. Challenge (Atlanta): A Journal of Research on African American Men, 14(1), 1-14. Retrieved from http://digitalcommons.auctr.edu/challenge/vol14/iss1/2/

Creswell, J. W. (2007). Five qualitative approaches to inquiry. Qualitative inquiry and research design: Choosing among five approaches, 2, 53-80.

Creswell, J. (2012). W.(1994). Research design: Qualitative and quantitative approaches. Thousand Oaks, CA: Sage Publications.

Crockett, D. (2004). Critical issues children face in the 2000s. School Psychology Review, 33(1), 78. http://doi.org/10.1521/scpq.18.4.446.26997

Cross, W. E., Jr., Parham, T. A., \& Helms, J. E. (1991). The stages of Black identity development: Nigrescence models. In R. L. Jones (Ed.), Black psychology (pp. 319-338). Berkeley, CA, US: Cobb \& Henry Publishers.

Cross, W. E., Jr. (1995). The psychology of nigrescence: Revising the Cross model. In J. G. Ponterotto, J. M. Casas, L. A. Suzuki, \& C. M. Alexander (Eds.), Handbook of multicultural counseling (pp. 93-122). Thousand Oaks, CA: Sage Publications, Inc.

Cuyjet, M. J. (1997). African American men on college campuses: Their needs and their perceptions. New Directions for Student Services, 1997(80), 5-16. http://doi.org/10.1002/ss.8001

Cuyjet, M. J. (2006). African American Men in College. Indianapolis, IN: Jossey-Bass.

Dale, P. M. (1995). A successful college retention program. Retrieved from https://eric.ed.gov/?id=ED380017 
Davis, R. B. (1991). Social support networks and undergraduate student academic-successrelated outcomes: A comparison of Black students on Black and White campuses. In W. R. Allen, E. G. Epps, \& N. Z. Haniff(Eds.), SUNY series, frontiers in education. College in Black and White: African-American students in predominantly White and in historically Black public universities (pp. 143-157). Albany, NY: State University of New York Press.

Demetriou, C., \& Schmitz-Sciborski, A. (2011). Integration, motivation, strengths and optimism: Retention theories past, present and future. In Proceedings of the 7th National Symposium on student retention (pp. 300-312). Norman, OK: University of Oklahoma.

DesJardins, S. L., \& McCall, B. P. (2007). The impact of the Gates Millennium Scholars Program on selected outcomes of low-income minority students: A regression discontinuity analysis. Bill and Melinda Gates Foundation Working Paper.

Dodd, C., Kirby, D., Seifert, T., \& Sharpe, D. (2009). The impact of high school distance elearning experience on rural students' university achievement and persistence. Online Journal of Distance Learning Administration, 12(1), 1-12. Retrieved from https://www.westga.edu/ distance/ojdla/spring121/dodd121.html

Dorsey, M. S., \& Jackson, A. P. (1995). Afro-American students' perceptions of factors affecting academic performance at a predominantly white school. The Western Journal of Black Studies, 19(3), 189. Retrieved from https://eric.ed.gov/?id=EJ528848

Du Bois, W. B. (1935). Does the Negro need separate schools? Journal of Negro Education, 4(3), 328-335. Retrieved from http://www.jstor.org/stable/2291871

Dulabaum, N. L. (2016). Barriers to academic success: A qualitative study of African American and Latino male students. Innovative Showcase, 11(6). Retrieved from 
https://www.league.org/innovation-showcase/barriers-academic-success-qualitative$\underline{\text { study-african-american-and-latino-male }}$

Durkheim, E. (1951). Suicide: A study in sociology (JA Spaulding \& G. Simpson, trans.). Glencoe, IL: Free Press.

Elam, C., \& Brown, G. (2005). The inclusive university: Helping minority students choose a college and identify institutions that value diversity. Journal of College Admission, 187, 14-17. Retrieved from https://eric.ed.gov/?id=EJ922064

Feintuch, H. (2010). Black Male Rising. Diverse: Issues In Higher Education, 27(2), 18-19. Retrieved from https://eric.ed.gov/?id=EJ889743

Fries-Britt, S., \& Turner, B. (2002). Uneven stories: Successful Black collegians at a Black and a White campus. The Review of Higher Education, 25(3), 315-330. https://doi.org10.1353/rhe.2002.0012

Fusch, P. I., \& Ness, L. R. (2015). Are we there yet? Data saturation in qualitative research. The Qualitative Report, 20(9), 1408-1416. Retrieved from https://nsuworks.nova.edu/tqr/vol20/iss9/3/

Gardner, J. D. (2005). A successful minority retention project. The Journal of Nursing Education, 44(12), 566-568. Retrieved from https://www.researchgate.net/publication/7368708_A_successful_Minority_Retention_Pr oject

Gill, E. L., Jr., \& Farrington, K. (2014). The impact of an Intensive Learning Program (ILP) on Black male football student-athlete academic achievement. Journal of College Student Development, 55(4), 413-418. http://doi.org10.1353/csd.2014.0037 
Gladieux, L. E., \& Swail, W. S. (2000). Beyond access: Improving the odds of college success. The Phi Delta Kappan, 81(9), 688-692. Retrieved from https://eric.ed.gov/?id=EJ606461

Gloria, A. M., Kurpius, S. E. R., Hamilton, K. D., \& Willson, M. S. (1999). African-American students' persistence at a predominantly white university: Influence of social support, university comfort, and self-beliefs. Journal of College Student Development, 40(3), 257268. Retrieved from https://asu.pure.elsevier.com/en/publications/african-americanstudents-persistence-at-a-predominantly-white-un

González, K. P. (2002). Campus culture and the experiences of Chicano students in a predominantly White university. Urban Education, 37(2), 193-218. Retrieved from http://journals.sagepub.com/doi/pdf/10.1177/0042085902372003

Green, R. L., \& Wright, D. L. (1991). African-American males: A demographic study and analysis. Retrieved from https://eric.ed.gov/?id=ED346167

Greene, T. G., Marti, C. N., \& McClenney, K. (2008). The effort-outcome gap: Differences for African American and Hispanic community college students in student engagement and academic achievement. The Journal of Higher Education, 79(5), 513-539. Retrieved from https://eric.ed.gov/?id=EJ809570

Grier-Reed, T. L., Na'im H, M., \& Buckley, C. G. (2008). Low Black student retention on a predominantly White campus: Two faculty respond with the African American student network. Journal of College Student Development, 49(5), 476-485. Retrieved from https://eric.ed.gov/?id=EJ812144

Griffin, K. A., Jayakumar, U. M., Jones, M. M., \& Allen, W. R. (2010). Ebony in the ivory tower: Examining trends in the socioeconomic status, achievement, and self-concept of 
black, male freshmen. Equity \& Excellence in Education, 43(2), 232-248. https://doi.org/10.1080/10665681003704915

Groenewald, T. (2004). A phenomenological research design illustrated. International Journal of Qualitative Methods, 3(1), 42-55. https://doi.org/10.1177/160940690400300104

Guba, E. G., \& Lincoln, Y. S. (2005). Paradigmatic controversies, contradictions, and emerging confluences. In N. K. Denzin \& Y. S. Lincoln (Eds.), The Sage handbook of qualitative research (pp. 191-215). Thousand Oaks, CA: Sage Publications.

Guest, G., Bunce, A., \& Johnson, L. (2006). How many interviews are enough? An experiment with data saturation and variability. Field Methods, 18(1), 59-82. Retrieved from http://journals.sagepub.com/doi/pdf/10.1177/1525822X05279903

Guiffrida, D. A. (2004). Friends from home: Asset and liability to African-American students attending a predominantly White institution. Naspa Journal, 41(4), 693-708. Retrieved from https://www.tandfonline.com/doi/abs/10.2202/1949-6605.1394

Guiffrida, D. (2005). To break away or strengthen ties to home: A complex issue for African American college students attending a predominantly White institution. Equity \& Excellence in Education, 38(1), 49-60. Retrieved from https://urresearch.rochester.edu/institutionalPublicationPublicView.action?institutionalIte $\underline{\mathrm{mId}=1866}$

Guiffrida, D. A., \& Douthit, K. Z. (2010). The Black student experience at predominantly White colleges: Implications for school and college counselors. Journal of Counseling \& Development, 88(3), 311-318. Retrieved from https://eric.ed.gov/?id=EJ892761

Hamilton, T. (2010). Understanding the Black college student experience: The relationships between racial identity, social support, general campus, academic, and racial climate, 
and GPA (Doctoral dissertation). Retrieved from http://scholarship.shu.edu/cgi/viewcontent.cgi?article=2748\&context=dissertations.

Hamilton, C. V., \& Ture, K. (2011). Black power: Politics of liberation in America. New York, NY: Vintage.

Harper, S., \& Newman, C. (2016). Surprise, sensemaking, and success in the first college year: Black undergraduate men's academic adjustment experiences. Teachers College Record, 118(6). Retrieved from https://eric.ed.gov/?id=EJ1100377

Harper, S. R. (2006). Black male students at public flagship universities in the US: Status, trends, and implications for policy and practice. Joint Center for Political and Economic Studies, Health Policy Institute.

Harper, S. R. (2009). Niggers no more: A critical race counternarrative on Black male student achievement at predominantly White colleges and universities. International Journal of Qualitative Studies in Education, 22(6), 697-712. Retrieved from https://eric.ed.gov/?id=EJ870927

Harper, S. R. (2012). Black male student success in higher education: A report from the National Black Male College Achievement Study. University of Pennsylvania, Graduate School of Education, Center for the Study of Race and Equity in Education.

Harper, S. R., Davis, R. J., Jones, D. E., McGowan, B. L., Ingram, T. N., \& Platt, C. S. (2011). Race and racism in the experiences of Black male resident assistants at predominantly White universities. Journal of College Student Development, 52(2), 180-200. Retrieved from https://eric.ed.gov/?id=EJ930269

Harper, S. R., \& Griffin, K. A. (2010). Opportunity beyond affirmative action: How low-income and working-class black male achievers access highly selective, high-cost colleges and 
universities. Harvard Journal of African American Public Policy, 17. Retrieved from $\underline{\text { https://web- }}$

app.usc.edu/web/rossier/publications/231/Harper\%20and\%20Griffin\%20(2011).pdf

Harper, S. R., \& Harris III, F. (2006). The role of Black fraternities in the African American male undergraduate experience. In M. J. Cuyjet (Ed.), African American men in college (pp. 128-153). San Francisco, CA: Jossey-Bass.

Harper, S. R., \& Harris III, F. (2012). Men of Color: A Role for Policymakers in Improving the Status of Black Male Students in US Higher Education. Institute for Higher Education Policy.

Harper, S. R., Patton, L. D., \& Wooden, O. S. (2009). Access and equity for African-American students in higher education: A critical race historical analysis of policy efforts. The Journal of Higher Education, 80(4), 389-414. Retrieved from https://repository.upenn.edu/gse_pubs/205/

Harrison, L., \& Harrison, C. (2002). African American racial identity: Theory and application to education, race, and sport in America. African American Research Perspectives, 8(1), 35-46. https://doi.org/10.1080/1357332022000018823

Hayes, D. (2013). Where Are They Now? Diverse Issues in Higher Education, 30(13), 18.

Hess, F., \& Leal, D. (1997). Minority teachers, minority students, and college matriculation: A new look at the role-modeling hypothesis. Policy Studies Journal, 25(2), 235-248. https://doi.org/10.1111/j.1541-0072.1997.tb00018.x

Holzman, M. (2006). Public education and Black male students: The 2006 state report card. Schott Foundation for Public Education. 
Hoover, E. (2013). Minority applicants to colleges will rise significantly by 2020. Chronicle of Higher Education, Jan 2013. Retrieved from https://eric.ed.gov/?id=EJ991534

Hotchkins, B. K. (2013). The soul of leadership: African-American students' experiences in historically Black and predominantly White organizations. The University of Utah.

Hotchkins, B. (2016). African-American males navigate racial microaggressions. Teachers College Record, 118(6). Retrieved from https://www.depts.ttu.edu/education/ourpeople/Faculty/documents/african-american-males-navigate-racial-microaggressionshotchkins-2016.pdf

Howard, C. (2017). Ranking America's top colleges 2014. Forbes.

Hurtado, S. (1992). The campus racial climate: Contexts of conflict. The Journal of Higher Education, 63(5), 539-569. http://doi.org10.2307/1982093

Kanter, J. W., Williams, M. T., Kuczynski, A. M., Manbeck, K. E., Debreaux, M., \& Rosen, D. C. (2017). A preliminary report on the relationship between microaggressions against Black people and racism among white college students. Race and Social Problems, 9(4), 291-299. https://doi.org/10.1007/s12552-017-9214-0

Keels, M. (2013). Getting them enrolled is only half the battle: college success as a function of race or ethnicity, gender, and class. American Journal of Orthopsychiatry, 83(2-3), 310. https://doi.org/10.1111/ajop.12033

Kimbrough, W. M. (1995). Self-assessment, participation, and value of leadership skills, activities, and experiences for Black students relative to their membership in historically Black fraternities and sororities. Journal of Negro Education, 64(1), 63-74. http://doi.org/10.2307/296728563-74 
Kimbrough, W. M. (2003). Black Greek 101: The culture, customs, and challenges of Black fraternities and sororities. Lanham, MD: Fairleigh Dickinson University Press.

King, J. E. (1999). Money matters: The impact of race/ethnicity and gender on how students pay for college. Retrieved from https://eric.ed.gov/?id=ED443364

Kobrak, P. (1992). Black student retention in predominantly white regional universities: The politics of faculty involvement. The Journal of Negro Education, 61(4), 509-530. Retrieved from http://www.jstor.org/stable/2295368

Krueger R A. (1998) Moderating focus groups. London: Sage Publications.

Kuh, G. D., Cruce, T. M., Shoup, R., Kinzie, J., \& Gonyea, R. M. (2008). Unmasking the effects of student engagement on first-year college grades and persistence. The Journal of Higher Education, 79(5), 540-563. http://doi.org10.1353/jhe.0.0019

Kuh, G. D., Kinzie, J., Buckley, J. A., Bridges, B. K., \& Hayek, J. C. (2007). Major theoretical perspectives on student success in college. Piecing Together the Student Success Puzzle: Research, Propositions, and Recommendations: ASHE Higher Education Report, 32(5), $13-20$.

Kuh, G. D., Kinzie, J., Schuh, J. H., \& Whitt, E. J. (2011). Student success in college: Creating conditions that matter. San Francisco, CA: Jossey-Bass.

Kuh, G. D., Pace, C. R., \& Vesper, N. (1997). The development of process indicators to estimate student gains associated with good practices in undergraduate education. Research in Higher Education, 38(4), 435-454. https://doi.org/10.1023/A:1024962526492

Kvale, S., \& Brinkmann, S. (2009). Learning the craft of qualitative research interviewing. Thousand Oaks, CA: Sage Publications. 
Ladson-Billings, G. (1992). Liberatory consequences of literacy: A case of culturally relevant instruction for African-American students. The Journal of Negro Education, 61(3), 378391. https://doi.org/10.1177/004005990603900211

LaVant, B. D., Anderson, J. L., \& Tiggs, J. W. (1997). Retaining African American men through mentoring initiatives. New Directions for Student Services, 1997(80), 43-53. https://doi.org/10.1002/ss.8004

Lea, J. (2000). The Macpherson Report and the question of institutional racism. The Howard Journal of Crime and Justice, 39(3), 219-233. https://doi.org/10.1111/1468-2311.00165

Léger, G. S. (2012). Black male retention initiatives: exploring students' experiences and program effectiveness at predominantly white institutions. West Virginia University. Retrieved from https://eric.ed.gov/?id=ED550954

Levitz, R. (2001). What's Working Right Now in Student Retention! Building Blocks for Retention Success - the Basis for Recruiting Success. Unpublished report prepared for the National Conference for Student Retention July 2001.

Macpherson, W. (1999). The Stephen Lawrence inquiry: report of an inquiry by Sir William Macpherson of Cluny. Stationary Office.

Maldonado, D. E. Z., Rhoads, R., \& Buenavista, T. L. (2005). The student-initiated retention project: Theoretical contributions and the role of self-empowerment. American Educational Research Journal, 42(4), 605-638. https://doi.org/10.3102/00028312042004605

Maxwell, J. A. (2012). Qualitative research design: An interactive approach (Vol. 41). Thousand Oaks, CA: Sage Publications. 
Mayhew, M. J., Bowman, N. A., Rockenbach, A. N., Seifert, T. A., \& Wolniak, G. C. (2016). How college affects students: 21st century evidence that higher education works (Vol. 3). San Francisco, CA: Jossey-Bass.

McClain, S., \& Cokley, K. (2017). Academic disidentification in Black college students: The role of teacher trust and gender. Cultural Diversity and Ethnic Minority Psychology, 23(1), 125. http://doi.org/10.1037/cdp0000094

McNeely, J. H. (1937). College student mortality. U.S. Office of Education, Bulletin 1937, no. 11. Washington, D.C.: U.S. Government Printing Office.

Merriam, S. B. (1998). Qualitative research and case study applications in education. Revised and expanded from case study research in education. San Francisco, CA: Jossey-Bass.

Museus, S. D. (2008). The role of ethnic student organizations in fostering African American and Asian American students' cultural adjustment and membership at predominantly White institutions. Journal of College Student Development, 49(6), 568-586. http://10.1353/csd.0.0039

Museus, S. D. (2014). The culturally engaging campus environments (CECE) model: A new theory of college success among racially diverse student populations. In M. B. Paulsen (Ed.), Higher Education: Handbook of Theory and Research. New York: Springer.

National Center for Public Policy and Higher Education. (2008). Measuring up 2008: The state report card on higher education. West Virginia. National Center for Public Policy and Higher Education. Retrieved from http://www.highereducation.org/reports/reports.shtml Nevarez, C., \& Wood, J. L. (2010). Community college leadership and administration: Theory, practice, and change (Vol. 3). New York, NY: Peter Lang. 
Nichols, A., \& Evans-Bell, D. (2017). A look at Black student success: Identifying top-and bottom-performing institutions. A report for The Education Trust. Retrieved April, 2, 2017.

Palinkas, L. A., Horwitz, S. M., Green, C. A., Wisdom, J. P., Duan, N., \& Hoagwood, K. (2015). Purposeful sampling for qualitative data collection and analysis in mixed method implementation research. Administration and Policy in Mental Health and Mental Health Services Research, 42(5), 533-544. http://doi.org10.1007/s10488-013-0528-y

Palmer, R. T., Davis, R. J., \& Hilton, A. A. (2009). Exploring challenges that threaten to impede the academic success of academically underprepared Black males at an HBCU. Journal of College Student Development, 50(4), 429-445. Retrieved from https://eric.ed.gov/?id=EJ852899

Palmer, R. T., Davis, R. J., \& Maramba, D. C. (2011). The impact of family support on the success of Black men at an historically Black university: Affirming the revision of Tinto’s theory. Journal of College Student Development, 52(5), 577-597. http://doi.org10.1353/csd.2011.0066

Palmer, R., \& Gasman, M. (2008). "It takes a village to raise a child": The role of social capital in promoting academic success for African American men at a Black college. Journal of College Student Development, 49(1), 52-70. Retrieved from https://repository.upenn.edu/gse_pubs/173/

Palmer, R. T., \& Wood, J. L. (Eds.). (2012). Black men in college: Implications for HBCUs and beyond. Florence, KY: Routledge. 
Palmer, R. T., Wood, J. L., Dancy, T. E., \& Strayhorn, T. L. (2014). Black Male Collegians: Increasing Access, Retention, and Persistence in Higher Education: ASHE Higher Education Report 40: 3. San Francisco, CA: John Wiley \& Sons.

Pascarella, E. T., \& Terenzini, P. T. (2005). How college affects students (Vol. 2). San Francisco, CA: Jossey-Bass.

Pascarella, E. T., Terenzini, P. T., \& Feldman, K. A. (1991). How college affects students. San Francisco , CA: Jossey-Bass.

Patton, L. D., Morelon, C., Whitehead, D. M., \& Hossler, D. (2006). Campus-based retention initiatives: Does the emperor have clothes?. New Directions for Institutional Research, 2006(130), 9-24. https://doi.org/10.1002/ir.176

Patton, M. Q. (2002). Two decades of developments in qualitative inquiry: A personal, experiential perspective. Qualitative social work, 1(3), 261-283. https://doi.org/10.1177/1473325002001003636

Phillips, C. (2005). Facing inwards and outwards? Institutional racism, race equality and the role of Black and Asian professional associations. Criminal justice, 5(4), 357-377. https://doi.org/10.1177/1466802505057716

Ponterotto, J. G., Casas, J. M., Suzuki, L. A., \& Alexander, C. M. (Eds.). (2009). Handbook of multicultural counseling. Thousand Oaks, CA: Sage Publications.

Potter, A. (2013, November, 21). Five College Trends You Need to Know About [Web log post]. Retrieved from https:/www.envisionexperience.com/blog/five-college-trends-you-needto-know-about

Prescott, B. T., \& Bransberger, P. (2012). Knocking at the College Door: Projections of High School Graduates. Western Interstate Commission for Higher Education. 
Price, J. L. (1977). The study of turnover. Ames, IA: Iowa State Press.

Reid, K. W. (2013). Understanding the relationships among racial identity, self-efficacy, institutional integration and academic achievement of black males attending research universities. The Journal of Negro Education, 82(1), 75-93. Retrieved from https://eric.ed.gov/?id=EJ1010785

Reid, L. D., \& Radhakrishnan, P. (2003). Race matters: The relation between race and general campus climate. Cultural Diversity and Ethnic Minority Psychology, 9, 263-275. Retrieved from https://eric.ed.gov/?id=EJ672661

Roebuck, J. B., \& Murty, K. S. (1993). Historically Black colleges and universities: Their place in American higher education. Westport, CT: Praeger Publishers.

Ross, M. J. (1998). Success Factors of Young African-American Males at a Historically Black College. Westport, CT: Greenwood Publishing Group, Inc.

Sáenz, V. B., \& Ponjuán, L. (2016). The Texas education consortium for male students of color: Cross-sector collaboration as a model for improving educational outcomes. Washington, DC: American Council on Education.

Schwitzer, A. M., Griffin, O. T., Ancis, J. R., \& Thomas, C. R. (1999). Social adjustment experiences of African American college students. Journal of Counseling \& Development, 77(2), 189-197. https://doi.org/10.1002/j.1556-6676.1999.tb02439.x

Sedlacek, W. E. (1987). Black students on White campuses: 20 years of research. Journal of College Student Personnel.

Sherman, T. M., Giles, M. B., \& Williams-Green, J. (1994). Assessment and retention of Black students in higher education. The Journal of Negro Education, 63(2), 164-180. Retrieved from http://www.jstor.org/stable/2967381 
Shultz, E. L., Colton, G. M., \& Colton, C. (2001). The adventor program: Advisement and mentoring for students of color in higher education. The Journal of Humanistic Counseling, 40(2), 208-218. https://doi.org/10.1002/j.2164-490X.2001.tb00118.x

Smith, W. A., Allen, W. R., \& Danley, L. L. (2007). "Assume the position... you fit the description" psychosocial experiences and racial battle fatigue among African American male college students. American Behavioral Scientist, 51(4), 551-578. https://doi.org/10.1177/0002764207307742

Smith, W. A., Hung, M., \& Franklin, J. D. (2011). Racial battle fatigue and the miseducation of Black men: Racial microaggressions, societal problems, and environmental stress. The Journal of Negro Education, 63-82. Retrieved from https://eric.ed.gov/?id=EJ942380

Smith, W. A., Yosso, T. J., \& Solórzano, D. G. (2007). Racial primes and Black misandry on historically White campuses: Toward critical race accountability in educational administration. Educational Administration Quarterly, 43(5), 559-585. Retrieved from http://journals.sagepub.com/doi/pdf/10.1177/0013161X07307793

Snapshot Report - First-Year Persistence and Retention (pp. 1-12, Rep.). (June 12, 2017). NSC Research Center. Retrieved December 1, 2017, from https://nscresearchcenter.org/wpcontent/uploads/SnapshotReport28a.pdf

Solorzano, D., Ceja, M., \& Yosso, T. (2000). Critical race theory, racial microaggressions, and campus racial climate: The experiences of African American college students. Journal of Negro Education, 69(1/2) 60-73. Retrieved from http://www.jstor.org/stable/2696265

Spady, W. (1971). Dropouts from higher education: An interdisciplinary review and synthesis. Interchange, 1, 64-85. https://doi.org/10.1007/BF02214313 
Spurgeon, S. L., \& Myers, J. E. (2010). African American males: Relationships among racial identity, college type, and wellness. Journal of Black Studies, 40(4), 527-543. Retrieved from http://www.jstor.org/stable/40648526

Stake, R. E. (1995). The art of case study research. Thousand Oaks, CA: Sage Publications.

Stewart, D. W., \& Shamdasani, P. N. (2014). Focus groups: Theory and practice (Vol. 20). Thousand Oaks, CA: Sage publications.

Stewart, E. B. (2006). Family-and individual-level predictors of academic success for AfricanAmerican students: A longitudinal path analysis utilizing national data. Journal of Black Studies, 36(4), 597-621. Retrieved from http://journals.sagepub.com/doi/pdf/10.1177/0021934705276798

Strauss, A., \& Corbin, J. (1990). Open coding. Basics of qualitative research: Grounded theory procedures and techniques. Thousand Oaks, CA: Sage Publications.

Strayhorn, T. L. (2008). The role of supportive relationships in facilitating African American males' success in college. Naspa Journal, 45(1), 26-48.

Strayhorn, T. L. (2013). Measuring race and gender differences in undergraduate students' perceptions of campus climate and intentions to leave college: An analysis in Black and White. Journal of Student Affairs Research and Practice, 50(2), 115-132. https://doi.org/10.1515/jsarp-2013-0010

Strayhorn, T. L. (2014). What role does grit play in the academic success of black male collegians at predominantly white institutions? Journal of African American Studies, 18(1), 1-10. https://doi.org/10.1007/s12111-012-9243-0 
Stolle-McAllister, K. (2011). The case for summer bridge: Building social and cultural capital for talented Black STEM students. Science Educator, 20(2), 12. Retrieved from https://eric.ed.gov/?id=EJ960632

Stromei, L. K. (2000). Increasing retention and success through mentoring. New Directions for Community Colleges, 2000(112), 55-62. https://doi.org/10.1002/cc.11205

Sue, D. W., Capodilupo, C. M., Torino, G. C., Bucceri, J. M., Holder, A., Nadal, K. L., \& Esquilin, M. (2007). Racial microaggressions in everyday life: Implications for clinical practice. American Psychologist, 62(4), 271. http://doi.org10.1037/0003-066X.62.4.271

Summerskill, J. (1962). Dropouts from college. In N. Sanford (Ed.), The American college: A psychological and social interpretation of the higher learning (pp. 627-657). Hoboken, NJ: John Wiley \& Sons Inc. http://dx.doi.org/10.1037/11181-019

Swail, W. S. (2003). Retaining minority students in higher education: A framework for success. ASHE-ERIC Higher Education Report. San Francisco, CA: Jossey-Bass.

Swail, W.S. (2004). The art of student retention: A handbook for practitioners and administrators. Paper presented at the Texas Higher Education Coordinating Board 20th Annual Recruitment and Retention Conference, Austin, TX, Education Policy Institute.

Tatum, B. (1992). Talking about race, learning about racism: The application of racial identity development theory in the classroom. Harvard Educational Review, 62(1), 1-25. Retrieved from https://equity.ucla.edu/wp-content/uploads/2017/01/Tatum-Talking$\underline{\text { About-Race.pdf }}$ 
Tinto, V. (1975). Dropout from higher education: A theoretical synthesis of recent research. Review of educational research, 45(1), 89-125. https://doi.org/10.3102/00346543045001089

Tinto, V. (1987). Leaving college: Rethinking the causes and cures of student attrition. Chicago, IL: University of Chicago Press.

Tinto, V. (1993). Leaving college: Rethinking the causes and cures of student attrition. Chicago, IL: University of Chicago Press.

Tinto, V. (1999). Taking retention seriously: Rethinking the first year of college. NACADA journal, 19(2), 5-9. https://doi.org/10.12930/0271-9517-19.2.5

Tinto, V., \& Pusser, B. (2006). Moving from theory to action: Building a model of institutional action for student success. National Postsecondary Education Cooperative, 1-51. Retrieved from https://web.ewu.edu/groups/academicaffairs/IR/NPEC 5 Tinto Pusser_Report.pdf

Toldson, I. A. \& Lewis, C.W. (2012). Challenge the status quo: Academic success among school-age African American males. Washington, D.C.: Congressional Black Caucus Foundation, Inc.

Utsey, S. O., Ponterotto, J. G., Reynolds, A. L., \& Cancelli, A. A. (2000). Racial discrimination, coping, life satisfaction, and self-esteem among African Americans. Journal of Counseling \& Development, 78(1), 72-80. https://doi.org/10.1002/j.1556$\underline{6676.2000 . t b 02562 . x}$

Van Gennep, A. (1960). The rights of passage. London: Routledge. 
Walton, G. M., \& Cohen, G. L. (2007). A question of belonging: race, social fit, and achievement. Journal of Personality and Social Psychology, 92(1), 82. http://doi.org10.1037/0022-3514.92.1.82

Watson, L. W. (2002). How minority students experience college: Implications for planning and policy. Stylus Publishing, LLC.

Watson, J. (2011). For the public good?: Land-Grant schools straying from public missions, education trust reports say. Diverse: Issues in Higher Education, 28(14), 24-25.

Weiher, G. R., \& Tedin, K. L. (2006). Minority student achievement. Review of Policy Research, 23(5), 963-967. https://doi.org/10.1111/j.1541-1338.2006.00244.x

West, C. (2000). Race matters. Boston, MA: Beacon Press.

Wilson, Z. S., Holmes, L., Sylvain, M. R., Batiste, L., Johnson, M., McGuire, S. Y., ... \& Warner, I. M. (2012). Hierarchical mentoring: A transformative strategy for improving diversity and retention in undergraduate STEM disciplines. Journal of Science Education and Technology, 21(1), 148-156. https://doi.org/10.1007/s10956-011-9292-5

Wong, A. (2016). Where are all the high school grads going. The Atlantic.

Yin, R. K. (2009). Case study research: Design and Methods. Thousand Oaks, CA: Sage Publications.

Yin, R. K. (2015). Qualitative research from start to finish. New York, NY: Guilford Publications.

Zajacova, A., Lynch, S. M., \& Espenshade, T. J. (2005). Self-efficacy, stress, and academic success in college. Research in higher education, 46(6), 677-706. http://doi10.1007/s11162-004-4139-z 


\section{Appendix A}

Interview Questions for Administrators (based on research questions):

+ How do Black male students perceive the purpose, processes, and effectiveness of a retention initiative aimed to increase Black college male retention?

+ How do college administrators perceive the purpose, processes, and effectiveness of a retention initiative aimed to increase Black college male retention?

+ Are there differences in how Black male students and college administrators perceive the purpose, processes, and effectiveness of a retention initiative aimed to increase Black college male retention?

1. How does this initiative help to retain Black college male students attending a land-grant PWI located in the Appalachian region?

2. What are your perceptions of the way this initiative functions?

3. What are your perceptions of the effectiveness related to this initiative?

4. What impact (if any) has this initiative had on student decisions to remain at the University?

5. If you could design the initiative differently, what would you do? 


\section{Appendix B}

Interview Questions for Students

(based on research questions):

+ How do Black male students perceive the purpose, processes, and effectiveness of a retention initiative aimed to increase Black college male retention?

+ How do college administrators perceive the purpose, processes, and effectiveness of a retention initiative aimed to increase Black college male retention?

+ Are there differences in how Black male students and college administrators perceive the purpose, processes, and effectiveness of a retention initiative aimed to increase Black college male retention?

1. In your own words, describe this initiative?

2. What are your perceptions of the way this initiative functions?

3. What are your perceptions of the effectiveness related to this initiative?

4. What impact (if any) has this initiative had on your decision to remain at the University?

5. If you were to design this initiative what things would you offer? 